\title{
CONTRIBUIÇÃO DOS ISÓTOPOS ESTÁVEIS DA ÁGUA (H E O) NO CONHECIMENTO DOS AQUÍFEROS BRASILEIROS: ESTADO DA ARTE E PERSPECTIVAS FUTURAS
}

Didier GASTMANS

Lia Nogueira GARPELLI

Vinícius dos SANTOS

Camila de LIMA

Carolina Stager QUAGGIO

Lucas Vituri SANTAROSA

Roberto Eduardo KIRCHHEIM

\section{RESUMO}

As águas subterrâneas abastecem cerca de $50 \%$ de todos os municípios brasileiros, e sua crescente utilização deve-se à conjunção de condições climáticas, com excedentes hídricos importantes que possibilitam a recarga dos aquíferos, e ao arcabouço hidrogeológico do território nacional, constituído por vários aquíferos (porosos, fraturados e cársticos), associados às províncias geológicas e estruturais do país. Em função da importância das águas subterrâneas, isótopos estáveis de $\mathrm{H}$ e $\mathrm{O}$ vêm sendo empregados de maneira regular em estudos hidrogeológicos no Brasil desde a década de 1970. Observa-se um incremento em sua utilização no início do século XXI, associado ao estabelecimento de inúmeros grupos de pesquisa em hidrogeologia e ao desenvolvimento de técnicas analíticas que possibilitaram uma otimização analítica. O presente trabalho apresenta uma revisão sobre a aplicação de isótopos estáveis de $\mathrm{H}$ e $\mathrm{O}$ em estudos hidrogeológicos nos aquíferos brasileiros a partir de uma leitura crítica da bibliografia disponível, e divide-se em cinco capítulos. Inicialmente são apresentadas as bases teóricas para a aplicação de isótopos estáveis de $\mathrm{H}$ e $\mathrm{O}$ em estudos hidrológicos, seguida por uma revisão do conhecimento a respeito da composição isotópica da precipitação no país e seus controles, e do estado da arte da aplicação de isótopos estáveis no conhecimento hidrogeológico nacional. Finalmente são traçadas as lições aprendidas e apresentadas algumas oportunidades que se descortinam para as aplicações isotópicas em futuros estudos hidrogeológicos. Essa revisão permitiu a constatação de uma boa cobertura de dados isotópicos da precipitação, dados suficientes para estudos regionais, mas que apresentam uma defasagem temporal, pois a paralisação das observações nos anos 1980 prejudicou o monitoramento dos dados climáticos. De maneira geral observa-se que as maiores variações na composição isotópica são encontradas nos aquíferos de grande extensão e com porções confinadas, como os aquíferos da Bacia do Paraná e da Bacia Amazônica, refletindo condições de recarga pretéritas, estendendo-se por grandes períodos de tempo, entretanto a relação com aspectos climáticos e de posicionamento geográfico também acabam se refletindo na composição isotópica das águas subterrâneas. Apesar do número crescente de estudos que utilizam isótopos estáveis de $\mathrm{H}$ e $\mathrm{O}$, especialmente nos aquíferos sedimentares mais importantes, existem desafios vislumbrados, que oferecem inúmeras novas possibilidades científicas. Observou-se que não existe, dentre os trabalhos analisados, uma visão holística acerca da movimentação da água no ciclo hidrológico, partindo da compreensão da associação existente entre os fenômenos climáticos de larga escala e a recarga das águas subterrâneas. $\mathrm{O}$ mesmo vale para a sua aplicação conjunta com outros traçadores isotópicos (gases nobres e isótopos radioativos, por exemplo), com reconhecido potencial para fornecer 
estimativas de tempos de trânsito e misturas de águas, além de estudos voltados à compreensão das interações entre águas subterrâneas e superficiais.

Palavras-chave: Águas subterrâneas; Isótopos estáveis; Aquíferos; Brasil.

\begin{abstract}
HYDROGEN AND OXYGEN STABLE ISOTOPES CONTRIBUTIONS FOR BRAZILIAN AQUIFERS KNOWLEDGE: STATE OF ART AND FUTURE PERSPECTIVES. Groundwater supplies circa $50 \%$ of all Brazilian municipalities, and its increasing use results from the combination of (i) climatic conditions, as the high precipitation rates lead to important water surpluses, providing conditions to the recharge of aquifers, and (ii) the hydrogeological framework, consisting of a variety of aquifers (porous, fractured and karst) encompassed by different geological and structural provinces. Due to the importance of groundwater to Brazil, $\mathrm{H}$ and $\mathrm{O}$ stable isotopes have been regularly used in hydrogeological studies since the 1970's, with an increase in the application of stable isotope methods at the beginning of the 21 st century. This increase is associated with the establishment of numerous research groups in hydrogeology and the development of analytical techniques that enabled the optimization of the analyses. In this sense, we present a review of the application of $\mathrm{H}$ and $\mathrm{O}$ stable isotopes to the hydrogeological study of Brazilian aquifers, based on a critical reading of the available scientific literature. This paper is divided into five chapters. Initially, the theoretical foundations for the application of stable $\mathrm{H}$ and $\mathrm{O}$ isotopes in hydrological studies are presented, followed by a review of the knowledge about the rainwater isotopic composition and climatic controls. Then, the state-of-the-art of the application of stable isotopes in Brazil is complemented with the lessons learned and the opportunities revealed for the application of the methods in hydrogeological studies. This review attested the good coverage of rain water data and corresponding isotopic composition, allowing considerations at the regional scale, despite the time lag that occurred due to the interruption of the meteorological observations in the 1980's. Regarding groundwater isotopic composition, the major variations were observed in regional aquifers, especially in confined portions, such as the aquifers of the Paraná Basin and of the Amazon Basin, reflecting past recharge conditions extending for long periods of time. The relationships between isotopic composition and regional climatic aspects and geographic localization are also reflected in the groundwater isotopic composition. Despite the growing number of studies using stable $\mathrm{H}$ and $\mathrm{O}$ isotopes, especially involving the most important sedimentary aquifers, there are still challenges those open new possibilities of study. There is a gap in knowledge regarding a holistic view about the water movement along the hydrological cycle, based on the understanding of the correlation between large-scale climatic phenomena and groundwater recharge, as well as the application of multi-isotopic tracer methods (involving noble gases and radioactive isotopes, for example), in order to determine groundwater residence times and water mixing, in addition to studies aiming at the understanding of groundwatersurface water interactions.
\end{abstract}

Keywords: Groundwater; Water stable isotopes; Aquifers; Brazil.

\section{INTRODUÇÃO}

As águas subterrâneas representam o principal reservatório global de água doce, armazenando cerca de $97 \%$ de toda a água (em estado líquido) doce disponível, utilizada no abastecimento público, como insumo na produção de alimentos e bens industriais, mas que deve ser vista como um bem a ser preservado em função dos serviços ecossistêmicos prestados, como a manutenção dos volumes de água em rios e lagos, essenciais à susten- 
tação dos ambientes aquáticos (SHIKLOMANOV 2000, GORELICK \& ZHENG 2015, ABBOTT et al. 2019).

Diante de um cenário em que as mudanças climáticas têm acelerado a busca por fontes subterrâneas para o abastecimento, essa pressão sobre os reservatórios tem levado a sua depleção em diversas partes do globo, tratando-se de uma questão relevante na gestão dos recursos hídricos (AESCHBACH-HERTIG \& GLEESON 2012, TAYLOR et al. 2012, CROSBIE et al. 2013, FAMIGLIETTI 2014, EZAKI et al. 2020).

Estima-se que mais de 2,5 milhões de poços extraiam o equivalente a cerca de $600 \mathrm{~m}^{3} \cdot \mathrm{s}^{-1}$, abastecendo (parcial ou totalmente) cerca de $52 \%$ de todos os municípios do território brasileiro (HIRATA et al. 2019). Apesar da importância das águas subterrâneas para o abastecimento da população brasileira, ainda existe grande desconhecimento em relação a aspectos relevantes relacionados com a sustentabilidade do recurso (recarga, tempo de residência e taxas de renovação) e a sua proteção, para os quais isótopos estáveis de $\mathrm{H}$ e $\mathrm{O}$ podem trazer valiosas contribuições.

Isótopos estáveis naturais dos elementos constituintes da água ( $\mathrm{H}$ e O) vêm sendo empregados de maneira regular em estudos hidrogeológicos no Brasil desde a década de 1970, pois constituem excelentes traçadores das transformações físicas sofridas pela água ao longo do ciclo hidrológico. Assim, fornecem informações importantes em relação à história de sua movimentação, o que reforça a sua utilidade como informação auxiliar na interpretação dos controles climáticos exercidos na precipitação e suas relações com a recarga das águas subterrâneas (COPLEN et al. 2000), especialmente devido a extensão temporal e espacial limitada da rede de monitoramento hidroclimático ao redor do globo (AGGARWAL et al. 2012).

Sua utilização sistemática em estudos hidrológicos e climáticos inicia-se a partir da criação da Rede Global de Isótopos na Precipitação (Global Network of Isotopes in Precipitation - GNIP) no ano de 1958, pela Agência Internacional de Energia Atômica (International Atomic Energy Agency - IAEA), em cooperação com a Organização Meteorológica Mundial (World Meteorological Organization - WMO). A GNIP tinha como objetivo inicial o monitoramento das concentrações de trítio na atmosfera, produzido pelos testes nucleares conduzidos à época. Posteriormente, iniciou-se a análise das variações espaço-temporais da composição isotópica de $\mathrm{O}$ e $\mathrm{H}$ na precipitação.
Atualmente, com o advento da técnica da Espectrometria de Absorção Laser (Laser Absorption Spectroscopy), a capacidade de determinação de um número maior de amostras faz com que novas fronteiras se abram para a utilização de isótopos estáveis em estudos hidrológicos e climáticos (WASSENAAR et al. 2014).

A possibilidade de se compreender a movimentação da água nos aquíferos com a utilização de isótopos da água, complementa informações hidrogeológicas que podem ser inferidas a partir de observações "físicas", como a piezometria, geofísica ou de concentração de elementos dissolvidos na água, sendo todas as técnicas aplicadas de maneira combinada (JASECHKO 2019). Além disso, o fato de a água possuir uma "assinatura isotópica" única, associada aos processos de fracionamento, que são dependentes da temperatura e consequentemente das variações climáticas, constitui um elo importante na compreensão dos processos de recarga a partir de uma visão mais sistêmica e global do ciclo hidrológico e suas relações com o clima.

Os primeiros estudos envolvendo a utilização de isótopos da água em território brasileiro foram realizados entre o final da década de 1960 e início da década de 1970, com forte apoio da IAEA. Os principais objetivos foram compreender os processos de salinização de águas no semiárido nordestino, o papel da evapotranspiração exercido pela floresta Amazônica na composição isotópica da precipitação e nas águas subterrâneas do Aquífero Botucatu, nome dado à época para o Sistema Aquífero Guarani (SILVEIRA \& SILVA Jr. 2002).

Com a popularização do uso de isótopos estáveis e o estabelecimento de inúmeros grupos de pesquisa em hidrogeologia no território brasileiro, é importante uma avaliação do atual estágio do conhecimento dos aquíferos brasileiros e das informações trazidas à luz por esses grupos, uma vez que a revisão feita por SILVEIRA \& SILVA Jr. (2002) mostrou um cenário em que os estudos ainda eram incipientes. Nesse sentido, o objetivo principal do presente trabalho é o de apresentar um panorama da aplicação de isótopos estáveis de $\mathrm{H}$ e $\mathrm{O}$ e qual a contribuição dada ao conhecimento hidrogeológico em território brasileiro, a partir de uma leitura crítica da bibliografia disponível (dissertações, teses, artigos científicos), possibilitando uma avaliação dos avanços obtidos, bem como a identificação de lacunas do conhecimento a serem preenchidas por pesquisas futuras.

Com vista a apresentar esse panorama, o presente artigo está subdividido em quatro capítulos 
gerais, além do presente capítulo de Introdução, a saber: no capítulo 2 são revisitados os conceitos gerais da aplicação de isótopos estáveis de $\mathrm{H}$ e $\mathrm{O}$ em estudos hidrológicos, mostrando os princípios básicos que norteiam a sua aplicação em estudos relacionadas à precipitação, bem como os fundamentos para a compreensão de processos relacionados à origem e movimentação da água subterrânea; no capítulo 3 , uma revisão do conhecimento sobre a variação espaço-temporal da composição isotópica da precipitação no território brasileiro e suas relações com as principais figuras que controlam o clima no Brasil; no capítulo 4 é apresentado o panorama do estado da arte da aplicação de isótopos estáveis em estudos dos aquíferos, nos principais compartimentos hidrogeológicos do território brasileiro; no capítulo 5 (final) são analisadas as oportunidades de novos estudos com base em lacunas do conhecimento observadas ao longo dessa extensiva revisão bibliográfica, bem como as principais conclusões e aprendizados ao longo dessa caminhada do conhecimento, percorrida pelos geocientistas brasileiros em busca do conhecimento da movimentação da água subterrânea e suas conexões com a chuva e com as águas superficiais no território nacional.

2 BASES CONCEITUAIS PARA A APLICAÇÃO DE ISÓTOPOS ESTÁVEIS DE H E O EM ESTUDOS HIDROGEOLÓGICOS

Isótopos são átomos de um mesmo elemento químico com igual número de prótons, porém com distintos número de nêutrons em seu núcleo, resultando em massas atômicas diferentes. São divididos em duas categorias: estáveis e os instáveis (ou radioativos). Esses últimos apresentam excesso de energia em seu núcleo, emitem partículas e se transformam em outros átomos, que podem ser estáveis ou não, em um processo denominado decaimento radioativo. Isótopos estáveis são caracterizados pela regra da simetria, que estabelece que em átomos de pequeno peso atômico a relação entre o número de prótons e nêutrons é próxima a 1 , podendo chegar a 1,5 em átomos mais pesados (HOEFS 2009).

Os isótopos estáveis de $\mathrm{O}$ e $\mathrm{H}$, por constituírem a molécula da água, vêm sendo amplamente utilizados para a compreensão da sua movimentação ao longo do ciclo hidrológico, pois durante as mudanças de fase da água ocorrem variações em suas abundâncias relativas, originando moléculas de água distintas, denominadas de isotopólogos (Figura 1) (CLARK \& FRITZ 1997, MOOK 2000).
As medidas das quantidades dos isótopos ambientais não são absolutas, mas sim representam a razão entre o isótopo menos abundante (pesado) e o mais abundante (leve) e sua notação está baseada na comparação das variações nas razões entre os isótopos em relação a um padrão. Utiliza-se para tanto a notação $\delta$, expressa em partes por mil (\%), comparado ao padrão denominado Vienna Standard Mean Ocean Water - VSMOW (MOOK 2000) (Equação 1). Assim, valores positivos de $\delta$ indicam razões isotópicas que excedem o VSMOW, e valores negativos de $\delta$ razões inferiores ao VSMOW, utilizando-se em termos relativos que águas com maior conteúdo em isótopos pesados são águas enriquecidas, e aquelas com maior conteúdo em isótopos leves de empobrecidas (CLARK \& FRITZ 1997, JASECHKO 2019).

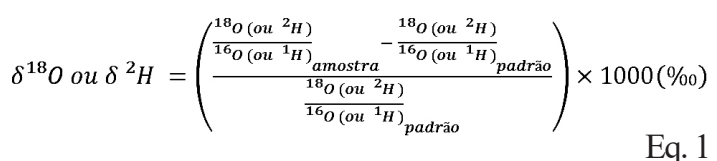

As variações espaciais e temporais nas razões isotópicas das moléculas de água, ao longo do ciclo hidrológico, estão associadas a um processo físico-químico denominado 'fracionamento isotópico', definido como o particionamento de isótopos quando submetidos a mudanças de fase (UREY 1947, DANSGAARD 1964, CLARK \& FRITZ 1997, MOOK 2000).

Há três tipos de fracionamento dependentes da massa (MOOK 2000): (i) fracionamento isotópico de equilíbrio, relacionado a preferências que distintas substâncias têm para dado isótopo, por exemplo, para os mais pesados que tendem a permanecer mais na forma líquida do que como vapor (YOSHIMURA 2015, JASECHKO 2019); (ii) fracionamento cinético (ou de não-equilíbrio), que ocorre devido às diferentes taxas de reação entre as moléculas (JASECHKO 2019), geralmente durante processos de evaporação em ambiente insaturado (CRAIG \& GORDON 1965), e em processos de condensação em ambiente supersaturado (JOUZEL \& MERLIVAT 1984) e; (iii) fracionamento por difusão molecular, devido às diferentes mobilidades das espécies isotópicas da água (MOOK 2000).

De modo geral, o fracionamento sob condições de equilíbrio está relacionado a processos de condensação (formação de nuvens, gotículas de gelo e chuva), enquanto o fracionamento cinético está relacionado aos processos de evaporação (do solo, na interface de corpos d'água e ar não saturado, durante a queda das gotas de chu- 
Oxigênio

\section{Isótopos estáveis}

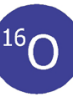

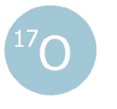

Abundância natural (\%)

\section{Razão \\ Isotópica}

Relativo ao (\%oVSMOW)
$99,985 \quad 0,015$

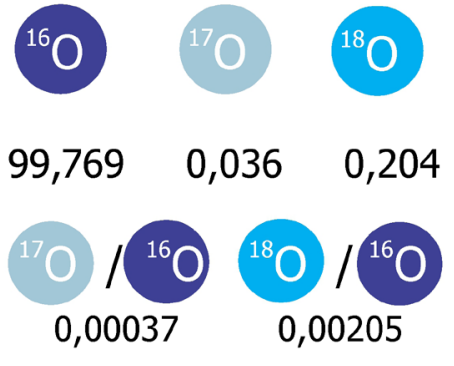

\section{Hidrogênio}

(H) $\mathrm{H}$ ou

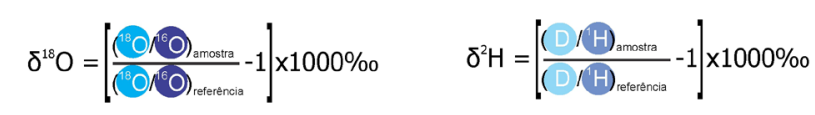

\section{Isotopólogos}

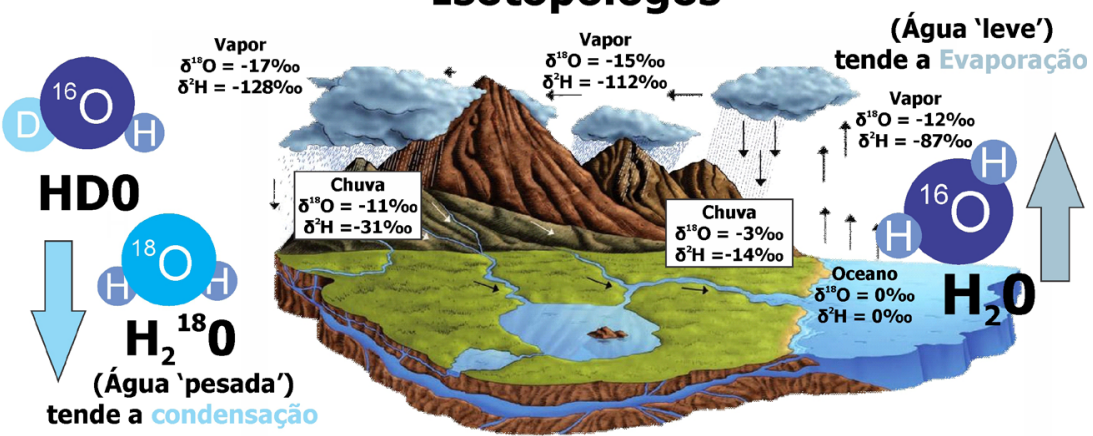

'Fracionamento' causa grande variabilidade temporal e espacial

FIGURA 1 - Isótopos estáveis da água no ciclo hidrológico. Na parte superior da figura são apresentados os isótopos estáveis de $\mathrm{H}$ e $\mathrm{O}$, com suas abundâncias naturais e as razões associadas a essa abundância natural (Fonte dos dados isotópicos: MOOK 2000). Na porção inferior, o comportamento dos isotopólogos frente aos processos de mudança de fases da água e seus reflexos na variabilidade temporal e espacial dos isótopos (Ilustração modificada de YOSHIMURA 2015).

va) (DANSGAARD 1964, MULLER et al. 2015, JASECHKO 2019).

A dependência da temperatura no processo de fracionamento, associado aos diferentes comportamentos dos isótopos frente ao tipo de fracionamento, cinético ou em equilíbrio, produz uma grande variabilidade espacial e temporal das assinaturas isotópicas, permitindo a compreensão quantitativa e de modelagem de processos dinâmicos no ciclo da água, abrangendo os diferentes reservatórios da água no ciclo hidrológico (HORITA et al. 2008) (Figura 1).

\subsection{Isótopos estáveis na precipitação}

Os primeiros estudos isotópicos envolveram a compreensão da composição isotópica da chuva, e criaram o alicerce para estudos nos demais reservatórios do ciclo hidrológico, com a determinação da Reta Meteórica Global (RMG, do inglês Global Meteoric Water Line - GMWL) (CRAIG 1961), e dos principais efeitos isotópicos provocados pelo fracionamento na composição isotópica da chuva (DANSGAARD 1964).

A RMG definida por CRAIG (1961) e sintetizada na clássica equação: $\delta^{2} \mathrm{H}=8^{*} \delta^{18} \mathrm{O}+10$, foi revista posteriormente por ROZANSKI et al. (1993) $\left(\delta^{2} \mathrm{H}=8,17 * \delta^{18} \mathrm{O}+11,27\right)$, e representa a relação média entre $\delta^{18} \mathrm{O}-\delta^{2} \mathrm{H}$ em escala global, capturando uma infinidade de processos climáticos em diferentes regiões climáticas do globo, e serve como referência em estudos isotópicos em qualquer região do globo terrestre.

Fatores geográficos e climáticos locais, que refletem diferentes tipos de fracionamento, alteram as relações entre $\delta^{18} \mathrm{O}-\delta^{2} \mathrm{H}$, produzindo retas com inclinações e interceptos distintos, denominadas de 
Retas Meteóricas Locais (RML). Assim, para determinada faixa de temperatura e composição isotópica, os desvios de RMLs ocorrem por processos de equilíbrio ou cinético (PUTMAN et al. 2019, MARCHINA et al. 2020).

Além dos valores das razões isotópicas, outro parâmetro isotópico, de segunda ordem, denominado excesso de deutério $\left(d\right.$-excess $=\delta^{2} \mathrm{H}-8^{*} \delta^{18} \mathrm{O}$, DANSGAARD 1964), foi definido para representar os processos de fracionamento cinético dos isótopos de $\mathrm{H}$ em relação aos de $\mathrm{O}$, visualizados nos desvios das RMLs (PUTMAN et al. 2019). Sua variação está normalmente relacionada aos gradientes de temperatura nas regiões em que se encontra a origem do vapor (grande parte é oceânico), a trocas isotópicas durante o transporte de vapor sobre os continentes $(>10 \%$ ) (MERLIVAT \& JOUZEL $1979)$ ou a processos de evaporação $(<10 \%$ o) locais (DANSGAARD 1964, RISI et al. 2010).

Por isso, o excesso de deutério é correlacionado à umidade relativa do ar, temperatura do ar, temperatura da superfície do oceano e velocidade dos ventos (MERLIVAT \& JOUZEL 1979, FROEHLICH et al. 2002, JASECHKO et al. 2013), sendo a principal ferramenta utilizada na interpretação de processos de evaporação na chuva, e em estudos de águas superficiais e subterrâneas (MARCHINA et al. 2020).

A variabilidade espacial observada na composição isotópica da precipitação pode ser correlacionada com uma série de fatores, denominados de "efeitos" isotópicos (DANSGAARD 1964), que estão associados a dependência da temperatura por parte do fracionamento e de processos de destilação Rayleigh (Figura 1) (CLARK \& FRITZ 1997).

Nesse sentido, a composição isotópica da precipitação acompanha a distribuição da temperatura do globo terrestre com a variação da latitude (efeito latitudinal), com valores enriquecidos localizados na zona equatorial, tornando-se empobrecidos em direção aos polos (ROZANSKI et al. 1993, CLARK \& FRITZ 1997).

Iniciando-se com a formação do vapor d'água no oceano, e seu posterior transporte e precipitação no interior de áreas continentais, a evolução da precipitação, como chuva ou neve, resulta em empobrecimento progressivo da água de chuva em isótopos pesados, resultando no que se convencionou denominar efeito de continentalidade (assinaturas isotópicas enriquecidas em áreas litorâneas e empobrecidas no interior do continente), explicado pelo processo de destilação Rayleigh (Figura 1) (ROZANSKI et al. 1993, CLARK \& FRITZ
1997). Atualmente, processos de reciclagem de vapor sobre o continente, a quantidade de advecção durante o transporte de massas de ar e mistura de diferentes massas de ar regionais também são considerados processos importantes na interpretação deste efeito (RISI et al. 2013, FREEMAN 2014, WINNICK et al. 2014).

Condições fisiográficas locais também são importantes fatores na interpretação dos efeitos do fracionamento isotópico. O relevo e a variação sazonal em determinadas regiões climáticas contribuem para variabilidade isotópica. $\mathrm{O}$ efeito de altitude ocorre devido à diminuição da temperatura quando uma dada massa de ar é obrigada a elevar-se devido à orografia, resultando no empobrecimento da composição isotópica (ROZANSKI et al. 1993, CLARK \& FRITZ 1997). Este efeito pode acentuar o empobrecimento da precipitação, uma vez que outros processos podem contribuir para isso, como a mistura de massas de ar e recirculação de vapor antes da formação da chuva orográfica (WINDHORST et al. 2013, KONG \& PANG 2016).

Já o efeito sazonal está relacionado a uma grande amplitude térmica ao longo do ano em áreas continentais, provocando empobrecimento/enriquecimento durante períodos mais frios/quentes (CLARK \& FRITZ 1997) e a ocorrência de diferentes regimes de precipitação ao longo do ano, com empobrecimento/enriquecimento de $\delta^{18} \mathrm{O}$ em períodos chuvosos/secos, caracterizando o efeito de quantidade (ROZANSKI et al. 1993, CLARK \& FRITZ 1997). Para a região extratropical, a amplitude térmica tem papel fundamental, enquanto para áreas tropicais a sazonalidade é relacionada ao efeito de quantidade em análises isotópicas mensais (CLARK \& FRITZ 1997).

Este grande volume de chuva durante o verão tropical ocorre devido a padrões de circulação e ventos regionais com o transporte de vapor atmosférico, que caracterizam sistemas monçônicos, como o observado no sudoeste asiático (ARAGUÁS-ARAGUÁS et al. 1998, WU et al. 2015), ou sobre a América do Sul (VUILLE \& WERNER 2005, GASTMANS et al. 2017a, SANTOS et al. 2019a, b).

$\mathrm{O}$ efeito de quantidade em áreas tropicais tem fortes correlações negativas em escala mensal, não havendo consenso predominante na explicação deste efeito, principalmente na escala de coleta diária, na qual se observa uma diminuição nas correlações (KURITA et al. 2009). A dinâmica da formação de chuvas convectivas vem sendo um dos 
principais fatores utilizados para explicar o efeito de quantidade (RISI et al. 2008, KURITA et al. 2009, SÁNCHEZ-MURILLO et al. 2016).

Atualmente, a dinâmica e formação de chuvas convectivas $\left(\delta^{18} \mathrm{O}\right.$-enriquecido) versus estratiformes $\left(\delta^{18} \mathrm{O}\right.$-empobrecido) tem sido o principal tema discutido no entendimento da variabilidade da composição isotópica da precipitação mundial e, principalmente, para as regiões tropicais (RISI et al. 2008, KURITA et al. 2009, LEE et al. 2015, AGGARWAL et al. 2016, TORRI et al. 2017, LACOUR et al. 2018).

\subsection{Isótopos estáveis nas águas subterrâneas}

A composição isotópica das águas subterrâneas $(\mathrm{H} \mathrm{e} \mathrm{O})$ pode revelar muito a respeito de sua origem e movimentação. Sua utilização pode contribuir na compreensão de processos hidrogeológicos importantes como: (i) recarga, definindo condições climáticas específicas ou fontes para a água infiltrada; (ii) armazenamento e movimentação da água ao longo de linhas de fluxo; (iii) descarga de águas subterrâneas em direção a corpos de água superficial (CLARK 2015, JASECHKO 2019).

A recarga pode ser definida como o fluxo de água descendente que alcança a zona saturada de um aquífero livre, adicionando água ao volume armazenado. Pode ser classificada como difusa, quando a infiltração ocorre sobre grandes áreas em resposta a infiltração da precipitação; ou pontual, proveniente da infiltração de água na zona não saturada localizada sob corpos d'água ou outras fontes pontuais, como vazamentos de redes de distribuição, por exemplo (HEALY 2010).

Fontes e mecanismos de recarga podem ser avaliados a partir de diferenças nas assinaturas isotópicas, possibilitando que hipóteses sejam testadas, como no caso de origem e sazonalidade na recarga difusa ou pontual (p. ex. recargas provenientes de rios, lagos e/ou irrigação), ou definindo áreas de recarga e sua altitude, no caso de áreas montanhosas (MAZOR et al. 1985, JEELANI et al. 2015, JASECHKO 2019, SÁNCHEZ-MURILLO et al. 2017, CHERY et al. 2020, dentre outros).

De maneira geral, em função dos caminhos percorridos pela água na zona não saturada, as diferenças observadas na composição isotópica na precipitação são atenuadas, e a composição isotópica das águas subterrâneas respondem de maneira mais suave a essas variações, mantendo constante sua composição isotópica (CLARK \& FRITZ 1997), sendo pouco alteradas pela evapotranspi- ração ou interações com as rochas (JASECHKO 2019).

Estudos envolvendo isótopos estáveis em águas subterrâneas são baseados na comparação de diferenças existentes entre a composição isotópica da precipitação (anual e/ou sazonal) e a das águas subterrâneas de uma determinada região, permitindo a identificação dos tempos e/ou controles climáticos sobre a recarga das águas subterrâneas. A determinação das variações sazonais observadas na relação recarga/precipitação é informação fundamental nesse detalhamento.

O desvio da composição isotópica das águas subterrâneas em relação à média ponderada da precipitação, seja sazonal (inverno/verão ou estação chuvosa/seca) e/ou anual, pode indicar a prevalência de recarga devido à intensidade de chuva (estação seca/chuvosa) ou sazonalidade (inverno/ verão). Esse desvio pode ser determinado avaliando-se as relações existentes entre a composição isotópica da precipitação e da água subterrânea, de acordo com as equações 2 e 3 , apresentadas a seguir.

Inicialmente, é necessário calcular a média ponderada da composição isotópica da precipitação em uma determinada estação (Equação 2) e, posteriormente, a proporção entre as contribuições para as recargas em uma estação ou outra (Equação 3) (JASECHKO et al. 2014, JASECHKO \& TAYLOR 2015, JASECHKO et al. 2017, SANCHÉZMURILLO et al. 2017, CHERRY et al. 2020):

$$
\delta_{P(a-b)}=\frac{\sum_{i=1}^{6} \delta_{P(i)} P_{i}}{\sum_{i=1}^{6} P_{i}} \quad \text { Eq. } 2
$$

Onde: $\delta_{\mathrm{P}(\mathrm{a}-\mathrm{b})}$ é a composição isotópica média ponderada da precipitação da estação "a" ou "b", $\delta_{\mathrm{P}(i)}$ é a composição isotópica do mês i e $\mathrm{P}_{\mathrm{i}}$ é a quantidade de precipitação do mês "i".

$$
\frac{(R / P)_{a}}{(R / P)_{b}}=\frac{\left(\frac{\delta_{G}-\delta_{P(b)}}{\delta_{P(\text { anual })}-\delta_{P(b)}}\right)}{\left(\frac{\delta_{G}-\delta_{P(a)}}{\delta_{P(\text { anual })}-\delta_{P(a)}}\right)} \quad \text { Eq. } 3
$$

Onde: R/P identifica a proporção da recarga devido à chuva de uma determinada estação (a ou b), $\delta_{\mathrm{G}}$ é a composição isotópica da água subterrânea; $\delta_{\mathrm{P}(\mathrm{a}-\mathrm{b})}$ é a composição isotópica média ponderada da precipitação de uma determinada estação (a ou b), que se tome como referência e $\delta_{\mathrm{P}(\text { anual) }}$ é a composição isotópica média ponderada da precipitação anual. 
A relação permite estimar a contribuição nas razões de recarga em função de variações sazonais importantes, deslocando a composição isotópica das águas subterrâneas da precipitação anual, em direção a chuvas mais depletadas ou enriquecidas, que podem estar associadas às condições climáticas específicas em que a recarga ocorre, ou mesmo indicando a existência de águas fósseis, recarregadas em condições climáticas pretéritas distintas (Figura 2B).

Em regiões tropicais a recarga das águas subterrâneas está geralmente associada à estação chuvosa, quando a quantidade de chuva é suficiente para que ocorra sua infiltração e, o efeito quantidade, associado aos processos de destilação que implicam em composições isotópicas empobrecidas (JASECHKO et al. 2014, JASECHKO \& TAYLOR 2015, SANTAROSA et al. 2021). A depender do período em que ocorra a recarga, a com-
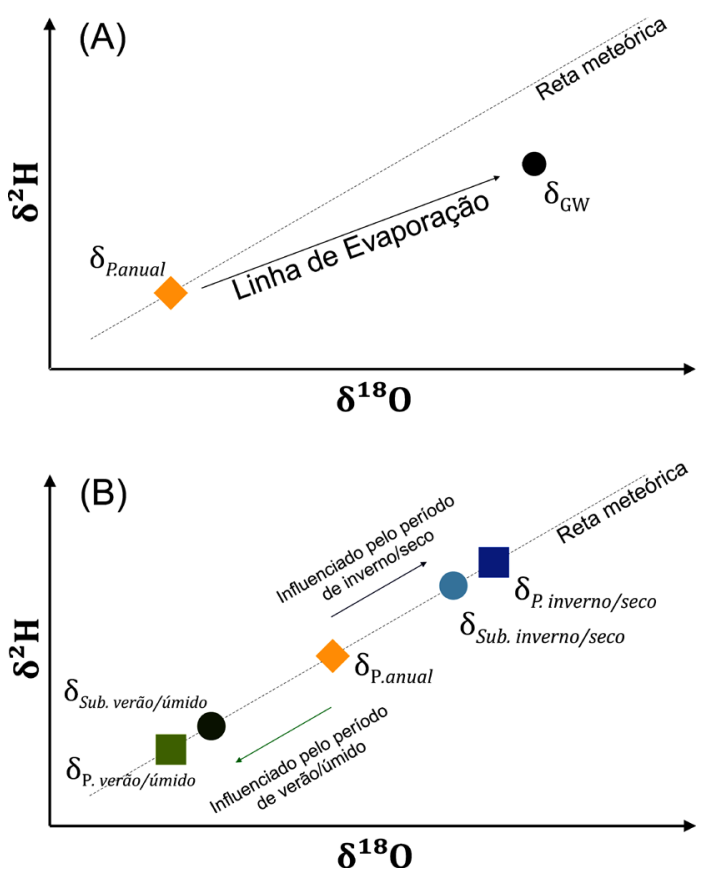

FIGURA 2 - Variações observadas na composição isotópica das águas subterrâneas em comparação com a precipitação anual local. (A) Processos de evaporação levam a um enriquecimento das águas subterrâneas, deslocando-as da reta meteórica. (B) Controles climáticos, ou recarga associada a um período específico do ano, tendem a deslocar a composição isotópica das águas subterrâneas em direção às médias das precipitações desses períodos (mais enriquecidos ou mais empobrecidos). posição isotópica das águas subterrâneas será semelhante à da composição isotópica ponderada da precipitação do período chuvoso, podendo inclusive, ser mais depletada que esse valor (Figura 2B).

A evaporação parcial, que pode ocorrer antes ou mesmo durante a infiltração da água no processo de recarga, produzirá um aumento dos valores de $\delta^{2} \mathrm{H}$ e $\delta^{18} \mathrm{O}$, e as águas subterrâneas apresentarão valores de excesso de deutério inferiores aos das retas meteóricas. A inclinação da reta de evaporação (Figura 2A) tende a ser menor em condições de baixa umidade, quando a evaporação ocorre no solo, durante a infiltração (BATISTA et al. 2018), se comparado aos valores observados em condições de evaporação de corpos d'água em regiões úmidas (CLARK \& FRITZ 1997, JASECHKO 2019).

A movimentação constante das águas subterrâneas em uma bacia hidrográfica em direção aos canais dos rios, aliada à capacidade dos aquíferos em armazenar grandes volumes de água, faz com que em diversas partes do globo, especialmente em áreas tropicais, as águas subterrâneas sejam responsáveis pela perenização dos cursos d'água (BISWAL \& KUMAR 2014). O fluxo de base representa esse processo, sendo um componente importante do sistema subterrâneo do ciclo hidrológico, pois reflete a conexão entre a precipitação, a água subterrânea e o fluxo dos rios (LOTT \& STEWART 2016, ZHANG et al. 2017).

Isótopos estáveis de $\mathrm{H}$ e $\mathrm{O}$ vêm sendo utilizados na compreensão dessas relações e nas estimativas de contribuições de fluxo das águas subterrâneas nas descargas dos rios, e sua aplicação está baseada no fato de que as águas superficiais e subterrâneas apresentam pequenas variações sazonais na composição isotópica se comparadas com a precipitação (DUTTON et al. 1995).

A composição isotópica das águas dos rios refletirá a variação temporal (e espacial) das contribuições de cada uma das fontes devido ao comportamento da precipitação e da descarga das águas subterrâneas nas bacias. Conhecendo as assinaturas isotópicas dessas fontes, e como elas modificam a composição isotópica dos rios, é possível compreender as dinâmicas hidrológicas predominantes em uma bacia. As variações sazonais serão maiores em rios onde a precipitação recente é a principal fonte de fluxo, e menores em rios onde a água subterrânea é a fonte dominante (KENDALL \& McDONNELL 1998, KENDALL \& COPLEN 2001). 


\section{ESTUDOS ISOTÓPICOS SOBRE A PRECIPITAÇÃO NO BRASIL}

Entre os anos de 1957 e 1990, como parte dos esforços vinculados ao estabelecimento da Global Network of Isotopes in Precipitation (GNIP: https://nucleus.iaea.org/wiser/index.aspx), e posterior processo de consolidação e de aquisição de dados isotópicos da precipitação, foram instaladas 28 estações para coleta de amostras de chuva no território nacional, com objetivos e intervalos temporais diversos. Entretanto, por diferentes motivos, esse monitoramento foi paralisado causando um impacto na cobertura de informação isotópica da chuva na América do Sul, apesar do extensivo uso desses dados (COTA et al. 2013).

Apenas em 2008, foi retomado o monitoramento isotópico da precipitação com o GNIP no Brasil, decorrente de iniciativas individuais, com a instalação de coleta mensal de precipitação em Belo Horizonte pelo Centro de Desenvolvimento de Tecnologia Nuclear (CDTN), seguido por Rio Claro no Centro de Estudos Ambientais (CEA/ UNESP) em 2013 e São Paulo na Universidade de São Paulo (USP) em 2018.

Com a instalação dessas primeiras estações de coleta da precipitação vinculadas à GNIP, foram realizados os primeiros estudos isotópicos em território nacional, desenvolvidos no Nordeste, promovidos pela Superintendência do Desenvolvimento do Nordeste (SUDENE), com intuito de identificar os mecanismos de recarga e salinização sobre os aquíferos nordestinos, e na Amazônia, com o objetivo de desvendar o papel da floresta Amazônica no balanço hídrico de sua grande bacia (SILVEIRA \& SILVA Jr. 2002, KIRCHHEIM et al. 2019).

Os estudos na bacia Amazônica tiveram reconhecimento internacional, demonstrando que o vapor proveniente da evapotranspiração da floresta (reevaporação) tem importante contribuição para geração de chuva na bacia, principalmente durante o período de inverno (abril-setembro) (MARQUES et al. 1977, DALL'OLIO et al. 1979, SALATI et al. 1979, MATSUI et al. 1983, GONFIANTINI 1985, GAT \& MATSUI 1991). Já naquela época, indicava-se que o desmatamento poderia provocar grandes mudanças no balanço hídrico local (MATSUI et al. 1983).

O importante papel da evapotranspiração se reflete na variabilidade isotópica da precipitação, que tem como característica principal, um efeito sazonal com valores empobrecidos durante o verão, associado à atuação da Zona de Convergência
Intertropical (ZCIT), e valores enriquecidos durante o inverno (SALATI et al. 1979, LEOPOLDO et al. 1982, MATSUI et al. 1983).

Este efeito sazonal estende-se para a região Centro-Sudeste do Brasil (GASTMANS et al. 2017a), sendo este fato demonstrado em estudos no estado de São Paulo (MARTINELLI et al. 2004; SANTOS et al. 2019a, b, c), e que realçaram a importância da evapotranspiração proveniente da floresta amazônica como fonte de umidade para a formação de chuvas na porção centro-sul do Brasil (MATSUYAMA et al. 2005). A variação sazonal indica que a origem e o caminho seguido pelo vapor são os principais controles sobre a variabilidade isotópica da chuva no estado de São Paulo, sendo o pano de fundo para interpretação do efeito de quantidade e da identificação dos tipos de chuva em estudos posteriores.

Além disso, avaliações moduladas em comparações interanuais (VUILLE \& WERNER 2005, SANTOS et al. 2019c), de longo prazo (GASTMANS et al. 2017a, SANTOS et al. 2019c) ou durante a ocorrência de eventos de El Niño Southern-Oscillation (ENSO) (SANTOS et al. 2019a), também demonstram que a origem, transporte e disponibilidade de vapor são mecanismos fundamentais para explicar a variabilidade da composição isotópica da precipitação.

Apesar da evolução do entendimento da variabilidade isotópica no Brasil, são escassos os estudos que avaliaram em escala nacional a variação espacial da composição isotópica da precipitação, com base nos dados das estações GNIP (GASTMANS et al. 2017a). Uma avaliação da distribuição espacial da composição isotópica da precipitação em território brasileiro feita com base nesses dados é apresentada na figura 3.

O zoneamento observado está diretamente relacionado à variabilidade climática observada, e pode ser dividido em três grandes zonas: i) parte da região Norte e Nordeste do Brasil: valores de $\delta^{18} \mathrm{O}$ $>-4,0 \%$ influenciados pela umidade oceânica (maritimidade) e a atuação da ZCIT; ii) toda a região oeste do país, que se estende do sul da Amazônia em direção ao centro-sul do país: valores mais depletados $\delta^{18} \mathrm{O}<-4,5 \%$, influenciados pela umidade re-evaporada da Amazônia e atuação da Zona de Convergência do Atlântico Sul (ZCAS), resultando em um efeito sazonal bem demarcado; iii) litoral sul do Brasil, composição isotópica entre $-5,5 \%_{0}<$ $\delta^{18} \mathrm{O}<-4,5 \%$, relacionada a ocorrência de sistemas extratropicais, como Frentes Frias (FF) e ciclones, marcada pela maritimidade. 

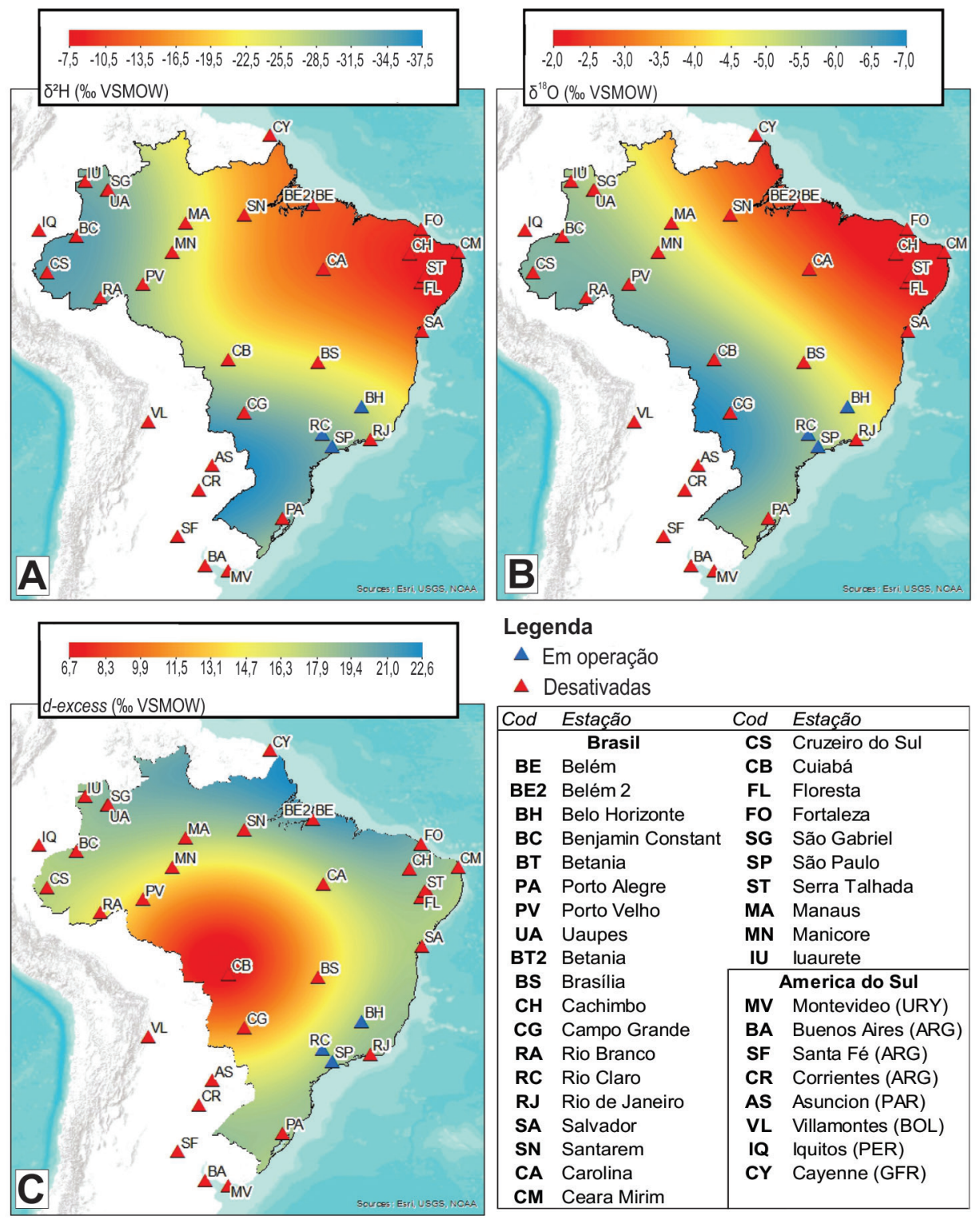

\section{Legenda \\ Em operação \\ - Desativadas}

\begin{tabular}{|c|c|c|c|}
\hline Cod & Estação & Cod & Estação \\
\hline & Brasil & CS & Cruzeiro do Sul \\
\hline BE & Belém & CB & Cuiabá \\
\hline BE2 & Belém 2 & FL & Floresta \\
\hline $\mathrm{BH}$ & Belo Horizonte & FO & Fortaleza \\
\hline BC & Benjamin Constant & SG & São Gabriel \\
\hline BT & Betania & SP & São Paulo \\
\hline PA & Porto Alegre & ST & Serra Talhada \\
\hline PV & Porto Velho & MA & Manaus \\
\hline UA & Uaupes & MN & Manicore \\
\hline BT2 & Betania & IU & luaurete \\
\hline BS & Brasilia & \multicolumn{2}{|c|}{ America do Sul } \\
\hline $\mathrm{CH}$ & Cachimbo & MV & Montevideo (URY) \\
\hline CG & Campo Grande & BA & Buenos Aires (ARG) \\
\hline RA & Rio Branco & SF & Santa Fé (ARG) \\
\hline RC & Rio Claro & CR & Corrientes (ARG) \\
\hline RJ & Rio de Janeiro & AS & Asuncion (PAR) \\
\hline SA & Salvador & VL & Villamontes (BOL) \\
\hline SN & Santarem & IQ & lquitos (PER) \\
\hline CA & Carolina & CY & Cayenne (GFR) \\
\hline CM & Ceara Mirim & & \\
\hline
\end{tabular}

FIGURA 3 - Distribuição espacial das médias ponderadas das composições isotópicas da precipitação no Brasil: (A) $\delta^{2} \mathrm{H}$; (B) $\delta^{18} \mathrm{O}$; (C) excesso de deutério. A localização das estações GNIP também é apresentada em todos os mapas (dados disponíveis em: https://www.iaea.org/services/networks/gnip).

A distribuição espacial da composição isotópica da chuva em território brasileiro, especialmente na região centro-sul do Brasil, é semelhante à observada nas águas subterrâneas de aquíferos livres por CHANG et al. (2020). É possível observar a influência exercida pela ZCAS na precipitação, refletindo-se na composição isotópica das águas subterrâneas, caracterizada pela existência de uma faixa com valores mais empobrecidos, tanto para chuva, como para as águas subterrâneas, que se estende do sul da Amazônia em direção a São Paulo e Paraná.
Também se observam valores mais enriquecidos para ambas as águas no litoral nordestino brasileiro, confirmando como os isótopos demonstram de maneira direta e objetiva a conexão entre as águas e seus diferentes reservatórios.

\section{ESTUDOS ISOTÓPICOS SOBRE AS ÁGUAS SUBTERRÂNEAS NO BRASIL}

Estudos hidrológicos utilizando isótopos estáveis de $\mathrm{H}$ e $\mathrm{O}$ vêm sendo realizados no Brasil des- 
de os anos 1960, juntamente com o estabelecimento mundial da técnica, e iniciaram-se motivados pela necessidade de se avaliar as águas subterrâneas no semiárido brasileiro e os processos de salinização associados, além da compreensão da movimentação da água na Bacia Amazônica (SILVEIRA \& SILVA Jr. 2002, KIRCHHEIM et al. 2018).

Em função do crescente uso de águas subterrâneas para o abastecimento público, especialmente no estado de São Paulo, a aplicação de isótopos estáveis em estudos sistemáticos dos aquíferos no Brasil iniciou-se na década de 1980 (SILVEIRA \& SILVA Jr. 2002). Os estudos pioneiros de GALLO \& SINELLI (1980), SILVA (1983), KIMMELMANN et al. (1986, 1989 e 1995) em muito auxiliaram na compreensão das condições de circulação e tempos de residência das águas subterrâneas no Aquífero Botucatu, como era conhecido na época o Sistema Aquífero Guarani (SAG).

A partir desses estudos iniciais, o levantamento de bases bibliográficas mostra que a produção científica brasileira sobre águas subterrâneas passou a considerar de maneira relevante a utilização de dados isotópicos, seja como suporte a estudos hidrogeoquímicos ou a compreensão da movimentação da água em diversos aquíferos brasileiros (Figura 4C). Com o advento da espectroscopia laser de cavidade oca nos anos 2010, uma técnica analítica mais simples e robusta (WASSENAR et al. 2014), observa-se um aumento importante na produção científica nacional e mundial (Figura 4A e 4E).

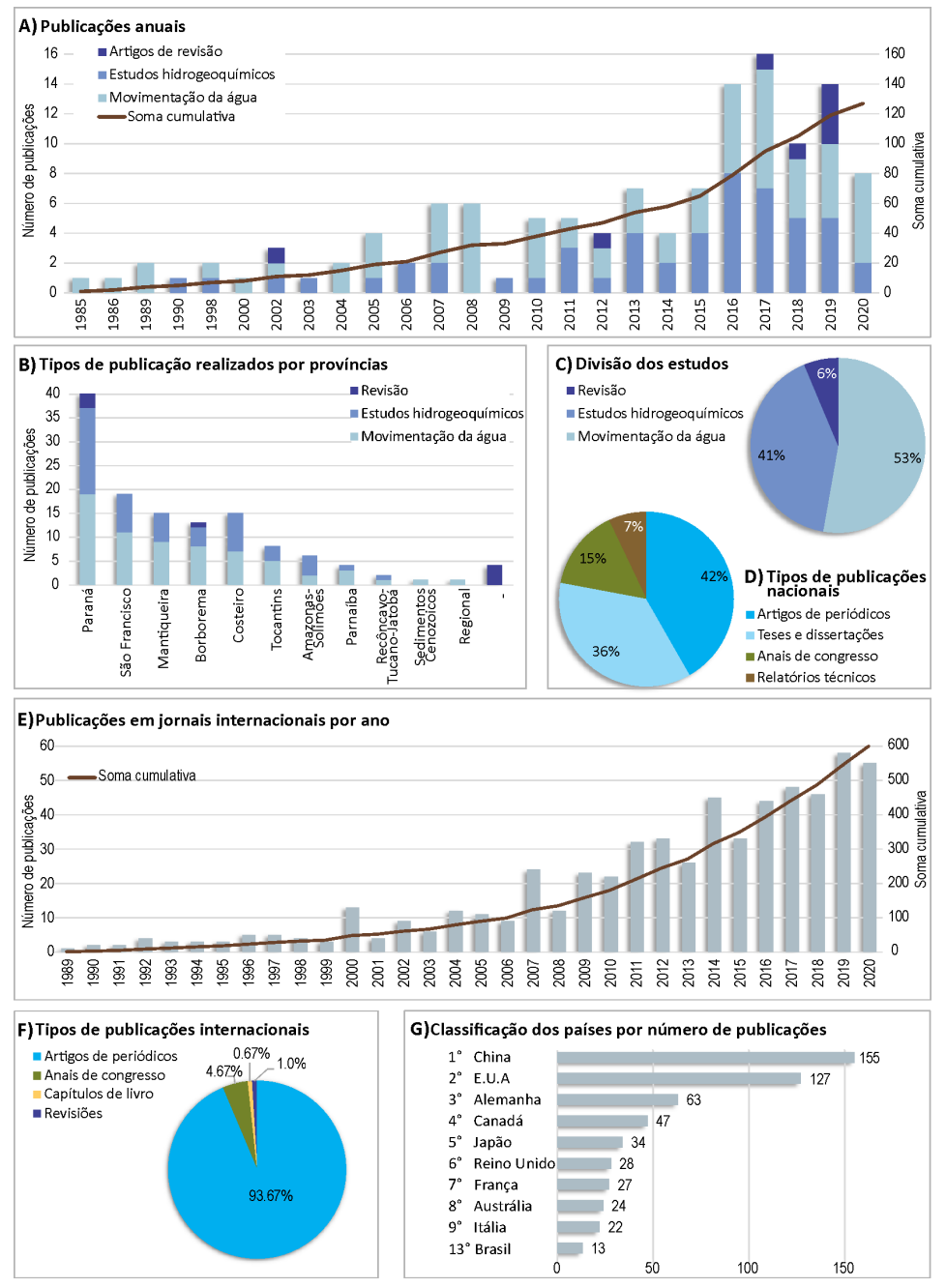

FIGURA 4 - Avaliação da produção científica nacional em relação ao número total de publicações (A), distribuição por províncias estruturais (B), classificação dos estudos (C) e tipos de publicação (D) no período de 1985-2020; a evolução das publicações internacionais com utilização de isótopos estáveis em hidrogeologia (E), os tipos de material bibliográfico (F) e os países de origem desses estudos (G) no período de 1989-2020 (Base de dados Scopus acessada em 16/09/2020). 
A divulgação da produção científica atual brasileira está dividida, essencialmente, entre artigos em revistas científicas (42\%) e dissertações e teses (36\%) (Figura 4D). Os resultados têm sido apresentados em conferências científicas, em fóruns importantes como o Congresso Brasileiro de Águas Subterrâneas (CABAS), organizado pela Associação Brasileira de Águas Subterrâneas (ABAS) a cada dois anos. Estudos realizados recentemente pela Agência Nacional de Águas (ANA) também vêm utilizando análises isotópicas como dados complementares em estudos regionais nos principais aquíferos brasileiros.

Entretanto, quando se analisa a divulgação internacional da produção científica brasileira, observa-se que, apesar do incremento em termos nacionais, internacionalmente, a inserção da produção brasileira ainda é incipiente, com um total de 13 artigos publicados entre 1989-2020, frente a um total de quase 600 artigos, publicados apenas no ano de 2020, em que isótopos foram utilizados em estudos hidrogeológicos (Figura 4G).

A maior parte dos estudos realizados sobre o tema concentra-se nos aquíferos da Bacia do Paraná, com mais de 30\% do total da produção científica no período, seguido por estudos na Bacia São Franciscana, representada por dois importantes sistemas aquíferos: o Sistema Aquífero Urucuia (SAU) e o Sistema Aquífero Cárstico (SAC). Estudos nos aquíferos fissurais das províncias da Mantiqueira e Borborema vêm a seguir. Ressalta-se o pequeno número de estudos realizados nas Bacias do Tucano-Recôncavo, uma vez que as águas subterrâneas representam um importante manancial para o abastecimento das populações locais, e extensos programas de perfuração de poços são realizados na área (Figura 4B e 5).

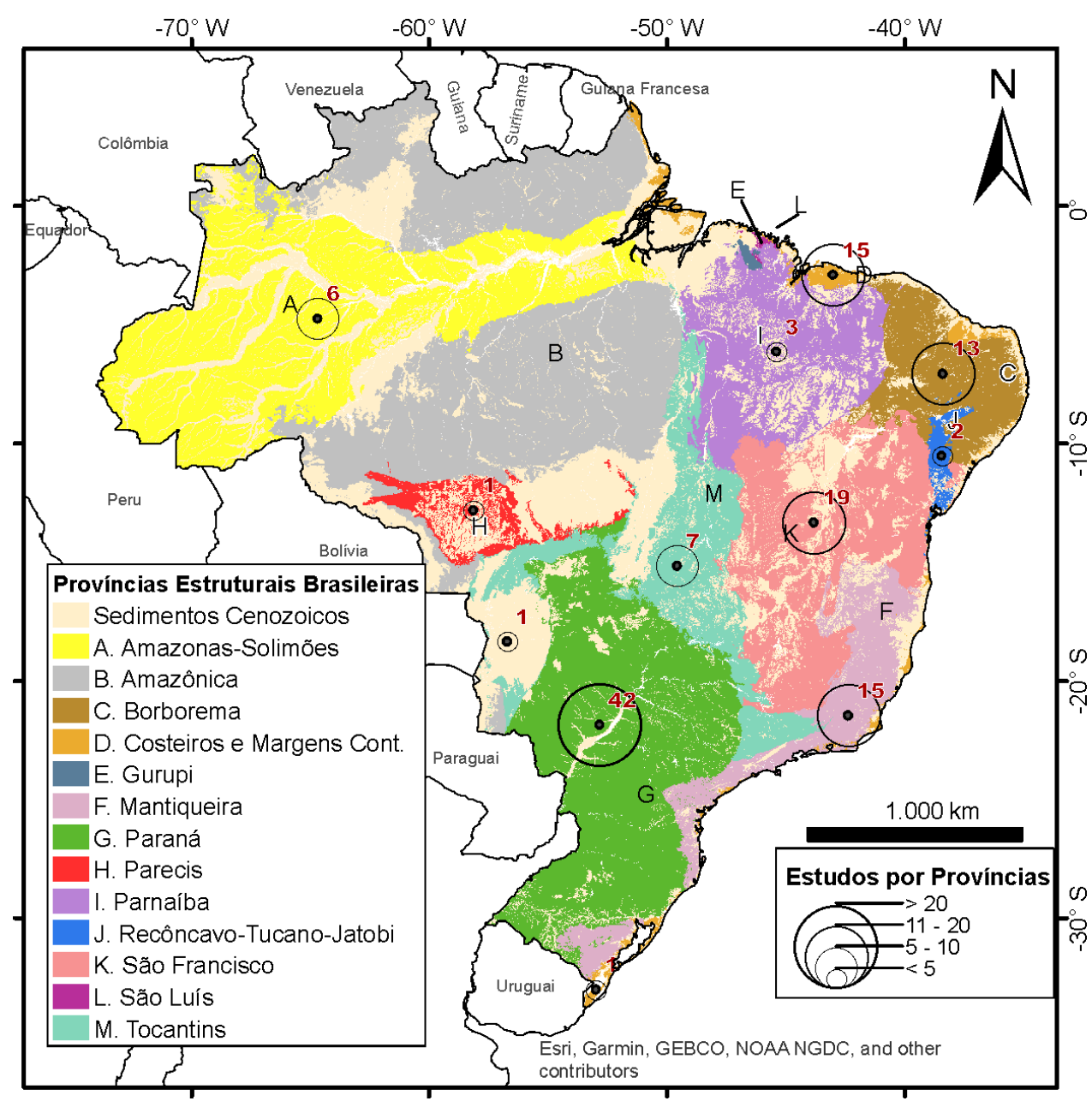

FIGURA 5 - Distribuição quantitativa dos estudos por província estrutural (Fonte: IBGE 2019). Essa distribuição será utilizada na apresentação dos estudos realizados e os principais resultados obtidos. 


\subsection{Estudos isotópicos em Aquíferos Cenozoicos}

O principal aquífero associado a sedimentos cenozoicos em território brasileiro está associado a uma Bacia Sedimentar Cenozoica ativa, representada pelas áreas alagadas do Pantanal Matogrossense. É uma região de baixa altitude e gradiente de inclinação extremamente baixo (menor que $1 \%$ ), formada principalmente por leques aluviais, planícies de inundação e sistemas deposicionais lacustres (ASSINE et al. 2015). Durante o período chuvoso, a propagação da inundação toma cerca de 4 a 6 meses (PADOVANI 2010). É a maior área alagada do mundo, com uma grande diversidade de ecossistemas, características que a qualificam como área de patrimônio mundial pela UNESCO, no qual as águas subterrâneas desempenham importante papel regulatório e são objeto de diversos estudos em áreas diversas como clima, solos, fauna, flora, hidrologia, entre tantos outros.

O Pantanal de Nhecolândia, situado no município de Corumbá (MS), é uma das maiores regiões da área pantaneira, caracterizada pela presença de áreas alagadas com características únicas: um mosaico de lagoas salinas arredondadas que dificilmente secam, e de água doce intermitentes, formadas nos períodos chuvosos.

Algumas questões relacionadas à dinâmica das águas subterrâneas e origem dessas lagoas foram estudadas com a aplicação de isótopos estáveis de $\mathrm{O}$ e H. ALMEIDA et al. (2010), com o objetivo de verificar os diferentes graus de isolamento hidráulico das salinas e das baías, analisaram amostras de águas superficiais e subterrâneas em três campanhas distintas. Os autores observaram um enriquecimento isotópico devido às altas taxas de evaporação nas salinas e secundariamente nas baías (valores médios de $\delta^{18} \mathrm{O}$ de $+10,5$ e $+6,8 \%$ respectivamente), enquanto as águas subterrâneas e superficiais são menos afetadas pela evaporação (valores médios de $\delta^{18} \mathrm{O}$ de $-1,9$ e $-1,5 \%$ respectivamente).

Como não foi analisada a composição isotópica da precipitação, e em função da posição topográfica relativa das salinas, abaixo das baías, os autores concluíram que o fluxo das águas subterrâneas também é responsável pela manutenção do volume de água reservado nas salinas (ALMEIDA et al. 2010).

Entretanto, quase uma década após, FREITAS et al. (2019) analisaram a dinâmica hidrológica da mesma região, com base em dados isotópicos e discordaram de ALMEIDA et al. (2010), entendendo que a recarga das águas subterrâneas na área de estudo ocorre nos baixos topográficos, por meio de um processo conhecido como recarga focada em depressão.

A origem das águas relacionada à precipitação e sua evolução devido a processos evaporativos é bastante claro, com uma reta de evaporação para a área com a seguinte equação: $\delta^{2} \mathrm{H}=$ $5,49 * \delta^{18} \mathrm{O}-8,45$ (Figura 6).

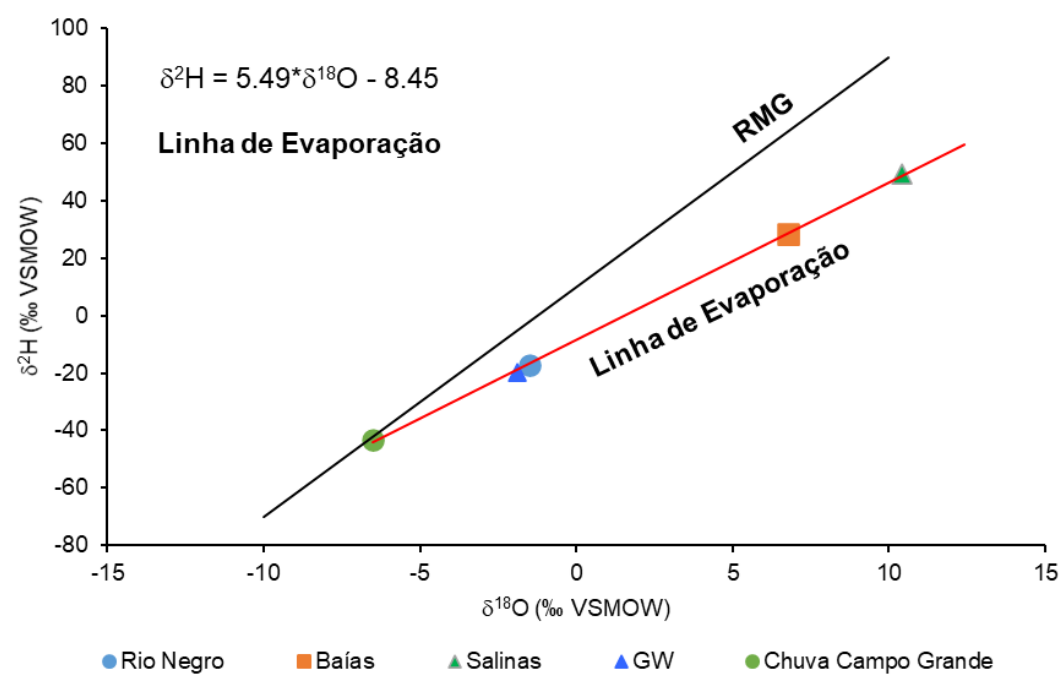

FIGURA 6 - Gráfíco $\delta^{18} \mathrm{O} v s \delta^{2} \mathrm{H}$ com a composição média das águas da precipitação em Campo Grande, e da região da Nhecolândia (superficial do Rio Negro, subterrâneas, baías e salinas). Observar a clara linha de evaporação formada a partir da chuva de Campo Grande, passando por pelas águas do Rio Negro e as águas subterrâneas (GW), que já apresentam sinais de evaporação (Modificado de ALMEIDA et al. 2010). 
4.2 Estudos isotópicos na Província Hidrogeológica Amazonas (PHA)

A Província Hidrogeológica Amazonas (PHA) compreende uma série de unidades aquíferas associadas a unidades estratigráficas que constituem as bacias sedimentares do Marajó, Amazonas, Solimões e Acre, que apesar de contíguas, possuem evoluções geológicas distintas e segmentadas por arcos estruturais. A PHA se desenvolveu sobre o Cráton Amazônico, composto pelo Escudo das Guianas e pelo Escudo Brasileiro (sistemas aquíferos fraturados), distribuída em cinco estados brasileiros: Amapá, Pará, Amazonas, Acre e Rondônia (Figura 5) (ANA 2015).

Embora seja a maior província em extensão no território nacional, com mais de 2 milhões de $\mathrm{km}^{2}$, seu conhecimento hidrogeológico ainda é incipiente, e consequentemente, a aplicação de técnicas isotópicas ainda não alcançou uma abrangência regional relevante. Os estudos hidrogeológicos com utilização de isótopos estáveis de $\mathrm{H}$ e $\mathrm{O}$ na PHA tiveram início na década de 70 , com foco nas águas superficiais e na chuva, seguidos de vários trabalhos relacionados à discussão do fracionamento isotópico da chuva e da evapotranspiração. A evolução dos estudos ocorreu com a caracterização do ciclo hidrológico, incluindo águas subterrâneas e expandindo o conhecimento das águas superficiais (SILVEIRA \& SILVA Jr. 2002, KIRCHHEIM et al. 2019).

Observa-se que, mesmo considerando a importância hidrogeológica da região, estudos com isótopos ambientais voltados às águas subterrâneas são escassos, e poucos trabalhos de escala local utilizaram isótopos ambientais, empregando essas informações como base para a construção de modelos conceituais de funcionamento dos sistemas aquíferos Alter do Chão (SAAC), e Içá-Solimões (SAIS) (LOPES 2005, SOUZA et al. 2015, PITA et al. 2018, AZEVEDO 2019, SILVA et al. 2020).

Independente da escala de estudo, o SAAC é sem dúvida o aquífero mais estudado na PHA. Classificado recentemente como o maior aquífero do planeta, com um volume maior que o SAG (ANA 2020), ele apresenta um comportamento hidrodinâmico complexo, com porções livres, semiconfinadas e confinadas (AZEVEDO 2019).

Nesse sentido, trabalhos combinando análises de dados hidrogeológicos, hidroquímicos e isotópicos auxiliaram na definição de modelos conceituais de fluxo em Porto de Trombetas (PA), mostrando que o SAAC é segmentado em várias pequenas bacias controladas por características estruturais, geomorfológicas (como por exemplo, platôs lateríticos bauxíticos, comuns na região) e lineamentos neotectônicos (AZEVEDO 2019).

$\mathrm{Na}$ região Metropolitana de Manaus, onde ocorre a interface entre o SAAC e o SAIS, o estudo combinado de hidrodinâmica, hidroquímica e isótopos permitiram aperfeiçoar o modelo conceitual de funcionamento do SAAC e definir duas origens para as águas subterrâneas na área: meteórica, resultando em águas pouco mineralizadas, associadas às camadas superiores em um aquífero livre e com recarga local; e uma origem remota, com águas mais mineralizadas, de maior tempo de residência e armazenada em aquífero confinado, mais profundo (PITA et al. 2018).

As condições climáticas da recarga dos aquíferos da Bacia Sedimentar do Acre (aquíferos Quaternário, Içá-Solimões e Tikuna) foram avaliadas a partir de dados isotópicos, uma vez que foram observadas diferenças entre a composição isotópica das águas subterrâneas (mais depletadas) do que a média ponderada da chuva. A partir de uma análise que envolveu estudos geológicos, hidroquímicos e de traçadores isotópicos, inclusive com a determinação dos tempos de residência, hipóteses foram levantadas para entender a recarga do sistema, que pode ocorrer em eventos de intensa chuva, ou recarregado sob condições climáticas diferentes das atuais (SILVA et al. 2020).

As águas mais jovens (até 6.000 anos) foram encontradas no Aquífero Tikuna, localizado abaixo do aquífero Içá-Solimões, que apresentou águas com tempos de residência superiores (entre 13.000 e 18.000 anos). Os autores descartam a possibilidade de recarga em região Andina, visto a idade relativamente jovem das águas, e sugerem que o tempo de trânsito é mais lento entre camadas do Içá (SILVA et al. 2020).

No ano de 2015, a Agência Nacional de Águas contratou um estudo objetivando uma caracterização dos aquíferos na PHA, envolvendo levantamentos locais em diversas regiões onde a utilização de água subterrânea mostrava-se relevante (ANA 2015). Foram avaliadas águas subterrâneas nos estados do Pará, Amazonas, Acre, Amapá e Rondônia, com foco principal na caracterização hidrogeológica e hidroquímica, e utilizando isótopos ambientais como ferramenta auxiliar. Ao todo foram analisadas 42 amostras de água subterrânea, $66 \%$ correspondendo aos sistemas aquíferos Alter do Chão e Içá, além de aquíferos aluviais. 
As águas subterrâneas apresentaram grandes variações em suas composições isotópicas, para o $\delta^{18} \mathrm{O}$ os valores variaram de $-8,13$ a $-4,38 \%$ e para o $\delta^{2} \mathrm{H}$ de $-50,8$ a $-21,96 \%$, com águas mais depletadas associadas às coberturas cenozoicas na cidade de Porto Velho, enquanto as amostras provenientes do aquífero costeiro na região da foz do Rio Amazonas, apresentaram os valores mais enriquecidos (ANA 2015). Esses valores são concordantes com a distribuição espacial da precipitação na região Amazônica (Figura 3).

Em todos os aquíferos da PHA foram identificadas misturas entre águas com recarga recente e águas mais antigas. Com a datação de águas subterrâneas utilizando o ${ }^{3} \mathrm{H} \mathrm{e} \mathrm{o}{ }^{14} \mathrm{C}$ como traçadores, definiram que os aquíferos superficiais apresentam tempos de residência inferiores a 3.000 anos, como o Sistema Aquífero Barreiras (<900 anos BP), o SAAC (2.100 a $2.700 \mathrm{BP})$ e o Aquífero Itaituba (> 900 anos BP), enquanto as águas subterrâneas armazenadas nos aquíferos confinados Pirabas e Tucunaré são mais antigas (>20.000 BP) (ANA 2015). Todos esses dados referem-se a amostras coletadas nas principais áreas urbanas da região amazônica.

\subsection{Estudos isotópicos na Província Borborema}

A Província Borborema localiza-se na região nordeste do território brasileiro. Inserida no contexto de clima semiárido e ocupando uma área de aproximadamente $380.000 \mathrm{~km}^{2}$ (Figura 5), representa uma das principais áreas de faixas de dobramento neoproterozoicas do país, constituindo parte de um sistema de orógenos diácronos resultantes do amalgamento do continente Gondwana Ocidental, ocorrido há aproximadamente 650-500 Ma (CPRM 1993).

Na região são reconhecidos aquíferos fraturados associados às rochas cristalinas predominantes na área, e aquíferos sedimentares localizados na região do Cariri, associados a duas bacias sedimentares encravadas nesse contexto de rochas magmáticas e metamórficas: a Bacia do Araripe, nos estados do Ceará, Pernambuco e Piauí, e os aquíferos sedimentares da Bacia Sedimentar Lavras da Mangabeira, em Pernambuco.

4.3.1 Sistemas Aquíferos Cristalinos na Província Borborema

Os primeiros estudos hidrogeológicos que envolveram a aplicação de isótopos ambientais nos aquíferos cristalinos da Província Estrutural da
Borborema foram realizados por FRISCHKORN et al. (1989), que estudaram as águas subterrâneas da Bacia Hidrográfica do Rio Acaraú. Com os resultados isotópicos, eles concluíram que as relações de ${ }^{18} \mathrm{O} /{ }^{16} \mathrm{O}$ exibem características claras da água da chuva, sem sinais de evaporação de superfície, e ainda que, a recarga acontece através da superfície rápida de escoamento após chuvas fortes.

A partir de medidas de razões $\delta^{18} \mathrm{O}$ e ${ }^{87} \mathrm{Sr} r{ }^{86} \mathrm{Sr}$ na água de abastecimento, na chuva e na água do lençol freático de Fortaleza, FRISCHKORN et al. (2002) estimaram as contribuições de águas "importadas", provenientes do sistema de abastecimento, que poderiam contribuir para a recarga das águas subterrâneas. As águas subterrâneas apresentaram assinaturas isotópicas enriquecidas $\left(\delta^{18} \mathrm{O}\right.$ entre $+1,08 \%$ e $+4,70 \%$ e média de $+3,07 \%$ ), evidenciando que sua origem estava associada a águas que passaram por processos evaporativos, indicando que $30 \%$ da água que recarrega o lençol freático tem origem nas fossas presentes nessa região. $\mathrm{O}$ trabalho visava avaliar essa porcentagem devido a uma implantação de serviço de esgoto na região, o que poderia causar um rebaixamento do lençol freático com consequências para o desempenho dos poços existentes, a sustentação de construções, as propriedades mecânicas dos solos e a posição da interface água doce/água do mar na orla marítima, com uma possível intrusão marinha.

A avaliação de dados hidroquímicos e isotópicos possibilitou a caracterização de uma área preservada localizada na Bacia de Aiuaba, região sudoeste do estado do Ceará. As águas do açude construído na área apresentaram claros sinais de evaporação, com valores para o $\delta^{2} \mathrm{H}$ variando entre $+61,13$ a $+81,21 \%$ em águas coletadas em um tanque, e entre $+61,13$ a $+79,92 \%$ em açude localizado na área. A relação entre os volumes de água evaporados e infiltrados no aquífero foi estimada a partir da utilização de três modelos distintos indicando que o açude estudado contribui para a recarga do fluxo de base de um riacho local, o que diminui os efeitos negativos das ações antrópicas sobre as reservas de água subterrânea (PEREIRA 2006).

A Bacia Hidrográfica do Rio Banabuiú, localizada no sertão central do estado do Ceará, foi estudada por MOURA (2013), com o objetivo de se determinar os mecanismos de recarga dos aquíferos aluvionares dessa região. A partir da análise de amostras de chuva (valores médios para $\delta^{18} \mathrm{O}$ de $-1,95 \%$ e $-5,84 \%$ p para $\delta^{2} \mathrm{H}$ ), do açude (valores de $\delta^{18} \mathrm{O}$ entre $-0,74 \mathrm{a}+1,07 \%$ ), e de águas subterrâneas do aquífero cristalino $\left(\delta^{18} \mathrm{O}\right.$ e $\delta^{2} \mathrm{H}$ com mé- 
dia de $-1,95 \%$ e $-13,77 \%$, respectivamente) e do aquífero aluvionar $\left(\delta^{18} \mathrm{O}\right.$ e $\delta^{2} \mathrm{H}$ médias de $+0,12 \%$ e $-4,31 \%$, respectivamente), o autor concluiu que a reta meteórica local é semelhante a reta meteórica global, que os aquíferos aluvionares recebem alimentação pelos rios Quixeramobim e Banabuiú (mais enriquecidas), com claros sinais de evaporação durante a recarga, e finalmente, que as águas dos poços do domínio cristalino sofreram recarga apenas por águas meteóricas.

Avançando na compreensão dos mecanismos de recarga e idades das águas subterrâneas nos aquíferos cristalinos do estado do Ceará, KREIS et al. (2020) observaram que a recarga ocorre através de zonas preferenciais de infiltração, mas que processos de evaporação são dominantes na assinatura isotópica, indicando que a recarga esteja também associada a acúmulo de água em depressões no terreno que acumula água durante o período chuvoso.

No Estado de Pernambuco, SILVA (2016) realizou estudo no Aquífero Cristalino, com o objetivo de avaliar a evolução da composição isotópica das águas subterrâneas antes e depois da implantação da recarga artificial na cidade de Petrolina. Os testes realizados mostraram que o sistema apresenta viabilidade hidráulica, e que seu sucesso depende da adequada localização e construção do sistema piloto.

4.3.2 Sistemas Aquíferos Sedimentares da Região do Cariri (Bacias Sedimentares Lavras da Mangabeira e do Araripe)

GRANJEIRO (2008) realizou estudo na região da Bacia Sedimentar Lavras da Mangabeira, utilizando dados isotópicos para caracterizar a recarga na região. A composição isotópica das águas subterrâneas indicou que as águas sofreram processos de evaporação $\left(\delta^{18} \mathrm{O}\right.$ entre $+0,2$ e $-3,1 \%$ e os valores de $\delta^{2} \mathrm{H}$ entre $-3,6$ e $-17,9 \%$ ), e a provável recarga se daria através dos riachos de cada sub-bacia.

A Bacia Sedimentar do Araripe está localizada na porção sul da Província de Borborema, e apresenta um arcabouço hidrogeológico constituído por uma sequência de aquíferos e aquitardes intercalados. Essas unidades foram divididas por MONT'ALVERNE et al. (1996) em três grandes unidades hidroestratigráficas: o Sistema de Aquífero Superior (SAR) que engloba as formações Exu e Arajara; o Sistema Aquífero Médio (SAM), constituído pelas formações Rio da Batateira, Abaiara e Missão Velha e o Sistema de Aquífero Inferior (SAI), constituído pela Formação Mauriti e parte basal da Formação Brejo Santo. Limitando o SAR do SAM ocorre o Aquiclude Santana, entre o SAM e o SAI o Aquiclude Brejo Santo.

Analisando conjuntamente a condutividade elétrica das águas subterrâneas, os valores de $\delta^{18} \mathrm{O}$ e os conteúdos de isótopos radioativos $\left({ }^{3} \mathrm{H} \mathrm{e}{ }^{14} \mathrm{C}\right)$, SANTIAGO et al. (1997) apresentam a caracterização das águas subterrâneas do Vale do Cariri, bem como um modelo conceitual de fluxo baseado nas diferenças observadas. Esse modelo engloba as unidades superiores da Chapada do Araripe e as inúmeras surgências existentes na região.

Segundo esses autores, as águas subterrâneas do Aquífero Rio da Batateira apresentam baixa mineralização, caracterizada por condutividades elétricas inferiores a $200 \mu \mathrm{S} . \mathrm{cm}^{-1}, \mathrm{com}^{14} \mathrm{C}$ acima de $70 \mathrm{PCM}$ e valores de $\delta^{18} \mathrm{O}$ entre $-3,5 \%$ e $-2,5 \%$, próximos a composição isotópica da precipitação. Já as águas do Aquífero Missão Velha apresentam condutividades elétricas superiores, variando entre 300 e $600 \mu \mathrm{S} . \mathrm{cm}^{-1}$, com ${ }^{14} \mathrm{C}$ entre 25 e $100 \mathrm{PCM}$ e valores de $\delta^{18} \mathrm{O}$ entre $-5,1 \%$ e $-3,0 \%$. Os valores mais enriquecidos estariam associados a recarga direta pela precipitação, enquanto fluxos ascendentes de águas mais antigas, seriam responsáveis pelos valores mais empobrecidos (SANTIAGO et al. 1997).

$\mathrm{Na}$ base da sequência hidroestratigráfica, o Aquífero Mauriti é caracterizado pelo armazenamento de águas com condutividades elétricas variando entre 600 e $1000 \mu \mathrm{S} . \mathrm{cm}^{-1}$, com ${ }^{14} \mathrm{C}$ entre $5 \mathrm{e}$ $100 \mathrm{PCM}$ e valores de $\delta^{18} \mathrm{O}$ entre $-3,8 \%$ e $-2,8 \%$. Os autores observam que, apesar das evidências de águas mais antigas e empobrecidas, todas as unidades apresentam evidências de recargas pela precipitação atual (SANTIAGO et al. 1997).

Avaliações sazonais das variações na composição isotópica de poços na Chapada do Araripe captando água no Aquífero Rio da Batateira, em situação de confinamento pelos calcários da Formação Santana, realizadas por MENDONÇA et al. (2004) e MENDONÇA et al. (2005), indicam que as razões isotópicas $\delta^{18} \mathrm{O}$ permanecem constantes ao longo de um ano de observação, mantendo valores de aproximadamente $-4,7 \%$. Os autores salientam para os valores um pouco mais depletados que àqueles observados na precipitação atual, apontando recarga ocorrida sob condições mais frias.

As variações sazonais na composição isotópica dos aquíferos situados na região do Vale do Cariri vêm sendo avaliados de maneira continua pela Companhia de Gestão de Recursos Hídricos 
do estado do Ceará (COGERH) (COGERH 2009, 2011 e 2017). Esse monitoramento é realizado em poços perfurados nas unidades constituintes dos aquíferos Médio e Inferior.

Inicialmente observou-se que nos municípios de Barbalha, Crato, Juazeiro do Norte e Missão Velha, logo após o período chuvoso, as águas subterrâneas apresentam valores para $\delta^{18} \mathrm{O}$ em torno de $-3,2 \%$, considerado o valor de referência para a precipitação, o que indicaria a recarga por chuvas recentes, enquanto durante o período seco observa-se em alguns poços, que as águas subterrâneas apresentam valores de $\delta^{18} \mathrm{O}$ bastante negativos ( -5\%), indicando a extração de águas mais antigas em alguns poços, que por questões construtivas captam águas de distintas unidades, especialmente nos municípios de Barbalha e Juazeiro do Norte, daqueles de Crato e Missão Velha, onde foi constatada a possibilidade de mistura de águas mais recentes com águas mais depletadas e antigas (COGERH 2009).

Entre os meses de janeiro e outubro de 2011 foi efetuada nova campanha de amostragem em poços na região do Vale do Cariri, e os resultados apontam que a recarga ocorreu em toda a área monitorada logo no início da estação chuvosa, com exceção de dois locais; estes resultados, obtidos das medidas isotópicas, mostram que as águas são regularmente renovadas principalmente em um ano de elevada pluviosidade, como em 2011 (COGERH 2011).

Novo estudo foi realizado pela COGERH entre janeiro/2016 e novembro/2017, compreendendo a coleta de amostras em 80 poços, em quatro campanhas, representando o SAM (64 poços) e o SAI (16 poços). No período também foram coletadas amostras de precipitação, que permitiram uma avaliação preliminar das variações sazonais da composição isotópica da chuva. Para o SAI as composições isotópicas variaram de $-5,52$ a $-2,74 \%$ para o $\delta^{18} \mathrm{O}$, com pequena variação entre as campanhas e uma tendência às águas mais empobrecidas apresentarem maiores valores de condutividade elétrica, indicando que essas águas se encontram armazenadas em camadas confinadas sem renovação pela infiltração da água da chuva (COGERH 2017, TEIXEIRA et al. 2018).

Para as amostras coletadas no SAM, observou-se uma variação de $-5,18$ a $-1,84 \%$ para as razões de $\delta^{18} \mathrm{O}$, com uma maior variação entre as campanhas, que indicariam uma possibilidade de misturas de águas de diferentes origens. Em alguns poços, a ocorrência de recarga é refletida pela va- riação sazonal observada na composição isotópica e nos valores de excesso de deutério, que indicam a ocorrência de evaporação durante a infiltração das águas meteóricas (COGERH 2017, TEIXEIRA et al. 2018).

\subsection{Estudos isotópicos na Província Costeira}

A aplicação de isótopos estáveis em estudos dos aquíferos costeiros em território brasileiro vem auxiliando na compreensão de processos relacionados à qualidade das águas subterrâneas, como suporte às avaliações hidroquímicas, permitindo a compreensão de processos de recarga em casos específicos, em que se observam processos de salinização, decorrentes da extensa explotação do recurso.

A principal unidade aquífera da Província Costeira é o Sistema Aquífero Barreiras, que tem sua distribuição espacial por todo o litoral brasileiro, desde o Pará até o Rio de Janeiro (SILVA et al. 2002), que ocorrem como extensos tabuleiros costeiros e formam uma superfície elevada, plana e pouco dissecada, sendo utilizado especialmente nas regiões Norte e Nordeste do Brasil. Importantes cidades utilizam sua água para o abastecimento, como: Maceió (AL), Belém (PA), São Luís (MA) e Itarema (CE).

No litoral dos estados do Rio Grande do Norte e do Ceará, as unidades associadas à Bacia Potiguar, que compreendem o aquífero cárstico associado a Formação Jandaíra e o aquífero poroso associado aos arenitos da Formação Açu, constituem um típico caso de aquíferos transfronteiriços dentro do território brasileiro, e representam uma importante fonte de água para a atividade agrícola na região, fortemente dependente da irrigação.

\subsubsection{Sistema Aquífero Barreiras}

Estudos hidrogeológicos foram realizados pela ANA nas regiões metropolitanas de Maceió (AL) (ANA, 2011) e Belém (PA) (ANA 2018), para as quais análises das razões isotópicas foram utilizadas como uma avaliação suplementar da análise qualitativa.

$\mathrm{Na}$ região metropolitana de Maceió (AL) foram coletadas amostras em 20 poços tubulares profundos, com valores de $\delta^{18} \mathrm{O}$ entre $-1,08 \mathrm{e}$ $-1,76 \%$ (média $-1,41 \pm 0,19 \%$ ) e de $\delta^{2} \mathrm{H}$ entre $-1,90$ e $+2,40 \%$ (média $+0,29 \pm 1,31 \%$ ), posicionadas acima da Reta Meteórica Global, mas próximos à composição dos Oceanos ( $0 \%$ para $\delta^{18} \mathrm{O}$ e $\left.\delta^{2} \mathrm{H}\right)$. A conclusão dos estudos indica que a recarga do 
aquífero é lenta, sujeita a evaporação antes da infiltração, e sugere que a recarga possa ocorrer a partir da água nas lagoas (ANA 2011).

$\mathrm{Na}$ cidade de Belém (PA) foram coletadas amostras de diversas unidades aquíferas utilizadas para o abastecimento, sendo 13 delas provenientes de poços com captação no Sistema Aquífero Barreiras. De acordo com o relatório, essas águas são geralmente mais enriquecidas que àquelas coletadas nos aquíferos subjacentes, apresentando claros efeitos de evaporação. A composição isotópica dessas águas apresenta valores de $\delta^{18} \mathrm{O}$ entre $-4,0$ e - $2,5 \%$ (média de $-3,1 \%$ ) e para os valores de $\delta^{2} \mathrm{H}$ entre $-18,0$ e $-9,0 \%$ (média de -15,0\%) (ANA 2018).

Estudos foram realizados na região metropolitana de São Luís (MA), também com o objetivo de avaliar a qualidade e identificar as condições de recarga do aquífero. Apesar do intervalo de tempo entre as duas publicações (PEREIRA et al. 2004, BARROS et al. 2015), os resultados apresentados e as conclusões são coincidentes. Mesmo com as estações bem marcadas, a composição isotópica das águas subterrâneas apresenta pouca variação entre o período seco e o chuvoso, entretanto, esses valores indicam que a recarga acontece nos períodos de chuvas mais intensas (BARROS et al. 2015).

O município de Itarema, na Zona Costeira do Ceará, também foi alvo de estudo relacionado à qualidade das águas subterrâneas, com o intuito de auxiliar no planejamento da urbanização, juntamente com o manejo da água. A avaliação da composição isotópica em poços rasos do Aquífero Barreiras permitiu identificar três grupos: um com efeito quantidade marcado, o segundo com efeito de recarga direta atual e o outro com efeito de infiltração de água evaporada de mananciais superficiais (ROCHA 2015).

As pesquisas com isótopos estáveis em regiões costeiras são, em grande parte, para compreender a movimentação da água e o processo de salinização, associado ao avanço de cunhas salinas para o continente, devido ao aumento do consumo e uso desregulado das águas subterrâneas.

Processos de salinização e de recarga das águas subterrâneas do Sistema Aquífero Barreiras foram estudados nas cidades de Fortim e Aracati, na região costeira do Baixo Jaguaribe no Ceará, com utilização dos isótopos estáveis. Os resultados mostraram que a composição isotópica das águas subterrâneas apresentou variação sazonal $\left(\delta^{18} \mathrm{O}\right.$ entre $-4,12$ e $-0,29 \%$ no período chuvoso e $-3,83$ e $+0,42 \%$ no período seco, e $\delta^{2} \mathrm{H}$ entre $-1,16 \%$ e
$+7,47 \%$ no período chuvoso e $-16,86$ e $+12,9 \%$ o no período seco), entretanto os valores de excesso de deutério são semelhantes para as duas estações $(\sim 11 \%)$, o que indica a inexistência de evaporação durante a recarga, que ocorreria preferencialmente durante a estação seca (CARACAS 2013).

4.4.2 Sistemas Aquíferos da Chapada do Apodi - Bacia Potiguar

Localizada na divisa entre os estados do Rio Grande do Norte e o Ceará, a Bacia Potiguar estende-se por cerca de $50.000 \mathrm{~km}^{2}$, dos quais $45 \%$ emersos, e tem sua evolução associada ao processo de abertura e rifteamento da margem continental brasileira. Em seu arcabouço hidrogeológico são reconhecidas duas unidades aquíferas importantes para a região: Sistema Aquífero Açu (SAA) e o Sistema Aquífero Jandaíra (SAJ), o primeiro associado a sedimentos fluviais da formação homônima, e o segundo associado a carbonatos depositados em plataforma de mar raso (MIRANDA 2011).

Buscando compreender as relações existentes entre as águas superficiais e as águas subterrâneas do SAJ, GOMES et al. (2007) utilizaram as razões isotópicas como traçadores. Os resultados indicaram que as águas subterrâneas são mais depletadas $\left(\delta^{18} \mathrm{O}\right.$ com média de $-2,43 \pm 0,1 \%$ ) que as águas superficiais $\left(\delta^{18} \mathrm{O}\right.$ com média de $+1,6 \pm$ $0,1 \%$ ), sugerindo que não existe uma conexão clara entre os rios e o aquífero. Entretanto, os valores da composição isotópica da precipitação na área $\left(\delta^{18} \mathrm{O}\right.$ com média de $-3,2 \%$ ) sugerem a ocorrência de evaporação durante a recarga do SAJ. Os autores ainda observaram que o aquífero fluvial, associado a depósitos aluvionares ao longo do Rio Quirexé, é recarregado pela precipitação, especialmente nas regiões em que a pressão exercida pelo bombeamento das águas é menor.

No ano de 2010, a Agência Nacional de Águas (ANA) desenvolveu um trabalho de avaliação dos recursos hídricos subterrâneos e proposição de um modelo de gestão compartilhada para os aquíferos da Chapada do Apodi. As diferenças observadas nas composições isotópicas das águas subterrâneas indicam que o SAA armazena paleoáguas $\left(\delta^{18} \mathrm{O}<-4 \%\right)$ que não recebem recarga do ciclo hidrológico atual, como acontece com o SAJ $\left(\delta^{18} \mathrm{O}>-4 \%\right)$, e que a ocorrência de águas mais enriquecidas no SAA estaria provavelmente associada ao rebaixamento produzido pelo bombeamento excessivo nos poços de abastecimento público (ANA 2010). 
A variação sazonal observada na composição isotópica das águas subterrâneas do SAJ mostra que a recarga ocorreria no início de janeiro, caracterizado por águas mais empobrecidas e valores menores de excesso de deutério, enquanto as amostras coletadas em setembro, mais enriquecidas e excesso de deutério inferior ao das amostras coletadas em janeiro, refletiriam o efeito da dissolução dos calcários (ANA 2010).

\subsubsection{Sistemas Aquíferos da Cabo e Beberibe}

Uma série de estudos foram realizados na Região Metropolitana de Recife (RMR), no intuito de compreender o processo de salinização na área. As avaliações se estenderam nos aquíferos profundos do Barreiras, o Cabo e o Beberibe, e no aquífero freático Boa Viagem. O primeiro estudo isotópico de COSTA FILHO et al. (1998) indica que a salinização dos aquíferos costeiros não ocorriam pelo avanço da cunha salina. Segundo os autores, provavelmente os sais teriam sido originados em um processo de dissolução das rochas e/ou mistura com águas provenientes dos manguezais.

De acordo com PAIVA (2004), os aquíferos na planície da RMR são interconectados verticalmente, e mais vulneráveis a contaminações dos aquíferos freáticos, como por exemplo o Boa Viagem. As análises isotópicas indicaram que o rio Capibaribe atua como um caminho de aceleração da salinização dos aquíferos, com significativa participação das águas superficiais no processo de salinização.

$\mathrm{O}$ projeto de pesquisa franco-brasileiro Coqueiral (2012 a 2015) representa os estudos mais recentes na RMR. Seu principal objetivo foi compreender os processos de salinização e a qualidade da água na questão urbana, por meio de uma avaliação conjunta de diversos traçadores (gases nobres, ${ }^{14} \mathrm{C}$, CFCs e SF6, ${ }^{86} \mathrm{Sr} r{ }^{88} \mathrm{Sr}$, $\delta^{11} \mathrm{~B}$, isótopos estáveis de $\mathrm{H}$ e $\mathrm{O}$ e C (CARY et al. 2015, CHATTON et al. 2016, BERTRAND et al. 2017). Os resultados do projeto corroboram em partes com as hipóteses levantadas por COSTA FILHO et al. (1998) e PAIVA (2004). As assinaturas químicas refletem a história e os caminhos percorridos pela água, sendo possível traçar os principais processos relacionados. As assinaturas isotópicas de $\mathrm{Sr}$ e $\mathrm{B}$ permitiram a identificação de uma transgressão marinha ocorrida durante o Pleistoceno. A região apresenta uma variedade de estratificações típicas de estuários com paleomangues, leques aluviais, camadas arenosas e argilosas (CARY et al. 2015). A dinâmica dos sistemas aquíferos foi recentemente afetada por proces- sos de mistura entre paleoáguas e águas modernas contaminadas, tendo como origem o aquífero livre Boa Viagem (CHATTON et al. 2016). Os autores notaram também que as intrusões salinas recentes ocorrem sob novas condições hidráulicas (modificação das direções de fluxos, causadas por intenso bombeamento) e por caminhos preferenciais através de paleocanais e paleomangues (formados na última transgressão marinha), estuários recentes e através do canal do Rio Capibaribe (CARY et al. 2015, CHATTON et al. 2016).

Quanto aos processos de recarga, os aquíferos rasos indicaram recarga por precipitação moderna seguido de processos evaporativos secundários. Em contraste, aquíferos profundos apresentam assinaturas mais enriquecidas do que os aquíferos recentes, sem significativa evaporação. Os padrões do excesso de deutério contrastam com as recargas usuais das paleoáguas em condições mais frias e úmidas do que diversos outros lugares do mundo, especialmente em ambientes subtropicais (BERTRAND et al. 2017).

\subsection{Estudos isotópicos na Província Mantiqueira}

A Província Mantiqueira representa uma unidade geotectônica localizada a leste dos crátons São Francisco e Rio de La Plata/Paraná, com rochas magmáticas e metamórficas de idades que vão do final do Neoproterozoico até início do Paleozoico. Estende-se por cerca de 3.000 km com orientação NNE-SSW ao longo da costa atlântica, de Montevidéu (Uruguai) ao sul da Bahia (Figura 5). Seu arcabouço hidrogeológico compreende uma série de aquíferos fraturados associados às unidades geológicas aflorantes, e os estudos hidrogeológicos realizados visam, essencialmente, a caracterização de estâncias hidrotermais presentes na região e a compreensão dos processos de recarga em diversas localidades.

As estâncias hidrotermais do sul de Minas Gerais foram alvo de dois estudos recentes, nos quais os isótopos estáveis de $\mathrm{He} \mathrm{O}$ foram utilizados em conjunto com outros dados hidroquímicos para se estabelecer as condições de ocorrência da mineralização dessas águas. SOLER \& BONOTTO (2020) utilizaram isótopos estáveis de O e H combinados ao de $\mathrm{S}$ para compreensão de processos de circulação natural e recarga em fontes de águas termais e minerais. A variação isotópica encontrada nas águas subterrâneas foi de $-14,1$ a $-5,7 \%$ para o $\delta^{18} \mathrm{O}$ e - 66,5 a $-31,5 \%$ p para o $\delta^{2} \mathrm{H}$, alinhando-se à reta meteórica global, sem uma relação direta entre a composição isotópica e algum efeito de altitude. 
Outro estudo de caráter técnico foi efetuado com o intuito de fazer a caracterização da origem das águas minerais do circuito das águas de Minas Gerais. Com ênfase nos parques hidrotermais de Caxambu, Cambuquira-Marimbeiro, Contendas e Lambari, foi utilizada uma série de traçadores, dentre os quais isótopos estáveis de $\mathrm{H} \mathrm{e} \mathrm{O}$ de amostras coletadas em diferentes campanhas, para identificar diferentes origens para as águas minerais (interação água-rocha e fluxo), bem como seu tempo de residência (PEDROSA-SOARES et al. 2018). Uma das boas iniciativas desse estudo foi a coleta de amostras da precipitação ao longo de um ano (2017-2018), como forma de se obter valores de referência para as águas subterrâneas e das fontes da região.

Para todas as localidades foram identificadas fontes, algumas delas carbogasosas, com águas de circulação mais profunda, com composição isotópica mais depletada que a média da precipitação local $\left(\delta^{18} \mathrm{O}<-7,5 \%\right)$, bem como fontes de circulação mais rasa, com composição isotópica próxima da composição média da precipitação local. Algumas fontes apresentam a possiblidade de mistura entre águas recentes e paleoáguas, evidenciada pela variação sazonal na composição isotópica dessas fontes (PEDROSA-SOARES et al. 2018).

Valores de $\delta^{18} \mathrm{O}$ foram utilizados junto aos de trítio para identificação das fontes e mistura de águas subterrâneas, e interconexão com os rios presentes em Poços de Caldas (MG) (MINARDI \& BOMTEMPO 2000).

Com vistas a investigar os possíveis impactos nas águas subterrâneas em área próxima a uma antiga mina de urânio devido a drenagem ácida, ALBERTI (2017) realizou um estudo no qual utilizou isótopos de $\mathrm{O}$ e $\mathrm{H}$ para fornecer informações sobre os fluxos subterrâneos e suas origens, identificando fluxos mais rasos, com possibilidade de relação com a drenagem ácida existente na área, e amostras com circulação mais profundas, sem indícios de contaminação. Misturas entre essas águas também foram encontradas.

$\mathrm{Na}$ bacia do Rio Itapemirim, no estado do Espírito Santo, com o objetivo de compreender os processos de recarga, NEVES et al. (2016) e OLIVEIRA et al. (2019) identificaram processos de recarga homogênea com assinaturas que indicam recarga recente e rápida, devido a semelhança entre as assinaturas das águas subterrâneas e da chuva.

Em estudo visando a caracterização hidrogeoquímica das águas subterrâneas do aquífero cris- talino na cidade de Porto Alegre (RS), SANTOS (2017) observou que as águas subterrâneas apresentam variação entre $-5,01$ e $-4,26 \%$ para o $\delta^{18} \mathrm{O}$ e $-37,3$ e $-22,9 \%$ para o $\delta^{2} \mathrm{H}$, e a variação estaria associada a processos de recarga rápida, além de controles geogênicos e antropogênicos nas águas subterrâneas.

Com objetivos semelhantes, GOMES (2012), realizou a caracterização de pequenas unidades sedimentares na cidade do Rio de Janeiro (RJ) (Aquíferos Macacu, Aluvial-Lacustrino e FluvialMarinho). A variação isotópica encontrada nas águas subterrâneas foi de $-6,40$ a $-3,64 \%$ para o $\delta^{18} \mathrm{O}$ e $-40,6$ a $-19,7 \%$ para o $\delta^{2} \mathrm{H}$. O autor identificou zonas de recarga e descarga e processo de recarga indireta proveniente do aquífero fraturado, recarga direta da chuva e mistura entre a recarga direta e intrusão marinha.

Diversos estudos empregando isótopos de $\mathrm{H}$ e $\mathrm{O}$ também foram realizados na cidade de São Paulo (DIAS 2005, VIVIANI-LIMA 2007, MARTINS 2008, PINO 2009, SILVA 2018) e no interior do estado de São Paulo (AYER et al. 2016, ENGELBRECHT 2017, CORRÊA 2019), investigando os processos de recarga no aquífero sedimentar e/ou cristalino com o intuito de identificar a origem das águas e a vulnerabilidade dos aquíferos urbanos. A variação geral das composições isotópicas encontradas nas águas subterrâneas por esses autores foi de -8 a $-2,5 \%$ para o $\delta^{18} \mathrm{O}$ e -54 a $-21 \%$ para o $\delta^{2} \mathrm{H}$.

Os resultados encontrados nesses estudos destacam-se por descrever processos de recarga rápida ou recente e um curto período de residência (ENGELBRECHT 2017, SILVA 2018). Em alguns casos, os resultados indicaram que a alteração na composição isotópica foi causada pela influência da urbanização, em que a recarga indireta por vazamento da rede de distribuição representa uma importante contribuição (DIAS 2005, VIVIANILIMA 2007, MARTINS 2008, SILVA 2018).

Na região litorânea do estado de São Paulo, os isótopos estáveis foram usados para compreensão dos processos de descarga subterrâneas na interface entre o continente e o oceano, no aquífero cristalino (POVINEC et al. 2008a, b). A variação das composições isotópicas encontradas nas águas subterrâneas foi de $-3,2$ a $0,49 \%$ para o $\delta^{18} \mathrm{O}$ e -14 a $-3,9 \%$ para o $\delta^{2} \mathrm{H}$. Os isótopos estáveis mostraram uma boa separação das águas subterrâneas e do mar.

Um estudo voltado para a compreensão dos processos de recarga no meio cárstico foi realiza- 
do por CRUZ et al. (2005). Os autores utilizaram amostras de água do solo e dos gotejamentos da caverna para detalhar a origem e tempo de movimentação da água. A variação das composições isotópicas encontradas nas águas subterrâneas foi de $-5,8$ a $-4,36 \%$ para o $\delta^{18} \mathrm{O}$. A combinação de diferentes fontes permitiu identificar os processos de recarga, identificados por curto tempo de residência e concentrados no período úmido.

\subsection{Estudos isotópicos na Bacia do Paraná}

As bacias do Paraná e Chacoparanaense apresentam extensão superior a $1.400 .000 \mathrm{~km}^{2}$, com espessura máxima de 7.000 metros de rochas sedimentares e ígneas, cujo registro estratigráfico estende-se do Ordoviciano Superior ao Cretáceo Superior, compreendendo, segundo MILANI (1997), seis supersequências: Rio Ivaí (RI), depositada durante o período compreendido entre o Ordoviciano e o Siluriano; Paraná (P), de idade devoniana; Gondwana I (GI), depositada durante o Carbonífero - Eo-Triássico; Gondwana II (GII), depositada entre o Meso e Neo-Triássico; Gondwana III (GIII), de idade neojurássica a eocretácea; e Bauru (B), de idade neocretácea. Segundo este autor, as três primeiras sequências correspondem a grandes ciclos transgressivos paleozoicos, e as demais são representadas por pacotes sedimentares continentais, com intenso magmatismo associado.

A esse quadro litoestratigráfico se associam importantes unidades aquíferas, utilizadas para o abastecimento da população e, em função de sua importância socioeconômica, é a província estrutural em que se concentra a maior parte do conhecimento hidrogeológico do país, com estudos sendo realizados desde o início da década de 1980 (KIRCHHEIM et al. 2019). As principais unidades aquíferas estão associadas as unidades litoestratigráficas de idade mesozoica (Sistema Aquífero Bauru, Sistema Aquífero Serra Geral e Sistema Aquífero Guarani), e especialmente no estado de São Paulo, as unidades Permo-Carboníferas (Sistema Aquífero Tubarão).

\subsubsection{Sistema Aquífero Rio Bonito (SARB)}

Com a finalidade de se compreender as condições de fluxo subterrâneo e a influência da presença de minas de carvão em porções das bacias hidrográficas dos rios Araranguá e do Tubarão, e integralmente na Bacia Hidrográfica do Rio Urussanga, localizadas no extremo sul do estado de Santa Catarina (SC), HOELZEL (2018) co- letou amostras de águas subterrâneas do Sistema Aquífero Rio Bonito (SARB) e encontrou uma grande variabilidade nos valores de $\delta^{2} \mathrm{H}$ e $\delta^{18} \mathrm{O}$, respectivamente de $-31,3$ a $-19,1 \%$ e de $-7,02$ a $-3,94 \%$, sem fazer inferências em relação aos controles responsáveis por essa variação.

\subsubsection{Sistema Aquífero Tubarão (SAT)}

O primeiro estudo hidrogeológico, no qual amostras de água subterrânea do SAT tiveram seu conteúdo isotópico analisado, remonta aos anos de 1990, quando DINIZ (1990) coletou amostras em 10 poços na cidade de Tietê (SP), em duas estações distintas (seca e chuvosa), e encontrou valores para $\delta^{2} \mathrm{H}$ entre $-59,8$ e $-42,1 \%$ e para $\delta^{18} \mathrm{O}$ entre $-8,84$ e $-7,11 \%$, observando pouca variação entre as campanhas e que as amostras posicionavam-se acima da Reta Meteórica Global, concluindo que as porções mais profundas do aquífero seriam recarregadas ao longo de todo o ano, o que posteriormente se provou uma interpretação errônea.

Em estudo em escala regional, realizado na porção central da área de afloramentos do SAT, VIDAL (2002) encontrou valores semelhantes aos de DINIZ (1990) para $\delta^{2} \mathrm{H}$ (entre -69,77 e -42,11\%o) e para $\delta^{18} \mathrm{O}$ (entre $-9,44$ e $-6,50 \%$ ), posicionadas acima da Reta Meteórica Global. O autor não observa correlações significativas entre os valores de $\delta^{18} \mathrm{O}$ e diversos parâmetros hidroquímicos, apenas com o $\mathrm{pH}(\mathrm{r}=-0,66)$ e com a $\mathrm{SiO}_{2}(\mathrm{aq})(\mathrm{r}=0,60)$, indicando uma tendência a águas mais enriquecidas nas regiões de recarga e uma depleção progressiva com o aumento da salinidade, associando esse processo a interação entre rocha e água.

EZAKI et al. (2016), utilizando dados hidroquímicos e isotópicos (isótopos estáveis de $\mathrm{H} \mathrm{e} \mathrm{O} \mathrm{e}{ }^{14} \mathrm{C}$ ), avaliaram as águas subterrâneas do SAT nas Unidades de Gestão de Recursos Hídricos (UGRHI) 5 (PCJ - Piracicaba, Capivari e Jundiaí) e em parte da UGRHI 10 (Sorocaba/Tietê), localizadas no centro do estado de SP, e associaram águas com valores isotópicos mais enriquecidos com tempos de residência inferiores à 10.000 anos; e valores mais empobrecidos a águas mais antigas que 10.000 anos.

Localmente, o SAT também foi estudado por CORRÊA (2019) na Estação Ecológica de MogiGuaçu (SP), com o objetivo de avaliar as características hidráulicas da planície aluvionar do Rio Mogi-Guaçu em distintos períodos chuvosos (Out/2015 e Mar/2016). A autora destaca que a assinatura isotópica do aquífero na região é semelhante à da precipitação, inferindo que as águas do 
SAT possuem origem pluvial e curto tempo de residência, e que períodos mais chuvosos produzem assinaturas isotópicas mais empobrecidas do que o período menos chuvoso.

EZAKI et al. (2020) propõem o modelo isotópico/hidrogeológico regional mais relevante do SAT no estado de São Paulo, uma vez que associam a assinatura isotópica de $\mathrm{O}$ e $\mathrm{H}$ com tempos de residência estimados por ${ }^{14} \mathrm{C}$ e a hidroquímica do aquífero. Os autores determinaram que a assinatura isotópica do SAT varia de $-9,24$ a $-6,81 \%$ para $\delta^{18} \mathrm{O}$ e entre $-63,5$ a $-40,6 \%$ para $\delta^{2} \mathrm{H}$; com valores de excesso de deutério entre 8,84 a $14,76 \%$. Foi observada uma distinção entre a assinatura isotópica das águas rasas e jovens $(<5.000$ anos $)$ e das águas profundas e antigas ( $>20.000$ anos), encontradas nas porções onde o SAT se encontra confinado pelo Grupo Passa Dois.

As assinaturas isotópicas das águas jovens são mais enriquecidas $\left(\delta^{18} \mathrm{O}=-7,49 \pm 0,43 \%\right.$ ) e apresentam maior excesso de deutério médio $(12,51 \pm 1,22 \%)$, enquanto para as águas mais antigas, as assinaturas são mais empobrecidas $\left(\delta^{18} \mathrm{O}=\right.$ $-8,34 \pm 0,62 \%$ o) e possuem menor excesso de deutério médio $(11,47 \pm 1,41 \%)$. A diferença de excesso de deutério indica as diferentes condições climáticas da recarga dessas águas: águas mais jovens representam a precipitação atual e águas mais antigas possuem influência do efeito da quantidade em áreas tropicais, associada a atuação da ZCAS.

\subsubsection{Sistema Aquífero Guarani (SAG)}

Estudos hidrogeológicos utilizando isótopos estáveis de $\mathrm{He} \mathrm{O}$ para a compreensão das condições de circulação das águas subterrâneas no Sistema Aquifero Guarani (SAG) vêm sendo realizados regularmente desde a década de 1980 (KIRCHHEIM et al. 2019), fazendo com que o SAG talvez seja a unidade aquífera para a qual os isótopos estáveis mais tenham contribuído, uma vez que a maior parte dos estudos hidroquímicos realizados incorporou determinações dos valores de $\delta^{2} \mathrm{H}$ e $\delta^{18} \mathrm{O}$ como atividade de rotina. Esse grande número de estudos realizados deve-se especialmente a sua importância como fonte de abastecimento para cerca de 90 milhões de pessoas que vivem sobre sua área de ocorrência (OEA 2009).

Uma excelente síntese a respeito do desenvolvimento das aplicações de técnicas isotópicas e sua associação com a evolução do conhecimento hidrogeológico do SAG foi realizada por KIRCHHEIM et al. (2019), que estabeleceram em três fases o desenvolvimento da aplicação dessas técnicas, as- sociadas às constantes atualizações do modelo hidrogeológico regional, decorrente da ampliação do conhecimento. Os autores também apontam que com a evolução do conhecimento hidrogeológico, a aplicação de isótopos de $\mathrm{H}$ e $\mathrm{O}$ também passou a abranger áreas geográficas maiores do aquífero, culminando com o Projeto Aquífero Guarani (OEA 2009), durante o qual extensa campanha de amostragem e compilação de resultados isotópicos de estudos anteriores, foram realizadas.

As primeiras determinações isotópicas em águas do SAG foram realizadas por MATSUI (1971), já indicando a importância do aquífero no contexto hidrogeológico brasileiro. Os primeiros estudos em escala regional foram realizados no estado de São Paulo, no início da década de 1980, por GALLO \& SINELLI (1980) e SILVA (1983), esse último retomado posteriormente por KIMMELMANN et al. (1986, 1989, 1995). Esses trabalhos pioneiros, além das informações advindas dos dados dos isótopos de $\mathrm{H}$ e $\mathrm{O}$, integraram essas informações com dados hidroquímicos e determinações de tempos de residência $\left({ }^{3} \mathrm{H} \mathrm{e}{ }^{14} \mathrm{C}\right)$, e foram agrupados nas fases I e II por KIRCHHEIM et al. (2019).

A partir desses estudos foi possível a elaboração de um primeiro esboço para a distribuição espacial para os valores de $\delta^{18} \mathrm{O}$ nas águas do SAG. A porção confinada do SAG no estado de São Paulo concentra os valores mais depletados $\left(\delta^{18} \mathrm{O}\right.$ entre $-8,1$ e $-9,8 \%$ ), enquanto nas porções próximas à faixa de afloramentos no estado do Mato Grosso do Sul, as águas subterrâneas apresentam valores de $\delta^{18} \mathrm{O}$ entre $-5,7$ e $-6,8 \%$, próximos a composição isotópica da precipitação. Essas variações, além de evidenciar a origem meteórica dessas águas, indicavam condições climáticas distintas para a recarga, possivelmente associadas a climas mais frios relacionados ao Máximo Glacial ocorrido há cerca de 40-50.000 anos (SILVA 1983; KIMMELMANN et al. 1986, 1989).

Posteriormente, de acordo com KIRCHHEIM et al. (2019), uma terceira fase consolida a utilização conjunta de informações isotópicas com modelos hidrogeoquímicos, como ferramentas de avaliação das condições de fluxo das águas subterrâneas do SAG. O marco inicial dessa fase é o trabalho de SRACEK \& HIRATA (2002), que retoma os dados de SILVA (1983). Novas amostras coletadas na porção norte do SAG (São Paulo, Minas Gerais, Mato Grosso do Sul, Goiás e Paraná) apontam uma similaridade da composição isotópica das águas do SAG, tanto em sua zona confinada, quando na 
área de recarga, com a composição isotópica da precipitação da estação chuvosa (GASTMANS et al. 2010a, b). Estudos localizados ao longo de linhas de fluxo predeterminadas e com a utilização de outros traçadores foram realizados por SOLER \& BONOTTO (2014), BONOTTO \& ELLIOT (2017) e ELLIOT \& BONOTTO (2017).

Esses estudos, em consonância com os resultados apresentados pelo Projeto de Desenvolvimento Sustentável do Sistema Aquífero Guarani (PSAG OEA 2009), mostram que águas mais enriquecidas em $\delta^{18} \mathrm{O}$ e $\delta^{2} \mathrm{H}$, com composição isotópica próxima a precipitação atual, são encontradas nas proximidades das áreas de recarga, enquanto águas mais empobrecidas nas porções confinadas (Figura 7). Essa distribuição também foi interpretada com base em mudanças nas condições climáticas na época da recarga, que indicam temperaturas próximas à $20^{\circ} \mathrm{C}$ para as águas recentes, e temperaturas até $10^{\circ} \mathrm{C}$ inferiores e condições mais úmidas para as águas mais empobrecidas (GASTMANS et al. 2010a).

Com a incorporação de técnicas isotópicas em estudos de caracterização hidroquímica local, dados isotópicos também auxiliaram na compreensão da circulação das águas subterrâneas em áreas específicas do SAG, como por exemplo na região de Santa Cruz do Sul e Venâncio Aires, onde MARIMON et al. (2007) investigaram a origem de anomalias de flúor, ou na região de São Carlos, em que águas mais depletadas que a precipitação atual indicaram a existência de uma compartimentação

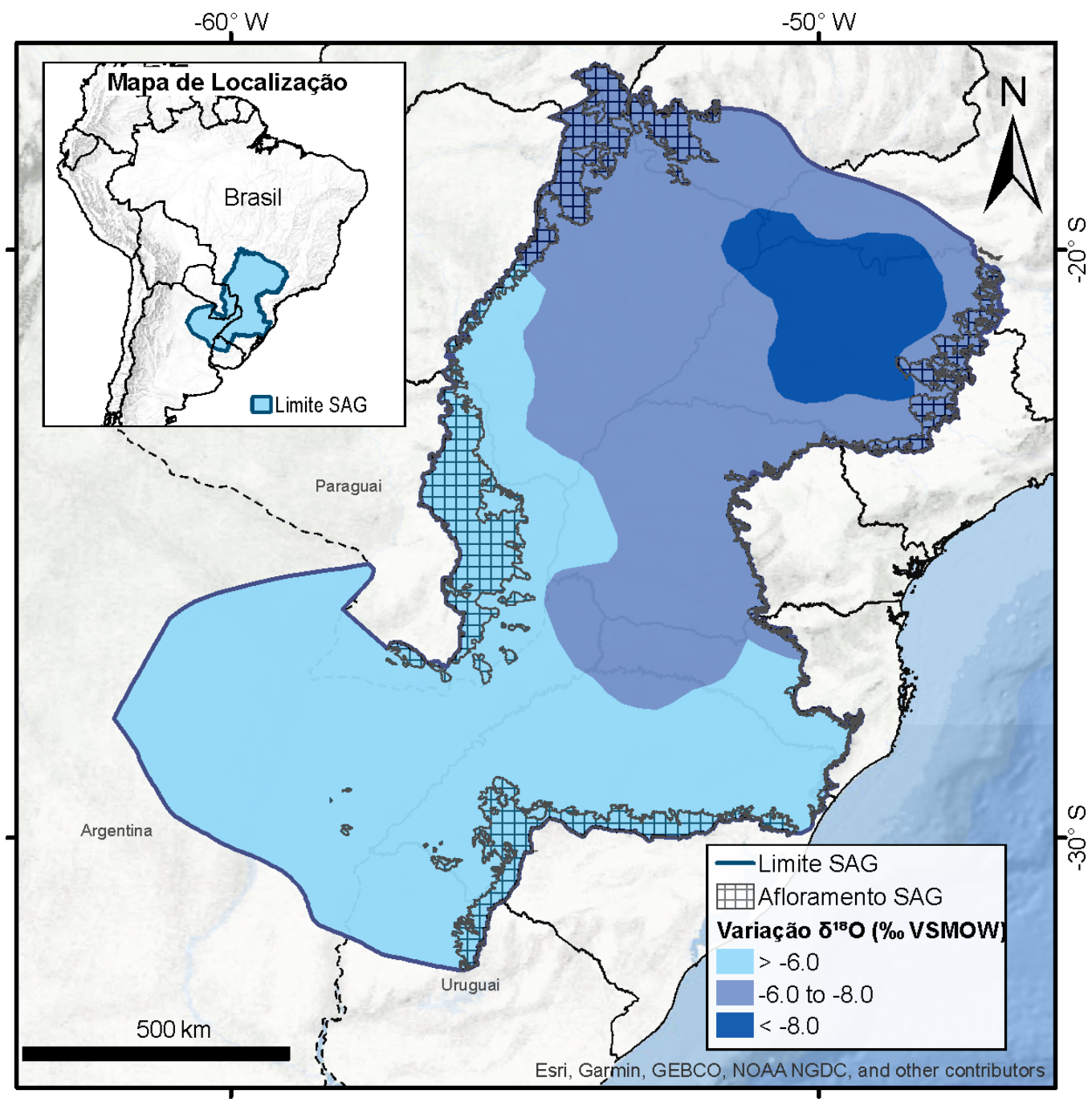

FIGURA 7 - Distribuição espacial da composição isotópica das águas subterrâneas no SAG (dados compilados de diversos trabalhos). 
local ocasionada pela intrusão de diabásios, interferindo nas condições de fluxo das águas subterrâneas no SAG (LEITE 2019).

As interações entre águas subterrâneas e superficiais em uma bacia hidrográfica nas áreas de afloramento do SAG, no estado de São Paulo, foram estudadas por BATISTA et al. (2018) e BATISTA (2019), que mostraram que a variação temporal nos valores de excesso de deutério é a mesma para as águas subterrâneas e as águas superficiais, indicando além da grande conexão entre os dois reservatórios, a ocorrência de processos evaporativos durante a recarga.

$\mathrm{O}$ estudo regional com o objetivo de se determinar a vulnerabilidade natural à contaminação em áreas de afloramento (recarga) do SAG, realizado pela Agência Nacional de Águas (ANA 2016), incorporou dados isotópicos mostrando a grande variação $\left(\delta^{18} \mathrm{O}\right.$ entre $-7,29$ e $-4,15 \%, \delta^{2} \mathrm{H}$ entre $-50,4$ e $-19,6 \%$ ), com tendência a empobrecimento das águas subterrâneas, cuja recarga está associada a influência da ZCAS, na porção norte do SAG, enquanto as águas mais enriquecidas estão localizadas nas região sul das áreas de recarga. Essa conexão entre a recarga e grandes figuras climáticas foi também aventada por GASTMANS et al. (2017b) e por CHANG et al. (2020).

\subsubsection{Sistema Aquífero Serra Geral (SASG)}

Em função da possibilidade de interação e fluxos entre as diversas unidades hidrogeológicas da Bacia do Paraná, os principais estudos isotópicos realizados no Sistema Aquífero Serra Geral (SASG) objetivaram sempre buscar compreender a conexão entre o SASG e os aquíferos sobrejacente e subjacente, respectivamente, o Sistema Aquífero Bauru (SAB) e o Sistema Aquífero Guarani (SAG).

$\mathrm{Na}$ região de Araguari (MG), MINARDI et al. (2008) avaliaram a relação entre o SAB e SASG, demonstrando que o efeito da altitude na região produz as diferenças isotópicas entre os aquíferos, com um empobrecimento das águas do SASG de $-0,43 \%$ em $\delta^{18} \mathrm{O}$ a cada $100 \mathrm{~m}$.

A relação entre as águas subterrâneas do SASG e o aquífero sobrejacente, o SAG, é um tema amplamente discutido, uma vez que não há um consenso quanto a conexão entre as unidades (FERNANDES et al. 2011, REGINATO et al. 2013, GASTMANS et al. 2017c, dentre outros). Neste sentido, WAHNFRIED (2010), utilizando isótopos de $\mathrm{O}$ e $\mathrm{H}$, observou que a mistura entre o SASG/SAG na região de Bonfim Paulista (SP) é pouca ou nenhuma. Entretanto, em um es- tudo regional que buscou avaliar as anomalias de flúor no SASG no estado do Rio Grande do Sul (RS), NANNI et al. (2013) indicam que as assinaturas isotópicas do SASG possuem grande contribuição das águas do SAG, mesmo em locais onde há maior espessura dos basaltos, devido ao intenso sistema de fraturas, produzindo assinaturas do SASG pouco mais empobrecidas que as do SAG.

As relações de fluxo entre o SASG e o SAG também foram estudadas por PAIVA (2014), procurando compreender os processos de descarga submarina desses aquíferos em estuário próximo à divisa dos estados de Rio Grande do Sul (RS) e Santa Catarina (SC). O autor, ao observar assinaturas isotópicas semelhantes e características hidroquímicas distintas entre as águas subterrâneas e o estuário marinho subterrâneo, comprovou a descarga dos aquíferos no mar.

Além dos trabalhos de NANNI et al. (2013) e PAIVA (2014) no estado do RS, o comportamento isotópico do SASG, em conjunto com dados hidroquímicos, foi avaliado em alguns estudos locais, como por BORTOLIN (2014) na região de Carlos Barbosa (RS) e FREITAS (2016) na região do Alto do Rio Uruguai (divisa RS e SC). BORTOLIN (2014) observou que a circulação ativa do SASG se encontra em profundidades de até $30 \mathrm{~m}$, com grande influência de recarga recente até $100 \mathrm{~m}$, e maior enriquecimento isotópico em poços com mais de $70 \mathrm{~m}$ de profundidade. Enquanto FREITAS (2016) constatou a circulação das águas subterrâneas do SASG associada aos sistemas de fratura dos basaltos e a valores isotópicos mais empobrecidos, entre 1,1 e $1,5 \mathrm{~km}$ de profundidade, podendo alcançar até $3 \mathrm{~km}$.

A composição isotópica das águas subterrâneas do SASG no RS apresenta grande variabilidade espacial. BORTOLIN (2014) encontrou valores entre $-8,93$ e $-3,41 \%$ para o $\delta^{18} \mathrm{O}$ e $-49,71$ e $-23,87 \%$ para $\delta^{2} \mathrm{H}$, mais empobrecidos que os encontrados regionalmente por NANNI et al. (2013), entre $-5,7$ e $-4,2 \%$ p para o $\delta^{18} \mathrm{O}$ e -37 a $-24,2 \%$ p para o $\delta^{2} \mathrm{H}$.

No estado de São Paulo, as águas do SASG apresentam assinatura isotópica entre e -8,9 a $-5,3 \%$ para o $\delta^{18} \mathrm{O}$ e $-61,31$ a $-31,64 \%$ para o $\delta^{2} \mathrm{H}$ (GASTMANS et al. 2016, GASTMANS et al. 2017c). Nestes importantes trabalhos regionais, os autores associam a variação temporal e espacial do ${ }^{18} \mathrm{O}$ e ${ }^{2} \mathrm{H}$ a diferentes condições climáticas da recarga, relacionada à intensidade do sistema de monções (Sistema da Monção Sul-Americana SASM) e a migração da ZCIT (GASTMANS et al. 
2016) e à influência da ZCAS, que produz assinaturas isotópicas mais empobrecidas em águas rasas (GASTMANS et al. 2017c).

\subsubsection{Sistema Aquífero Bauru (SAB)}

As primeiras determinações isotópicas nas águas subterrâneas do Sistema Aquífero Bauru (SAB) remontam aos estudos conduzidos por KIMMELMANN et al. (1989), que apresentaram alguns resultados para as águas do $\mathrm{SAB}$, apesar do trabalho ter como objetivo a caracterização isotópica do Aquífero Botucatu, atualmente SAG.

Os primeiros levantamentos regionais foram feitos no início dos anos 2000. BARISON (2003) realizou um estudo hidrogeoquímico na área de ocorrência do SAB ao sul do rio Tietê, no estado de São Paulo, e encontrou variações entre $-9,05$ e $-5,67 \%$ para o $\delta^{18} \mathrm{O}$ de $-65,50$ a $-39,80 \%$ para o $\delta^{2} \mathrm{H}$, nas águas subterrâneas do $\mathrm{SAB}$, posicionadas abaixo da Reta Meteórica Global, mas com valores médios próximos às das águas do rio Tietê.

Com a maior utilização de dados isotópicos, inúmeros grupos de pesquisa incorporaram essas informações aos seus estudos. MALDANER (2010) utilizou os isótopos de $\mathrm{H}$ e $\mathrm{O}$, em conjunto com isótopos radiogênicos, para determinar as distintas contribuições de águas no SAB na área urbana de Urânia (SP), identificando que entre 8 e $49 \%$ das águas rasas do SAB contribuem nas águas profundas, destacando a vulnerabilidade à contaminação do aquífero. CRESPI (2013) e RIOS (2016) fizeram uso das assinaturas isotópicas de oxigênio e hidrogênio visando determinar a origem das anomalias de bário nas águas subterrâneas do $\mathrm{SAB}$ em Gália (SP) e ao longo do Espigão de Marília (SP), respectivamente. CRESPI (2013) define que as anomalias de bário são de origem natural, associadas aos carbonatos da Formação Marília; origem também comprovada por RIOS (2016).

Além da caracterização da anomalia de bário, CRESPI (2013) observou que as águas do Aquífero Marília são mais enriquecidas, com composição isotópica variando entre -7,11 e -7,43\% para o $\delta^{18} \mathrm{O}$ e $-43,57$ a $-49,61 \%$ para o $\delta^{2} \mathrm{H}$, enquanto as águas do Aquífero Adamantina, são mais empobrecidas, com composição isotópica variando entre $-8,55$ e $-8,74 \%$ p para o $\delta^{18} \mathrm{O}$ e $-50,68$ a $-60,26 \%$ o para o $\delta^{2} \mathrm{H}$.

Em estudo de caráter regional STRADIOTO \& CHANG (2015) observam que para o SAB, as assinaturas isotópicas variam entre $-8,9$ e $-5,5 \% 0$ para o $\delta^{18} \mathrm{O}$ e $-62,5$ a $-25,4 \%$ p para o $\delta^{2} \mathrm{H}$, com um claro zoneamento regional, indicado pelo enriquecimento das águas subterrâneas do Aquífero Caiuá na borda sudeste do estado, com composições isotópicas variando entre $-7,0$ e $-5,5 \%$ para o $\delta^{18} \mathrm{O}$ e -42 a $-32 \%$ para o $\delta^{2} \mathrm{H}$. O empobrecimento das águas do $\mathrm{SAB}$ ocorre no sentido das bordas norte e leste/sudeste do estado, associado às assinaturas dos aquíferos Santo Anastácio e Marília (a norte e leste/sudeste) e do Aquífero Adamantina (centro e norte).

NOGUEIRA SANTOS et al. (2019) observam o controle climático sobre a recarga e sua influência na composição isotópica do SAB e SAG nos estados de SP, MS e PR. Os autores identificam um eixo NW-SE que separa a área de estudo a sul, associada a chuvas convectivas e a assinaturas mais enriquecidas (média de $-5,36 \%$ o $\delta^{18} \mathrm{O}$ e $-30,45 \%$ o $\delta$ ${ }^{2} \mathrm{H}$ ); e a norte, associada a chuvas estratiformes e a ausência da manifestação da ZCAS durante o período estudado, produzindo valores mais empobrecidos (média de $-6,53 \%$ o $\delta^{18} \mathrm{O}$ e $-41,2 \%{ }^{2} \mathrm{H}$ ).

\subsection{Estudos isotópicos na Província do Parnaíba}

Na Província Parnaíba encontram-se alguns aquíferos emblemáticos do território nacional: Serra Grande e Cabeças, no estado do Piauí, que apesar da sua importância e da produtividade dessas unidades, foi objeto de poucos estudos empregando isótopos de $\mathrm{H}$ e $\mathrm{O}$, realizados no final da década de 1990.

Com o objetivo de se compreender os processos de recarga e circulação das águas subterrâneas nessas unidades, BATISTA et al. (1998) e CARNEIRO et al. (1998) encontraram composições isotópicas para as águas subterrâneas variando entre $-5,5$ e $-2,3 \%$ p para o $\delta^{18} \mathrm{O}$ e $-33,5$ a $-10,8 \%$ o para o $\delta^{2} \mathrm{H}$, indicando a existência de águas mais antigas, conforme já apontado por STUTE et al. (1995), e águas mais jovens associadas a processos de recarga mais rápidos, com composição isotópica próxima à da precipitação.

\subsection{Estudos isotópicos na Província do Recôncavo-} -Tucano

Estudo realizado nos aquíferos sedimentares Barreiras e São Sebastião, na região metropolitana de Salvador, com intuito de identificar a inter-relação entre águas de rios, chuva e subterrânea, encontrou composições isotópicas médias no Aquífero São Sebastião (semiconfinado) de -2,2\%o para $\delta^{18} \mathrm{O}$ e $1 \%$ para $\delta^{2} \mathrm{H}$, enquanto o Aquífero Barreiras (livre) apresentou valores de $-1,1 \%$ p para $\delta^{18} \mathrm{O}$ e $-5 \%$ para $\delta^{2} \mathrm{H}$. Esses valores indicam que não existe conexão entre as unidades, mas que o 
Aquífero Barreiras contribui efetivamente com a manutenção do fluxo de base do rio Joanes (-1\%o para $\delta^{18} \mathrm{O}$ e $-0,7 \%$ para $\left.\delta^{2} \mathrm{H}\right)$ (COSTA et al. 2007).

PEREIRA (2009) avaliou outra importante unidade da Província, o Aquífero Marizal, e utilizando isótopos estáveis em conjunto com parâmetro hidrogeoquímicos para compreender os processos de recarga na Ilha de Itaparica, no litoral do estado da Bahia, encontrou razões isotópicas variando entre $-1,8$ a $-0,7 \%$ para o $\delta^{18} \mathrm{O}$ e entre 1,5 a $9,9 \%$ para o $\delta^{2} \mathrm{H}$.

\subsection{Estudos isotópicos na Província do São Fran-} cisco

Apesar da importância da bacia do rio São Francisco, estabelecida sob a Província Estrutural do São Francisco, estudos hidrogeológicos com a utilização de isótopos de $\mathrm{H}$ e $\mathrm{O}$, essencialmente como ferramenta auxiliar na determinação da movimentação da água junto a outras aplicações hidrológicas e em grande parte geoquímicas, somente iniciaram-se em meados dos anos 2000, sobretudo, em estudos locais em 4 sistemas aquíferos: Bambuí, Salitre e Cristalino, e um estudo regional realizado no Sistema Aquífero UrucuiaAreado, coordenado pela Agência Nacional de Águas (ANA 2020).

\subsubsection{Aquífero Cárstico (Grupo Bambuí)}

Dos aquíferos estudados, o Grupo Bambuí possui o maior número de artigos, com aplicações realizadas nos estados de Minas Gerais (MG) e Bahia (BA). O primeiro estudo isotópico disponível foi realizado no carste do Grupo Bambuí na região de Montes Claros (MG), com análises isotópicas de águas de subterrâneas, mananciais e rios, com valores mais depletados encontrados nas águas subterrâneas $\left(\delta^{18} \mathrm{O}=-6,00 \%\right.$ ), refletindo a precipitação local (MINARDI \& BOMTEMPO 2000).

No alto da Bacia do Rio Jequitibá, entre os municípios de Sete Lagoas e Prudente de Moraes (MG), também foram demonstradas brevemente as relações entre as águas subterrâneas e superficiais com o grau de evaporação que estas sofreram durante o seu fluxo (PIMENTA et al. 2017).

Englobando diferentes reservatórios (aquíferos, cursos d'água e lagoas), um dos estudos de destaque para a região de $\mathrm{MG}$, utilizou os isótopos estáveis para entender a dinâmica das fontes de recarga do aquífero cárstico urbano em Sete Lagoas (GALVÃO et al. 2017). Com médias de $\delta^{18} \mathrm{O}$ pró- ximas: $-6,04 \%$ (ponderada pela precipitação) e $-6,45 \%$ (água subterrânea), este aquífero urbano é recarregado diretamente pela precipitação local, por um período limitado de recarga, entre outubro a dezembro, com pouca interação entre água e rocha, durante a recarga. Na parte central da cidade, onde há contato entre o aquífero cárstico e depósitos não consolidados do Cenozoico, ocorre recarga de água proveniente dos lagos evaporativos (GALVÃO et al. 2017).

Também foi identificado que a água subterrânea da bacia hidrográfica do rio São Miguel, afluente do rio São Francisco, é derivada da recarga direta da precipitação local, durante o período chuvoso, bem como de áreas com recarga moderna, havendo interações diretas entre água subterrânea e superficial por meio do relevo cárstico, promovendo processos de recarga e descarga ao longo da bacia hidrográfica (LUCON 2018, LUCON et al. 2020).

Em um aquífero local na região norte da cidade de Belo Horizonte (BH), foi desenvolvida uma metodologia de análise isotópica de águas superficiais e subterrâneas, com intuito de agregar informações ao gerenciamento de bacias hídricas e aquíferos (AGUIAR 2015). Já para a região metropolitana de $\mathrm{BH}$, foram analisadas as origens do fluxo de água subterrânea de nascentes com os isótopos estáveis, sendo apresentados dois grupos de nascentes com composição isotópica distinta: i) relacionado de maneira direta pela chuva recente; ii) associado a interação entre água de superfície e subsuperfície, com composição isotópica mais enriquecida, indicando que em períodos de seca ou escassez de água, as nascentes do primeiro grupo tenham seu fluxo diminuído (RIBEIRO et al. 2020).

Ainda no Grupo Bambuí, sob a região de entorno da Serra do Ramalho (BA), estudos demonstraram que as águas subterrâneas são recarregadas por chuvas locais, que não sofrem evaporação (GONÇALVES 2014, CARVALHO 2018), infiltrando rapidamente no relevo cárstico (CARVALHO 2018).

\subsubsection{Aquífero Cristalino}

Os aquíferos cristalinos da Bacia do São Francisco estão concentrados na região semiárida, e os isótopos estáveis foram utilizados como ferramenta de compreensão dos mecanismos de recarga e evaporação, em que águas subterrâneas mais enriquecidas estão relacionadas a uma maior evaporação, enquanto as mais empobrecidas à menor 
evaporação durante a infiltração (SIMÕES FILHO et al. 2006, ARAÚJO et al. 2017). Além disso, também foi considerado o posicionamento das fraturas (menor fraturamento promove a recarga mais lenta, resultando em valores isotópicos mais negativos) como fator que determina a entrada de água nos poços (quanto menor a profundidade, maior a possibilidade de sofrer evaporação) (SIMÕES FILHO et al. 2006).

A evaporação associada ao processo de percolação da chuva através da zona não saturada, por um fluxo de pistão, proporciona o enriquecimento da água subterrânea em relação aos valores observados para a precipitação da estação chuvosa (ARAÚJO et al. 2017).

\subsubsection{Aquífero Salitre}

A maioria dos estudos elaborados para o Aquífero Salitre tem como principal interesse a problemática da salinização das águas subterrâneas na região central da Bahia, junto a Chapada Diamantina e a bacia do Irecê (BA). Apenas um estudo investigou a paleopluviosidade abrangendo diversas regiões do Nordeste Brasileiro, incluindo $\mathrm{a}$ área de ocorrência do Salitre.

A partir de registros de $\delta^{18} \mathrm{O}$ e ${ }^{13} \mathrm{C}$ e das taxas de crescimento de espeleotemas datados pelo método U-Th, é possível relacionar as assinaturas de $\delta^{18} \mathrm{O}$ da chuva junto às da água de gotejamento das estalagmites, uma vez que os valores de gotejamento refletem a assinatura isotópica de águas meteóricas (NOVELLO 2012). Assim, sobre os últimos $\sim 3000$ anos (Holoceno recente), valores de $\delta^{18} \mathrm{O}$ das estalagmites variaram entre -7,8 e -2,3\%, refletindo os intervalos áridos desta região, podendo este dado ser utilizado como um importante índice climatológico para modelos de circulação regional e global (NOVELLO 2012).

A salinização das águas subterrâneas do aquífero Salitre, demonstrada pela variabilidade isotópica, tem como principais agentes: a interação com a sequência carbonática que caracteriza a Formação Salitre, a evaporação e a transpiração das plantas (NOSSA 2011, VILLANUEVA et al. 2014, SALLES et al. 2019, SANTOS et al. 2019). A variabilidade demonstrada é caracterizada por valores médios de águas subterrâneas idênticos $\left(\delta^{18} \mathrm{O}\right.$ $=-3,1$ e $-3,2 \%$ ) em dois estudos distintos (NOSSA 2011, VILLANUEVA et al. 2014); estes valores são parecidos aos da precipitação $\left(\delta^{18} \mathrm{O}=-3,2 \%\right)$, que alimenta os aquíferos desta região durante a estação chuvosa (NOSSA 2011). Considerando as variações espaciais, foi demonstrado que o setor leste deste aquífero é mais enriquecido que o setor norte-noroeste (NOSSA 2011), enquanto o setor norte é um pouco mais empobrecido que o setor sul da bacia do Salitre (SANTOS et al. 2019).

Ainda sobre a área de abrangência da Chapada Diamantina, na bacia hidrográfica do Rio Jacuípe (BA), no trecho próximo a nascente, a contribuição predominante é da água subterrânea (principalmente durante o período seco), enquanto no trecho alto, o escoamento é mantido, predominantemente, pela ocorrência de chuva (durante o período chuvoso) (FONTES et al. 2011). Para os sistemas de áreas úmidas do Pantanal dos Marimbus, foi determinado que a composição isotópica predominante destas áreas provém de águas pluviais, com águas divididas em dois grupos, caracterizadas pela evaporação e pela conexão com o sistema de drenagem do Rio Santo Antônio (LESSA FILHO 2017).

\subsubsection{Sistema Aquífero Urucuia (SAU)}

$\mathrm{Na}$ década de 2000 foram realizados estudos isotópicos no $\mathrm{SAU}$, principalmente na Bacia Hidrográfica do Rio das Fêmeas no Estado da Bahia (NASCIMENTO et al. 2003), envolvendo coletas e comparações entre as assinaturas isotópicas de águas subterrâneas e águas superficiais. Esse estudo apontou similaridades isotópicas entre as assinaturas das águas subterrâneas e superficiais, fato que estaria em acordo com as observações hidráulicas e resultantes da modelagem, sem, entretanto, se aprofundar nos processos relacionados a interação entre os compartimentos.

Mais tarde, estudos isotópicos realizados por LUZ et al. (2009) mostraram para as águas subterrâneas valores médios de $\delta^{18} \mathrm{O}$ de $-4,4 \%$, enquanto os valores de $\delta^{2} \mathrm{H}$ variaram entre $-35,9 \%$ e $-10,9 \%$ em setembro de 2001 e de $-36,9 \%$ a $-13,6 \%$ em junho de 2002. Os autores encontraram razões semelhantes para as águas superficiais, sendo que na estação seca os valores apresentaram-se agrupados, indicando que toda a contribuição das águas superficiais provém do fluxo de base subterrâneo.

BARBOSA (2016) conduziu estudo amplo no SAU, no qual constava uma componente isotópica baseada em coletas de águas subterrâneas, águas de chuva e dos rios em diferentes estações. O objetivo do estudo foi utilizar informações isotópicas para complementar a avaliação hidroquímica e, assim, conceber modelo de circulação para a porção sul do SAU. O autor identifica um comportamento distinto da composição isotópica de acordo com sazonalidade. A composição isotópica das águas subterrâneas coincide com a da precipitação 
nos períodos úmidos, ajustando-se com a RMG, o que permitiu associar a ocorrência de recarga direta a partir da infiltração dos excessos pluviais e efeitos secundários de evaporação. Em contrapartida, na estação considerada seca, as assinaturas isotópicas das águas subterrâneas diferem das águas superficiais, devido ao enriquecimento provocado pela evaporação. O autor nota uma transição entre estes dois extremos sazonais, em conclusão ligeiramente distinta dos estudos anteriores.

Finalmente, um amplo estudo regional, envolvendo o SAU e o SAA, foi coordenado pela ANA e utilizou os isótopos como ferramenta complementar na caracterização hidrogeoquímica (ANA 2017). Os resultados indicaram que para as águas subterrâneas os valores de $\delta^{18} \mathrm{O}$ de variaram entre $-7,03 \%$ e $+1,23 \%$, enquanto os valores de $\delta^{2} \mathrm{H}$, entre $-45,91 \%$ 。 e $+0,84 \%$. A maioria das águas coletadas em nascentes e poços tem composição isotópica próxima à RMG, com amostras mais enriquecidas para o SAA em relação ao SAU, que pode ser relacionado a fatores climáticos da época de recarga e/ou misturas com águas dos outros aquíferos. Este fato também pode indicar uma rápida movimentação de recarga do aquífero.

Os estudos relacionados aos isótopos estáveis foram complementados por análises isotópicas de ${ }^{3} \mathrm{He}{ }^{14} \mathrm{C}$, indicando idades desde submodernas (anterior a 1952) até águas com cerca de 3.000 anos. Cabe destacar que as amostragens podem refletir misturas de águas em um mesmo poço, ou seja, águas mais antigas na parte mais profunda do poço, com águas mais jovens na parte mais superficial do poço, interferindo assim nos resultados.

\subsection{Estudos isotópicos na Bacia do Tocantins}

Na região do Distrito Federal, ocorrem quatro unidades aquíferas: Sistema Aquífero Paranoá, Sistema Aquífero Canastra, Sistema Aquífero Bambuí e Sistema Aquífero Araxá (CAMPOS \& FREITAS-SILVA 1998); diversos estudos foram realizados em função da importância das águas subterrâneas para a região.

O estudo isotópico pioneiro no Distrito Federal foi realizado por LOUSADA \& CAMPOS (2011) que, utilizando isótopos estáveis de $\mathrm{O}$ e $\mathrm{H}$, além de dados de trítio e concentrações de CFCs, avaliaram a origem e os tempos de residência das águas na região. Os valores $\delta^{18} \mathrm{O}$ variam entre -5,71 e -5,19\%o, indicando uma origem relacionada às precipitações locais ou em regiões próximas à bacia, com uma recarga que acontece de forma rápida.
As relações existentes entre as razões isotópicas de H, O e C possibilitaram a PACHECO (2012), compreender as relações de recarga e a interação da água com o solo na região do Distrito Federal. O autor encontrou valores médios nas águas subterrâneas para $\delta^{2} \mathrm{H}$ de $-38,21 \pm 3,36 \%$, e para o $\delta^{18} \mathrm{O}$ de $-5,79$ $\pm 0,53 \%$, alinhadas de acordo com a reta meteórica local, concluindo que os tempos de recarga dessas águas são provavelmente inferiores a seis meses, apontando para um sistema de águas recentes.

SOUZA (2013) fez um estudo na região de São Sebastião, também no Distrito Federal, coletando amostras de água subterrânea em 12 poços tubulares. Ela encontrou valores de $\delta^{18} \mathrm{O}$ que variam de $-6,0$ a $-5,8 \%$ em planos elevados e $-5,5$ a $-5,3 \%$ o em vales dissecados, já os valores de $\delta^{2} \mathrm{H}$ variam de $-36,0$ a $-34,8 \%$ em planos elevados e $-34,1$ a $-33,0 \%$ em vales dissecados. Essa variação possibilitou a autora concluir que a origem da recarga da água subterrânea nessa região é meteórica, identificando que essa água sofre influência da baixa umidade do ar e dos efeitos da evaporação da chuva antes de atingir o solo.

$\mathrm{Na}$ Chapada dos Veadeiros (GO), localizada próximo ao Distrito Federal, ocorrem três sistemas aquíferos de domínio fraturado: Sistema Aquífero Araí, Sistema Aquífero Traíras e Sistema Aquífero Paranoá, este último também abrange a área do Distrito Federal. JUNQUEIRA (2020) encontrou valores de $\delta^{18} \mathrm{O}$ entre $-6,35$ e $5,27 \%$ e $\delta^{2} \mathrm{H}$ entre $-38,02$ e 31,14\%, comparando os valores com a precipitação e a reta meteórica de Brasília. A partir dessa análise, a autora pode confirmar que houve longo tempo de interação água-rocha nesse local; além disso, ao combinar esses dados com dados hidroquímicos, foi possível confirmar a hipótese da existência de um regime de fluxo hidrogeológico regional que explica o hidrotermalismo da região estudada.

RAPOSO (2011) fez uma caracterização do aquífero associado ao Complexo AlcalinoCarbonático do Barreiro, na cidade de Araxá (MG), e para isso utilizou hidroquímica e isótopos ambientais em uma parte de seu estudo, para poder identificar diferentes populações de águas. Os valores de $\delta^{18} \mathrm{O}$ encontrados variaram de $-10,2$ a $-5,2 \%$ e os valores de $\delta^{2} \mathrm{H}$ variaram de $-69,1$ a $-40,5 \%$. O autor identificou três populações de águas, uma associada ao aquífero granular, semiconfinado, que ocorre no interior do complexo carbonático, outra com forte interferência do metassomatismo manifestado pelo anel de quartzitos fenetizados e retrata as águas da borda oeste do complexo e uma terceira, composta por águas mesotermais. 
Em Tocantins, no entorno do município da Lagoa da Confusão, SOUSA (2018) encontrou valores de $\delta^{2} \mathrm{H}$ nas águas subterrâneas entre $-21,2$ e $-14,6 \%$ e valores para $\delta^{18} \mathrm{O}$ entre $-3,98$ e $-3,0 \%$. Já nas águas superficiais (rio Urubu e Lagoa da Confusão), os valores são regularmente mais enriquecidos, indicando a ocorrência de processos evaporativos. Em relação às águas subterrâneas, o autor aponta que o aquífero cárstico local favorece uma rápida circulação da água, e que existe uma possível interação entre as águas superficiais e subterrâneas, mostrando que os recursos hídricos superficiais são abastecidos pelas águas subterrâneas em períodos de estiagem.

\section{CONSIDERAÇÕES FINAIS - OPORTUNIDADES E PERSPECTIVAS FUTURAS DE SUA UTILIZAÇÃO}

Em uma primeira análise conjunta de informações isotópicas sobre as águas subterrâneas dos aquíferos brasileiros, é possível se constatar a rela- ção existente entre aspectos climáticos e geográficos e a composição isotópica das águas subterrâneas. A figura 8 foi construída de forma a permitir essa análise comparativa entre os aquíferos.

De maneira geral observa-se um empobrecimento relativo das águas subterrâneas de Sul para Norte. Os aquíferos das regiões Norte e Nordeste possuem águas subterrâneas mais enriquecidas quando comparados com os aquíferos da Bacia do Paraná, com composições isotópicas bastante próximas às médias das precipitações, indicando, como apontado por diversos autores, que a precipitação influi diretamente na composição isotópica das águas subterrâneas, e que nos aquíferos mais rasos existe uma sazonalidade muito grande, reflexo da rápida infiltração da chuva. Além disso, deve-se salientar os efeitos do clima semiárido nas águas subterrâneas dos aquíferos localizados na região Nordeste, indicados pela posição relativa abaixo da reta meteórica global.

Na região Norte é notório também o efeito da continentalização sobre a composição isotópica tan-

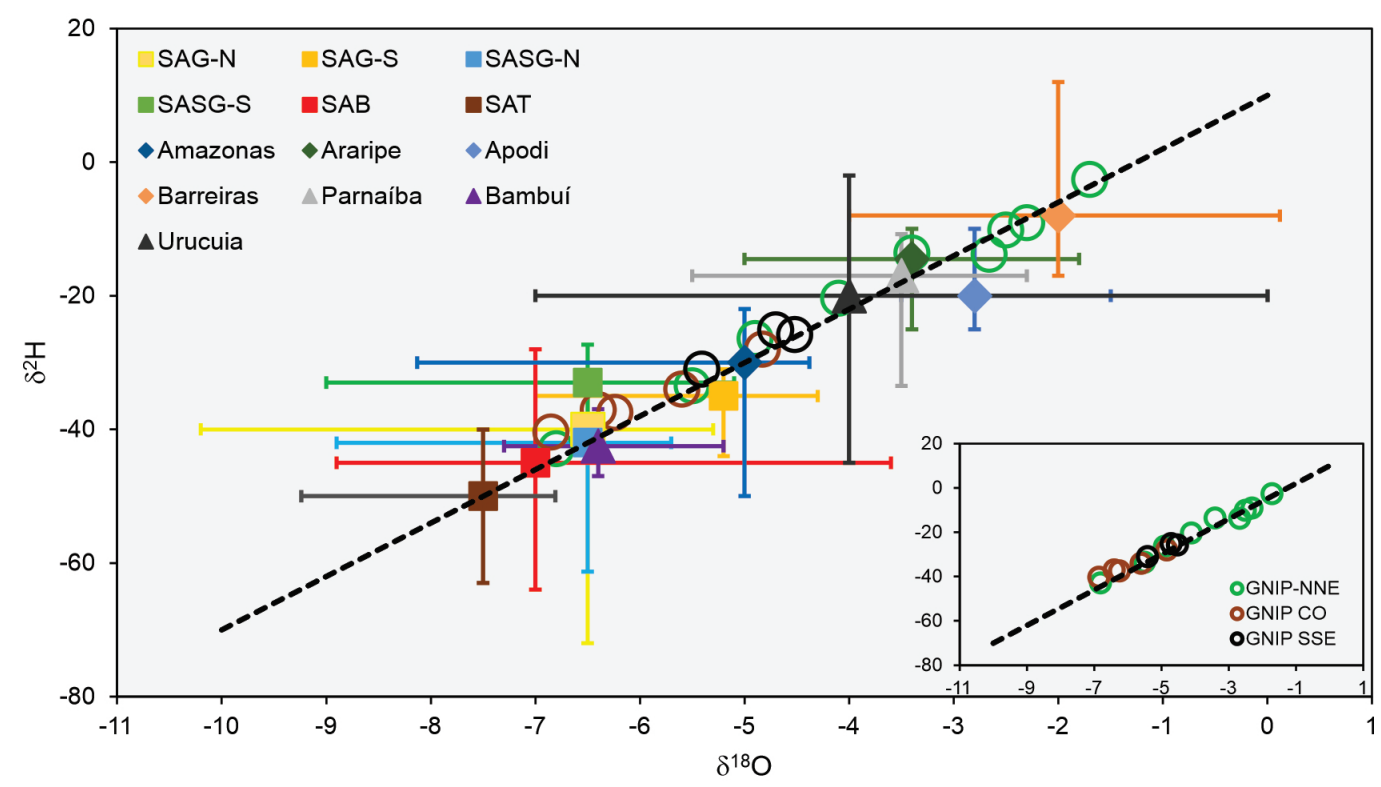

FIGURA 8 - Síntese das variações das composições isotópicas dos principais aquíferos brasileiros e dos valores médios da composição isotópica da precipitação em algumas regiões. Os aquíferos das regiões Norte e Nordeste estão indicados em losango, os da porção central do Brasil com triângulos e os aquíferos da Bacia do Paraná com quadrados. Os aquíferos Guarani (SAG) e Serra Geral (SASG) foram divididos em dois compartimentos, devido as diferenças existentes e o número de estudos realizados. As estações GNIP consideradas nessa síntese são: Belém, Porto Velho, Rio Branco, Salvador, Santarém, Ceará Mirim, Manicoré, Fortaleza e Manaus (GNIP-NNE); Brasília, Campo Grande, Cruzeiro do Sul, Cuiabá e Belo Horizonte (GNIP-CO), e Porto Alegre, Rio Claro e Rio de Janeiro (GNIP-SSE). A reta de referência é representada pela Reta Meteórica Global, com equação $\delta^{2} \mathrm{H}=8^{*} \delta^{18} \mathrm{O}+10$. 
to da precipitação quanto das águas subterrâneas, observado especialmente nas águas subterrâneas dos aquíferos da Bacia Amazônica, que apresentam composição isotópica mais depletada que a dos aquíferos localizados mais próximos à região costeira, refletindo a composição isotópica da precipitação no interior da Amazônia.

Em relação às águas subterrâneas dos aquíferos da Bacia do Paraná, observa-se que possuem composição isotópica normalmente mais depletada que a média da precipitação, indicando, conforme apontado por diversos autores, recargas em condições climáticas pretéritas distintas, uma vez que essas águas foram recarregadas em muitos casos há mais de 50.000 mil anos, ou mesmo devido à concentração da recarga em eventos climáticos específicos, associado à instalação da ZCAS sobre as região sudeste, que geralmente concentra a maior parte da chuva e com composições isotópicas mais empobrecidas.

Como síntese e lições aprendidas durante a realização dessa revisão, deve-se considerar que a compreensão de processos hidrológicos a partir de dados isotópicos, seja em superfície ou em subsuperfície, prescinde de informações a respeito da composição isotópica da precipitação, em diversas escalas espaço-temporal. Ainda que a rede GNIP tenha tido uma boa abrangência espacial em território nacional, sua interrupção nos anos 1980 dificultou o avanço nessa área. Apesar disso, os estudos realizados, mencionados no capítulo 3 , fornecem um excelente embasamento para a criação de retas meteóricas locais e dos efeitos climáticos regionais e locais, como o sintetizado no mapa da figura 4.

Esses trabalhos contribuíram de maneira efetiva para o entendimento dos controles climáticos sobre a precipitação, reforçando a importância da floresta Amazônica, como fonte de umidade para o regime de chuvas em grande parte do Brasil, e do regime sazonal com atuação de diferentes sistemas atmosféricos e tipos de chuva. Trata-se de ferramenta essencial para compreensão dos mecanismos de recarga dos sistemas aquíferos brasileiros e estudos hidrogeológicos em geral.

A retomada recente da operação da rede de monitoramento da composição isotópica da precipitação por meio da instalação de 10 estações GNIP para coleta da precipitação isotópica mensal $\left({ }^{18} \mathrm{O},{ }^{2} \mathrm{H} \mathrm{e}^{3} \mathrm{H}\right)$, em operação desde 2018 e com mais de 12 estações em plano de instalação (FRANZINI et al. 2019), a partir de uma parceria entre Serviço Geológico do Brasil-CPRM e a Agência Nacional de Águas (ANA) com apoio da AIEA, é relevante e irá produzir informação capaz de suprir as necessidades de diversos estudos hidrogeológicos que venham a ser realizados.

A existência de uma rede é um passo importante sem dúvida, mas faz-se necessário evoluir em linhas de investigação consideradas essenciais: (i) na determinação dos tipos de chuva, incluindo análise detalhada de eventos extremos e ciclones; (ii) estudos sobre o tempo de residência do vapor amazônico na atmosfera e sua relação com o desmatamento e a composição isotópica de vapor e chuva; e (iii) estudos de precipitação sobre a região Nordeste (principalmente no semiárido) e Sul do país, tendo em vista os limites da atuação da umidade amazônica. Ressalta-se aqui que a determinação das retas meteóricas locais para estas regiões pode contribuir de maneira mais efetiva na comparação com os demais reservatórios, melhorando o entendimento sobre os processos de recarga dos aquíferos.

A integração entre a composição isotópica da precipitação e a das águas subterrâneas, tanto em escala regional, como realizada por CHANG et al. (2020), quanto em escala local, ainda pouco explorada em estudos locais, pode acrescentar muito a compreensão de processos climáticos e suas relações com a recarga, presente e pretérita, das águas subterrâneas, devendo ser investigada e incorporada nos estudos futuros.

As relações entre as variações climáticas e eventos extremos e a recarga das águas subterrâneas no território nacional devem ser abordadas em estudos hidrogeológicos de maneira a possibilitar a identificação de controles estacionais sobre a infiltração da água.

Nesse sentido, dados de monitoramento de níveis d'água subterrânea, advindas das inúmeras redes existentes, como a Rede Integrada de Monitoramento de Águas Subterrâneas (RIMAS) da CPRM, poderão contribuir de maneira significativa na compreensão desses processos e fornecer subsídios, associados a monitoramento hidrológico, para a elaboração de balanços hídricos em diversas escalas, avaliar os processos de interação entre águas subterrâneas e superficiais, fornecendo importantes informações para a gestão integrada dos recursos e avaliação da resiliência hídrica de inúmeras bacias hidrográficas.

Mesmo com o grande aporte de conhecimento trazido pelos isótopos de $\mathrm{H}$ e $\mathrm{O}$ sobre as condições regionais de circulação das águas subterrâneas e suas relações, estimadas ainda que preliminarmente, com condições climáticas pretéritas e atuais 
da recarga, várias questões ainda permanecem em aberto no cenário nacional. Neste sentido, a utilização de isótopos estáveis de $\mathrm{H}$ e $\mathrm{O}$, associada a outros traçadores, como gases nobres, por exemplo, irá aportar elementos adicionais na avaliação de misturas entre águas com tempos de residência distintos, assim como na reconstituição climática de paleorrecargas, especialmente entre os aquíferos das grandes bacias sedimentares (Amazonas, Paraná e Araripe, por exemplo). Além disso, menciona-se aqui o excesso de deutério como sendo uma variável isotópica de segunda ordem de relevante importância na interpretação de processos hidrológicos e que, até o presente momento, não vem sendo analisada de maneira consistente na maior parte dos estudos.

A sistematização de informações relativas à composição isotópica da precipitação e das águas subterrâneas também abrem precedentes para ampliação de estudos relativos à composição isotópica de águas superficiais. Iniciativas como a GNIR (Global Network of Isotopes in Rivers), em implantação no Brasil, pode auxiliar no desenvolvimento de pesquisas que considerem a conexão entre águas subterrâneas e superficiais. Esses estudos ainda são muito incipientes no Brasil, e dependentes do conhecimento detalhado do comportamento de cada uma dessas fontes para interpretações de processos hidrológicos. Estudos isotópicos em bacias hidrográficas visam compreender: a variabilidade espacial (distribuição dos sistemas aquíferos) e temporal (período de predominância das fontes) das águas subterrâneas (fluxo de base) e das precipitações (escoamento direto) na formação das vazões; tempo de residência; processos evaporativos; efeitos da antropização nas bacias, separação de hidrogramas, entre outros.

\section{AGRADECIMENTOS}

Os autores gostariam de agradecer a FAPESP (processos 2012/00241-5, 2015/15749-2 e 2018/06666-4), CNPq (processo 404979/20181) e a Agência Internacional de Energia Atômica (Research Contract \#17984 e \#23531), pela concessão de auxílios que possibilitaram a realização de inúmeras pesquisas mencionadas nesse artigo. Ao CNPq pela concessão de bolsas de mestrado aos autores LNG (processo 134432/20193); CL (processo 134919/2019-0), CSQ (processo 130944/2019-0) e a FAPESP pela concessão de bolsa de doutorado aos autores VS (processo 2019/03467-3) e LVS (processo 2017/13576-9).
Finalizando os autores agradecem aos editores da Revista do Instituto Geológico, Dr. Silvio Hiruma e Dr ${ }^{a}$ Sibele Ezaki, e a um revisor anônimo pelas excelentes sugestões e comentários oportunos, que muito contribuíram para a melhoria do manuscrito original.

\section{REFERÊNCIAS BIBLIOGRÁFICAS}

ABBOTT, B.W.; BISHOP, K.; ZARNETSKE, J.P.; MINAUDO, C.; CHAPIN III, F.S.; KRAUSE, S.; HANNAH, D.M.; CONNER, L.; ELLISON, D.; GODSEY, S.E.; PLONT, S.; MARÇAIS, J.; KOLBE, T.; HUEBNER, A.; FREI, R.J.; HAMPTON, T.; GU, S.; BUHMAN, M.. SAYEDI, S.S.; URSACHE, O.; CHAPIN, M.; HENDERSON, K.D.; PINAY, G. 2019. Human domination of the global water cycle absent from depictions and perceptions. Nature Geoscience, 12: 533-540. https://doi.org/10.1038/s41561-0190374-y

AESCHBACH-HERTIG, W.; GLEESON, T. 2012. Regional strategies for the accelerating global problem of groundwater depletion. Nature Geoscience, 5(12): 853-861. https:// doi.org/10.1038/ngeo1617

AGGARWAL, P.K.; ALDUCHOV, O.A.; FROEHLICH, K.O.; ARAGUASARAGUAS, L.J.; STURCHIO, N.C.; KURITA, N. 2012. Stable isotopes in global precipitation: A unified interpretation based on atmospheric moisture residence time. Geophysical Research Letters, 39: 1-6. https://doi.org/10.1029/2012GL051937

AGGARWAL, P.K.; ROMATSCHKE, U.; ARAGUAS-ARAGUAS, L.; BELACHEW, D.; LONGSTAFFE, F.J.; BERG, P.; SCHUMACHER, C.; FUNK, A. 2016. Proportions of convective and stratiform precipitation revealed in water isotope ratios. Nature Geoscience, 9(8): 624-629. https://doi.org/10.1038/ngeo2739

AGUIAR, R.P.S. 2015. Uso de Isótopos como Traçadores Naturais de Águas Subterrâneas: Aplicação à Bacia do Córrego Engenho Nogueira. Centro de Desenvolvimento da Tecnologia Nuclear, Universidade Federal de Minas Gerais, Belo Horizonte, Dissertação de Mestrado, 137 p. 
ALBERTI, H.L.C. 2017. Estudo hidroquímico $e$ isotópico das águas subterrâneas impactadas pela drenagem ácida da mina de urânio - Osamu Utsumi, planalto de Poços de Caldas $(M G)$. Instituto de Geociências, Universidade Estadual de Campinas, Campinas, Tese de Doutorado, 198 p.

ALMEIDA, T.I.R.; KARMANN, I.; PARANHOS FILHO, A.C.; SÍGOLO, J.B.; BERTOLO, R.A. 2010. Os diferentes graus de isolamento da água subterrânea como origem de sua variabilidade: evidências isotópicas, hidroquímicas e da variação sazonal do nível da água no Pantanal da Nhecolândia. Geologia USP: Série Cientifica, 10(3): 37-47. https://doi.org/10.5327/Z1519 874X2010000300003

ANA - AGÊNCIA NACIONAL DE ÁGUAS. 2010. Vol. IV - Hidroquímica, Vulnerabilidade dos Aquíferos e Riscos de Contaminação. In: Avaliação dos recursos hídricos subterrâneos e proposição de modelo de gestão compartilhada para os aquíferos da Chapada do Apodi, entre os Estados do Rio Grande do Norte e Ceará. Brasília, ANA, 151 p. (Relatório Final).

ANA - AGÊNCIA NACIONAL DE ÁGUAS. 2011. Estudos Hidrogeológicos para Subsidiar a Gestão Sustentável dos Recursos Hídricos Subterrâneos na Região Metropolitana de Maceió. Brasília, ANA (Relatório Final).

ANA - AGÊNCIA NACIONAL DE ÁGUAS. 2015. Volume IV - Hidrogeoquímica da Província Hidrogeológica Amazonas. In: Avaliação dos aquíferos das Bacias Sedimentares da Província Hidrogeológica Amazonas no Brasil (escala 1:1.000.000) e Cidades Pilotos (escala 1:50.000). Brasília, ANA, $597 \mathrm{p}$.

ANA - AGÊNCIA NACIONAL DE ÁGUAS. 2016. Estudo de vulnerabilidade natural à contaminação e estratégias de proteção do sistema Aquífero Guarani nas áreas de afloramento. Brasília, ANA, 343 p. (Relatório Final - Tomo I).

ANA - AGÊNCIA NACIONAL DE ÁGUAS. 2017. Estudos hidrogeológicos e de vulnerabilidade do Sistema Aquífero Urucuia: Proposição de modelo de gestão integrada compartilhada. Caracterização hidrogeoquímica das águas dos Sistemas Aquiferos Urucuia (SAU) e Areado (SAA). Brasília, ANA, 179 p. (Relatório Técnico Temático).

ANA - AGÊNCIA NACIONAL DE ÁGUAS. 2018. Estudos hidrogeológicos para a Gestão das Águas Subterrâneas da Região de Belém/PA. Brasília, ANA, 164 p. (Relatório Final - Volume 2).

ANA - AGÊNCIA NACIONAL DE ÁGUAS. 2020. Aquifero Alter do Chão é o maior reservatório de água do planeta. Agência Nacional de Águas e Saneamento Básico. Acesso em 10 setembro de 2020. Disponível em: $\quad$ https://www.ana.gov.br/noticiasantigas/aquafero-alter-do-chapso-a-c-omaior-reservata3rio.2019-03-15.3692202018

ARAGUÁS-ARAGUÁS, L.; FROEHLICH, K.; ROZANSKI, K. 1998. Stable isotope composition of precipitation over Southeast Asia. Journal of Geophysical Research, 103(D22): 28721-28742. https://doi. org/10.1029/98JD02582

ARAÚJO, V.P.; SOBRINHO, G.A.N.; FREITAS, L.D.; FRANKLIN, M.R. 2017. Groundwater isotopic variations in a uranium mining site: subsidies for contamination studies. Brazilian Journal of Radiation Sciences, 05(2): 01-23. https://doi.org/10.15392/bjrs. v5i2.276

ASSINE, M.L.; MERINO, E.R.; PUPIM, F.N.; WARREN, L.V.; GUERREIRO, R.L.; MCGLUE, M.M. 2015. Geology and Geomorphology of the Pantanal Basin. In: I. Bergier, M. Assine (ed.) Dynamics of the Pantanal Wetland in South America. The Handbook of Environmental Chemistry, 37, p. 23-50. http://dx.doi. org/10.1007/698_2015_349

AYER, J.E.B.; CORRÊA, W. S.; PEREIRA, S.Y. 2016. Características físicas, químicas e isotópicas das águas subterrâneas de Águas de Lindóia e Lindóia - Revisão. In: ABAS, CONGRESSO BRASILEIRO DE ÁGUAS SUBTERRÂNEAS, 19, Campinas. https:// doi.org/10.14295/ras.v0i0.28748 
AZEVEDO, J.H. 2019. Fluxos subterrâneos e recarga do Sistema Aquifero Alter do Chão em lateritos amazônicos: estudo de caso em Porto Trombetas, Pará. Instituto de Geociências, Universidade de Brasília, Brasília, Tese de Doutorado, 139 p.

BARBOSA, N.S. 2016. Hidrogeologia do Sistema Aquifero Urucuia, Bahia. Instituto de Geociências, Universidade Federal da Bahia, Salvador, Tese de Doutorado, 168 p.

BARISON, M.R. 2003. Estudo hidrogeoquímico da porção meridional do Sistema Aquífero Bauru no Estado de São Paulo. Instituto de Geociências e Ciências Exatas, Universidade Estadual Paulista, Rio Claro, Tese de Doutorado, 153 p.

BARROS, J.F.; ALMEIDA, J.B.; SILVA, C.M.S.V.; MENDES FILHO, J.; MESQUITA, B.A.; SANTIAGO, M.M.F.; FRISCHKORN，H. 2015. Caracterização isotópica $\left({ }^{18} \mathrm{O}, \mathrm{D}\right)$ e hidroquímica das águas da bacia do rio da Prata de São Luís/MA e vizinhança. Revista Brasileira de Recursos Hídricos, 20(2): 404-410. http://dx.doi. org/10.21168/rbrh.v20n2.p404-410

BATISTA, J.R.X.; SANTIAGO, M.M.F.; FRISCHKORN, H.; FILHO, M.J.; FORSTER, M. 1998. Isótopos ambientais na água subterrânea de Picos - PI. In: ABAS, CONGRESSO BRASILEIRO DE ÁGUAS SUBTERRÂNEAS, 10, São Luiz, Anais, 10 p.

BATISTA, L.V.; GASTMANS, D.; SÁNCHEZMURILLO, R.; FARINHA, B.S.; SANTOS, S.M.R.; KIANG, C.H. 2018. Groundwater and surface water connectivity within the recharge area of Guarani aquifer system during El Niño 2014-2016. Hydrological Processes, 32: 2483-2495. https://doi. org/10.1002/hyp.13211

BATISTA, L.V. 2019. Desvendando a movimentação da água em área de recarga do Sistema Aquífero Guarani (SAG), utilizando análise hidrológica e traçadores isotópicos. Instituto de Geociências e Ciências Exatas, Universidade Estadual Paulista, Rio Claro, Tese de Doutorado, $112 \mathrm{p}$.

BERTRAND, G.; HIRATA, R.; AULER, A.; CRUZ, F.; CARY, L.; PÉTELET-
GIRAUD, E.; CHATTON, E.; AQUILINA, L.; MOQUET, J.;S.; BUSTAMANTE, G.; MILLO, C.; MARTINS, V.; MONTENEGRO, S.; CELLE-JEANTON, H. 2017. Groundwater isotopic data as potential proxy for Holocene paleohydroclimatic and paleoecological models in NE Brazil. Palaeogeography, Palaeoclimatology, Palaeoecology, 469: 92-103. https://doi. org/10.1016/j.palaeo.2017.01.004

BISWAL, B.; KUMAR, D.N. 2014. Study of dynamic behavior of recession curves. Hydrological Process. 28(3): 784-792. https://doi.org/10.1002/hyp.9604

BONOTTO, D.M.; ELLIOT, T. 2017. Trace elements, REEs and stable isotopes $(\mathrm{B}, \mathrm{Sr})$ in GAS groundwater, São Paulo State, Brazil. Environmental Earth Sciences, 76(7): 1-15. https://doi.org/10.1007/s12665-017-6590-0

BORTOLIN, T.A. 2014. Padrões hidroquímicos $e$ isotópicos do Sistema Aquifero Serra Geral no município de Carlos Barbosa, região nordeste do Estado do Rio Grande do Sul. Instituto de Pesquisas Hidráulicas, Universidade Federal do Rio Grande do Sul, Porto Alegre, Dissertação de Mestrado, 116 p.

CAMPOS, J.E.G.; FREITAS-SILVA, F.H. 1998. Inventário hidrogeológico e dos recursos hídricos superficiais do Distrito Federal. IEMA/SEMATEC/UnB, Brasília, 87 p. (Relatório Técnico Parte IV).

CARACAS, I.B. 2013. Influência da salinização em parâmetros de qualidade das águas subterrâneas na região costeira do Baixo Jaguaribe. Instituto de Ciências do Mar, Universidade Federal do Ceará, Dissertação do Mestrado, $90 \mathrm{p}$.

CARNEIRO, C.E.C.D.; SANTIAGO, M.M.F.; FRISCHKORN, H.; FILHO, J.M.; FORSTER, M. 1998. Oxigênio-18, deutério e condutividade elétrica para caracterização da água subterrânea no Vale do Gurguéia. In: ABAS, CONGRESSO BRASILEIRO DE ÁGUAS SUBTERRÂNEAS, 10, São Luiz, Anais. Disponível em: https:// aguassubterraneas.abas.org/asubterraneas/ article/view/22258 
CARVALHO, J.V. 2018. Hidrogeoquímica e Isótopos Estáveis das Águas Subterrâneas do Aquífero Bambuí (Bahia, Brasil). Instituto de Geociências, Universidade Federal da Bahia, Salvador, Dissertação de Mestrado, $54 \mathrm{p}$.

CARY, L.; PÉTELET-GIRAUD, E.; BERTRAND, G.; KLOPPMANN, W.; AQUILINA, L.; MARTINS, V.; HIRATA, R.; MONTENEGRO, S.; PAUWELS, H.; CHATTON, E.; FRANZEN, M.; AUROUET, A. 2015. Origins and processes of groundwater salinization in the urban coastal aquifers of Recife (Pernambuco, Brazil): A multi-isotope approach. Science of The Total Environment, 530-531: 411-429. https://doi.org/10.1016/j. scitotenv.2015.05.015

CHANG, H.K.; GONÇALVES, R.D.; AGGARWAL, P.K.; STRADIOTO, M.R.; HESPANHOL, E.C.B.; STURCHIO, N.; ROMATSCHKE, U.; ARAGUAS, L.J.A. 2020. Groundwater isotope ratios reflect convective and stratiform (paleo)precipitation fractions in Brazil. Journal of Hydrology, 585: 124801. https://doi. org/10.1016/j.jhydrol.2020.124801

CHATTON, E.; AQUILINA, L.; PÉTELETGIRAUD, E.; CARY, L.; BERTRAND, G.; LABASQUE, T.; HIRATA, R.; MARTINS, V.; MONTENEGRO, S.; VERGNAUD, V.; AUROUET, A.; KLOPPMANN, W.; PAUWELS, H. 2016. Glacial recharge, salinisation and anthropogenic contamination in the coastal aquifers of Recife (Brazil). Science of The Total Environment, 569-570: 1114-1125. https:// doi.org/10.1016/j.scitotenv.2016.06.180

CHERRY, M.; GILMORE, T.; MITTELSTET, A.; GASTMANS, D.; SANTOS, V.; GATES, J.B. 2020. Recharge seasonality based on stable isotopes: Nongrowing season bias altered by irrigation in Nebraska. Hydrological Processes, 34(7): 1-12. https:// doi.org/10.1002/hyp.13683

CLARK, I.; FRITZ, P. 1997. Environmental Isotopes in Hydrogeology. Boca Raton, CRC Press, $342 \mathrm{p}$.

CLARK, I.D. 2015. Groundwater Geochemistry and Isotopes. Boca Raton, CRC Press, 456 p. https://doi.org/10.1201/b18347
COGERH - COMPANHIA DE GESTÃO DOS RECURSOS HÍDRICOS. 2009. Plano de Monitoramento e Gestão dos Aquiferos da Bacia do Araripe. Governo do Estado do Ceará, Fortaleza, 270 p. Disponível em: https://portal.cogerh.com.br/wp-content/ uploads/2018/10/Plano-de-Monitoramentoe-Gest $\%$ c3\%a3o-dos-Aqu \%c3\%adferos-daBacia-do-Araripe.pdf

COGERH - COMPANHIA DE GESTÃO DOS RECURSOS HÍDRICOS. 2011. Estudo de qualidade das águas subterrâneas da Bacia Araripe, Ceará. COGERH, Governo do Estado do Ceará, Fortaleza, 115 p. (Vol. 1, Relatório Final).

COGERH - COMPANHIA DE GESTÃO DOS RECURSOS HÍDRICOS. 2017. Estudos Qualiquantitativos das Águas Subterrâneas das Águas Subterrâneas da Bacia do Araripe (2016-2017). COGERH, Governo do Estado do Ceará, Fortaleza, 450 p.

COPLEN, T. R.; HERCZEG, A. L.; BARNES, C. 2000. Isotope Engineering - Using Stable Isotopes of the Water Molecule to Solve Practical Problems. In: P. Cook \& A.L. Herczeg (eds.), Environmental Tracers in Subsurface Hydrology. Boston, Springer, p. 79-110. https://doi.org/10.1007/978-1-46154557-6_3

CORRÊA, W.S. 2019. Planície aluvionar do Rio Mogi - Guaçú - SP: Caracterização hidroquímica e isotópica das águas. Instituto de Geociências, Universidade Estadual de Campinas, Campinas, Dissertação de Mestrado, $152 \mathrm{p}$.

COSTA, A.B.; EXPEDITO, A.; AZEVEDO, G. 2007. Avaliação do Padrão da Composição Isotópica de Águas na Bacia do Rio Joanes: Implicações para a Interação entre Águas Superficiais e Subterrâneas. Revista Brasileira de Recursos Hídricos, 12(3): 211-219. https://doi.org/10.21168/rbrh.v12n3. p211-219

COSTA FILHO, W.D.; SANTIAGO, M.M.F.; COSTA, W.D.; MENDES FILHO, J. 1998. Isótopos estáveis e a qualidade das águas subterrâneas na planície do Recife. In: ABAS, CONGRESSO BRASILEIRO DE ÁGUAS SUBTERRÂNEAS, 10, 
São Luiz, Anais. Disponível em: https:// aguassubterraneas.abas.org/asubterraneas/ article/view/22274

COTA, S.; PEIXOTO, C.M.; BARRETO, A. A.; GASTMANS, D.; SANTOS, V.; TERZER, S.; ARAGUÁS-ARAGUÁS, L. 2013. Gnip Stations in Brazil: Importance, past and current developments. In: ABAS, CONGRESSO INTERNACIONAL DE MEIO AMBIENTE SUBTERRÂNEO, 3, São Paulo, Anais. Disponível em: https:// aguassubterraneas.abas.org/asubterraneas/ article/view/27504

CPRM - SERVIÇO GEOLÓGICO DO BRASIL. 1993. Geologia, tectônica e recursos minerais do Brasil: texto, mapas \& SIG. BIZZI, L.A.; SCHOBBENHAUS, C.; GONÇALVES, J.H.; BAARS, F.J.; DELGADO, I.M.; ABRAM, M.B.; LEÃO NETO, R.; MATOS, G.M.M.; SANTOS, J.O.S. (eds). - Brasília, 692p. Disponível em: http://rigeo.cprm.gov.br/jspui/handle/ $\operatorname{doc} / 5006$

CRAIG, H. 1961. Isotopic Variations in Meteoric Waters. Science, 133(3465): 1702-1703. https://doi.org/10.1126/science.133.3465.1702

CRAIG，H.; GORDON，L. 1965. Deuterium and oxygen-18 variations in the ocean and the marine atmosphere. In: E. Tongiorgi (ed.) Stable Isotopes in Oceanographic Studies and Paleotemperatures. Consiglio Nazionale Delle Ricerche, Laboratorio di Geologia Nucleare, Pisa, p. 9-130.

CRESPI, A.M. 2013. Aplicação de isótopos de estrôncio, oxigênio e hidrogênio como traçadores de anomalias hidrogeoquímicas de bário no Sistema Aquífero Bauru no município Gália (SP). Instituto de Geociências, Universidade de São Paulo, São Paulo, Dissertação de Mestrado, 74p. https://doi. org/10.11606/D.44.2013.tde-06122013091126

CROSBIE, R.S.; SCANLON, B.R.; MPELASOKA, F.S.; REEDY, R.C.; GATES, J.B.; ZHANG, L. 2013. Potential climate change effects on groundwater recharge in the High Plains Aquifer, USA. Water Resources Research, 49(7): 39363951. https://doi.org/10.1002/wrcr.20292
CRUZ JR.; F.W.; KARMANN, I.; VIANNA JR., O.; BURNS, S.J.; FERRARI, J.A.; VUILLE, M.; SIAL, A.N.; MOREIRA, M.Z. 2005. Stable isotope study of cave percolation waters in subtropical Brazil: Implications for paleoclimate inferences from speleothems. Chemical Geology, 220 (3/4): 245-262. https://doi.org/10.1016/j. chemgeo.2005.04.001

DALL'OLIO, A.; SALATI, E.; AZEVEDO, C.T., MATSUI, E. 1979. Modelo de fracionamento isotópico da água na bacia Amazônica (Primeira aproximação). Acta Amazonica, 9(4): 675-678. https://doi.org/10.1590/180943921979094675

DANSGAARD, W. 1964. Stable isotopes in precipitation. Tellus, 16(4): 436-468. https:// doi.org/10.3402/tellusa.v16i4.8993

DIAS, J.P.R.V. 2005. Composição isotópica de oxigênio e hidrogênio $\left(\delta^{18} \mathrm{O}\right.$ e $\left.\delta D\right)$ da precipitação e sua relação com as águas subterrâneas na cidade de São Paulo. Instituto de Geociências, Universidade de São Paulo, São Paulo. Dissertação de Mestrado, 98 p. https:// doi.org/10.11606/D.44.2016.tde-22012016142421

DINIZ, H.N. 1990. Estudo hidrogeológico do subgrupo Itararé no Médio Rio Tiête, Município de Tiête, SP. Instituto de Geociências, Universidade de São Paulo, São Paulo, Dissertação de Mestrado, 121 p.

DUTTON, A.R. 1995. Groundwater isotopic evidence for paleorecharge in US High Plains aquifers. Quaternary Research, 43(2): 221-231. https://doi.org/10.1006/ qres.1995.1022

ELLIOT, T.; BONOTTO, D.M. 2017. Hydrogeochemical and isotopic indicators of vulnerability and sustainability in the GAS aquifer, São Paulo State, Brazil. Journal of Hydrology: Regional Studies, 14: 130-149. https://doi.org/10.1016/j.ejrh.2017.10.006

ENGELBRECHT, B.Z. 2017. Modelo conceitual de circulação de água subterrânea em aquífero cristalino no município de Itu/SP. Instituto de Geociências e Ciências Exatas, Universidade Estadual Paulista, Rio Claro, Dissertação de Mestrado, 88 p. 
EZAKI, S.; IRITANI, M.A.; ODA, G.H.; GASTMANS, D.; YOSHINAGAPEREIRA, S. 2016. Estudo hidroquímico e isotópico das águas subterrâneas na porção central do Aquífero Tubarão, estado de São Paulo - Resultados Preliminares. In: ABAS, CONGRESSO BRASILEIRO DE ÁGUAS SUBTERRÂNEAS, 19, Campinas, Anais. https://doi.org/10.14295/ras.v0i0.28765

EZAKI, S.; GASTMANS, D.; IRITANI, M.A.; SANTOS, V.; STRADIOTO, M.R. 2020. Geochemical evolution, residence times and recharge conditions of the multilayered Tubarão aquifer system (State of São Paulo - Brazil) as indicated by hydrochemical, stable isotope and ${ }^{14} \mathrm{C}$ data. Isotopes in Environmental and Health Studies, 56(5-6): 495-512. https://doi.org/10.1080/10256016.2 020.1797714

FAMIGLIETTI, J.S. 2014. The global groundwater crisis. Nature Climate Change, 4: 945-948, https://doi.org/10.1038/nclimate2425

FERNANDES, A.J.; MANDANER, C.H.; ROULEAU, A. 2011. Análise das fraturas nos basaltos de Ribeirão Preto, SP: aplicação à elaboração de modelo hidrogeológico conceitual. Geologia USP (Série Científica), 11(3): 43-64. http://dx.doi.org/10.5327/ Z1519-874X2011000300003

FONTES, A.S.; ZUCCHI, M.R.; MEDEIROS, Y.D.P.; AZEVEDO, A.E.G. 2011. Estudo da Dinâmica do Fluxo de Água na Bacia do Rio Jacuípe por Meio de Traçadores Ambientais. Revista Brasileira de Recursos Hidricos, 16(3): 27-36. https://10.21168/rbrh.v16n3. p27-36

FRANZINI, A.S.; KIRCHHEIM, R.E.; NOGUEIRA， G.S.; NIEMAYER， A.F.; OLIVEIRA, F.R.; GASTMANS, D. 2019. The new GNIP Network in Brazil: An example of Sound Institutional Arrangements. In: INTERNATIONAL SYMPOSIUM ON ISOTOPE HYDROLOGY: ADVANCING THE UNDERSTANDING OF WATER CYCLE PROCESSES. Vienna: International Atomic Energy Agency (IAEA).

FREEMAN, K.H. 2014. Earth science: Controls on isotopic gradients in rain. Nature, 516: 41-42. https://doi.org/10.1038/516041a
FREITAS, M.A. 2016. Hidrogeoquímica e isótopo de águas com alta salinidade do Sistema Aquífero Serra Geral na região do Alto Rio Uruguai, Brasil. Instituto de Geociências, Universidade Federal do Rio Grande do Sul, Porto Alegre, Tese de Doutorado, 195 p.

FREITAS, J.G.; FURQUIM, S.A.C.; ARAVENA, R.; CARDOSO, E.L. 2019. Interaction between lakes' surface water and groundwater in the Pantanal wetland, Brazil. Environmental Earth Sciences, 78(139). https://doi.org/10.1007/s12665-019-8140-4

FRISCHKORN, H.; SANTIAGO, M.F.; SEREJO, A.N. 1989. Isotope study of wells in crystalline rock of the semi-arid northeast of Brazil. In: ESTUDIOS DE HIDROLOGIA ISOTÓPICA EN AMERICA LATINA, Isotope Hydrology Investigations in Latin America, Viena, OIEA, p. 73-89.

FRISCHKORN, H.; HORN, P.; SANTIAGO, M.M.F.; MENDONÇA, L.A.R. 2002. Origem da água no lençol de Fortaleza. In: ABAS, CONGRESSO BRASILEIRO DE ÁGUAS SUBTERRÂNEAS, 12, Florianópolis, Anais . Disponível em: https:// aguassubterraneas.abas.org/asubterraneas/ article/view/22811

FROEHLICH, K.; GIBSON, J.J.; AGGARWAL, P. 2002. Deuterium excess in precipitation and its climatological significance. International conference on study of environmental change using isotope techniques; Vienna, p. 54-66.

GALLO, G.; SINELLI, O. 1980. Estudo hidroquímico e isotópico das águas subterrâneas na região de Ribeirão Preto (SP). Revista Brasileira de Geociências, 10(2): 129140.

GALVÃO, P.; HIRATA, R.; HALIHAN, T.; TERADA, R. 2017. Recharge sources and hydrochemical evolution of an urban karst aquifer, Sete Lagoas, MG, Brazil. Environmental Earth Science, 76(159). https://doi.org/10.1007/s12665-017-6482-3

GASTMANS, D.; CHANG, H.K..; HUTCHEON, I. 2010a. Stable isotopes $\left({ }^{2} \mathrm{H},{ }^{18} \mathrm{O}\right.$ and $\left.{ }^{13} \mathrm{C}\right)$ in groundwaters from the northwestern portion of the Guarani Aquifer System 
(Brazil). Hydrogeology Journal, 18: 1497-

1513. https://doi.org/10.1007/s10040-010-

0612-2

GASTMANS, D.; CHANG, H.K.; HUTCHEON, I. 2010b. Groundwater geochemical evolution in the northern portion of the Guarani Aquifer System (Brazil) and its relationship to diagenetic features. Applied Geochemistry, 25(1): 16-33. http://dx.doi. org/10.1016/j.apgeochem.2009.09.024

GASTMANS, D.; HUTCHEON, I.; MENEGÁRIO, A.A.; CHANG, H.H. 2016. Geochemical evolution of groundwater in a basaltic aquifer based on chemical and stable isotopic data: Case study from the Northeastern portion of Serra Geral Aquifer, São Paulo state (Brazil). Journal of Hydrology, 535: 598-611. http://dx.doi. org/10.1016/j.jhydrol.2016.02.016

GASTMANS, D.; SANTOS, V.; GALHARDI, J.A.; GROMBONI, J.F.; BATISTA, L.V.; MIOTLINSKI, K.; CHANG, H.K.; GOVONE, J.S. 2017a. Controls over spatial and seasonal variations on isotopic composition of the precipitation along the central and eastern portion of Brazil. Isotopes in Environmental and Health Studies, 53(5): 518-538. http://dx.doi.org/10. 1080/10256016.2017.1305376

GASTMANS, D.; MIRA, A.; KIRCHHEIM, R.; VIVES, L.; RODRÍGUEZ, L.; VEROSLAVSKY, G. 2017b. Hypothesis of groundwater flow through geological structures in Guarani Aquifer System (GAS) using Chemical and Isotopic Data. Procedia Earth and Planetary Science, 17: 136-139. https://doi.org/10.1016/j.proeps.2016.12.030

GASTMANS, D.; MENEGÁRIO, A.A.; HUTCHEON, I. 2017c. Stable isotopes, carbon-14 and hydrochemical composition from a basaltic aquifer in São Paulo State, Brazil. Environmental Earth Sciences, 76: 150. http://dx.doi.org/10.1007/s12665-0176468-1

GAT, J.R.; MATSUI, E. 1991. Atmospheric Water Balance in the Amazon Basin: An Isotopic Evapotranspiration Model. Journal of Geophysical Research, 96(D7): 13,17913,188. https://doi.org/10.1029/91JD00054
GONÇALVES, M.V.P. 2014. Flúor nas Águas Subterrâneas do Aquífero Bambuí no Sudoeste da Bahia (Brasil). Instituto de Geociências, Universidade Federal da Bahia, Salvador, Tese de Doutorado, 193 p.

GOMES, D.F.; FRISCHKORN, H.; FREIRE, J.S.S. 2007. Medidas de ${ }^{18} \mathrm{O}$ e hidroquímica de águas superficiais e subterrâneas no estudo da interação rio-aquífero, na região de Limoeiro do Norte - Baixo Jaguaripe - CE. Águas Subterrâneas, 21(1): 93-109. https://doi.org/10.14295/ras.v21i1.16173

GOMES, O.V.O. 2012. Hidrogeoquímica dos aquiferos da Bacia Sedimentar do Macacu - Itaboraí, RJ. Instituto de Química, Universidade Federal Fluminense, Niterói, Tese de Doutorado, $244 \mathrm{p}$.

GONFIANTINI, R. 1985. On The Isotopic Composition of Precipitation in Tropical Stations. Acta Amazonica, 15(1-2): 121-139. https://doi.org/10.1590/1809-43921985152139

GORELICK, S.M.; ZHENG, C. 2015. Global change and the groundwater management challenge. Water Resources Research, 51(5): 3031-3051. https://doi. org/10.1002/2014WR016825

GRANJEIRO, M.L. 2008. Contribuição dos isótopos ambientais e hidroquímicos para o conhecimento das águas subterrâneas na bacia de Lavras da Mangabeira. Centro de Ciências, Universidade Federal do Ceará, Fortaleza, Dissertação de Mestrado, 95 p.

HEALY, R.W. 2010. Estimating Groundwater Recharge. Cambridge University Press, Cambridge, 245 p. https://doi.org/10.1017/ CBO9780511780745

HIRATA, R.A.; SUHOGUSOFF, A.V.; MARCELINI, S.S.; VILAR, P.C.; MARCELINI, L. 2019. A revolução silenciosa das águas subterrâneas no Brasil: uma análise da importância do recurso e os riscos pela falta de saneamento. Instituto Trata Brasil, Disponível em: http://www.tratabrasil.org.br/images/estudos/itb/aguas-subterraneas-e-saneamento-basico/Estudo_aguas subterraneas_FINAL.pdf 
HOEFS, J. 2009. Stable Isotope Geochemistry. Springer-Verlag, Berlin, Heidelberg, $286 \mathrm{p}$. https://doi.org/10.1007/978-3-540-70708-0

HOELZEL, M. 2018. Interconectividade de aquíferos e os efeitos da drenagem ácida de mina na qualidade das águas da Bacia Carbonifera de Santa Catarina (SC). Instituto de Geociências, Universidade Federal do Rio Grande do Sul, Porto Alegre, Dissertação de Mestrado, 63 p.

HORITA，J.; ROZANSKI，K.; COHEN， S. 2008. Isotope effects in the evaporation of water: a status report of the Craig-Gordon model. Isotopes in Environmental and Health Studies, 44(1): 23-49. https://doi. org/10.1080/10256010801887174

IBGE - INSTITUTO BRASILEIRO DE GEOGRAFIA E ESTATÍSTICA. 2019. Mapa de Províncias Estruturais do Brasil, 1:12.000.000. Disponível em: https://www. ibge.gov.br/apps/macrocaracterizacao. Acessado em 28 jul. 2020.

JASECHKO, S. 2019. Global isotope hydrogeology - Review. Reviews of Geophysics, 57(3): 835965. https://doi.org/10.1029/2018RG000627

JASECHKO, S.; TAYLOR, R.G. 2015. Intensive rainfall recharges tropical groundwaters. Environmental Research Letters, 10: 124015. https://doi.org/10.1088/1748-9326/10/12/124015

JASECHKO, S.; SHARP, Z.D.; GIBSON, J.J.; BIRKS, S.J., YI, Y.; FAWCETT, P.J. 2013. Terrestrial water fluxes dominated by transpiration. Nature, 496: 347-350. https:// doi.org/10.1038/nature11983

JASECHKO, S.; BIRKS, S.J.; GLEESON, T.; WADA, Y.; FAWCETT, P.J.; SHARP, Z.D.; MCDONNELL, J.J.; WELKER, J.M. 2014. The pronounced seasonality of global groundwater recharge. Water Resources Research, 50: 8845-8867. https://doi. org/10.1002/2014WR015809

JASECHKO, S.; WASSENAAR, L.I.; MAYER, B. 2017. Isotopic evidence for widespread coldseason-biased groundwater recharge and young streamflow across central Canada. Hydrological Processes, 31(12): 2196-2209. https://doi.org/10.1002/hyp.11175
JEELANI, G.; KUMAR, U.S.; BHAT, N.A.; SHARMA, S.; KUMAR, B. 2015. Variation of $\delta^{18} \mathrm{O}, \delta \mathrm{D}$ and ${ }^{3} \mathrm{H}$ in karst springs of south Kashmir, western Himalayas (India). Hydrological Processes, 29(4): 522-530. https://doi.org/10.1002/hyp.10162

JOUZEL, J.; MERLIVAT, L. 1984. Deuterium and oxygen 18 in precipitation: Modeling of the isotopic effects during snow formation. Journal of Geophysical Research Atmospheres. 89(D7): 11.749-11.757. https:// doi.org/10.1029/JD089iD07p11749

JUNQUEIRA, T.P. 2020. Modelo conceitual das águas termais da região da Chapada dos Veadeiros (GO): estudos estruturais, hidroquímicos e isotópicos. Instituto de Geociências, Universidade de Brasília, Brasília, Dissertação de Mestrado, 101 p.

KENDALL, C.; COPLEN T.B. 2001. Distribution of oxygen-18 and deuteriun in river waters across the United States. Hydrological Process, 15(7): 1363-1393. https://doi. org/10.1002/hyp. 217

KENDALL, C.; MCDONNELL, J.J. 1998. Isotope tracers in catchment hydrology. Elsevier, New York, 839 p. https://doi.org/10.1016/ C2009-0-10239-8

KREIS, M.; TAUPIN, J. D.; PATRIX, N.; MARTINS, E.S.P.R. 2020. Isotopic characterisation and dating of groundwater recharge mechanisms in crystalline fractured aquifers: example of the semi-arid Banabuiú watershed (Brazil). Isotopes in Environmental and Health Studies, 56(5-6): 418-430. https://doi.org/10.1080/10256016.2 020.1797275

KIMMELMANN, A.A.S.; SILVA, R.B.G.; REBOUÇAS, A.C.; SANTIAGO, M.M.F. 1986. Hidrologia isotópica do Aqüífero Botucatu, Bacia do Paraná, Brasil. In: ABAS, CONGRESSO BRASILEIRO DE ÁGUAS SUBTERRÂNEAS, 4, São Paulo, Anais, p. 1-25.

KIMMELMANN, A.A.S.; REBOUÇAS, A.C.; MARLUCIA, M.; SANTIAGO, F. 1989. ${ }^{14} \mathrm{C}$ Analyses of groundwater from the Botucatu Aquifer System in Brazil. Radiocarbon, 
31(3): 926-933. https://doi.org/10.1017/ S0033822200012546

KIMMELMANN, A.A.S.; FORSTER, M.; COELHO, R. 1995. Environmental isotope and hydrogeochemical investigation of Bauru and Botucatu aquifers. In: International Atomic Energy Agency (IAEA), Investigations on hydrology and hydrogeology in Latin America on water resources and groundwater pollution, Vienna, p. 57-74.

KIRCHHEIM, R.E.; GASTMANS, D.; CHANG, H.K.; GILMORE, T.E. 2019. The use of isotopes in evolving groundwater circulation models of regional continental aquifers: The case of the Guarani Aquifer System. Hydrological Processes, 33(17): 2266-2278. https://doi.org/10.1002/hyp.13476

KONG, Y.; PANG, Z. 2016. A positive altitude gradient of isotopes in the precipitation over the Tianshan Mountains: Effects of moisture recycling and sub-cloud evaporation. Journal of Hydrology, 542(2016): 222-230. https://doi.org/10.1016/j.jhydrol.2016.09.007

KURITA, N.; ICHIYANAGI, K.; MATSUMOTO, J.; YAMANAKA, M.D.; OHATA, T. 2009. The relationship between the isotopic content of precipitation and the precipitation amount in tropical regions. Journal of Geochemical Exploration, 102(3): 113-122. https://doi.org/10.1016/j.gexplo.2009.03.002

LACOUR, J.L.; RISI, C.; WORDEN, J.; CLERBAUX, C.; COHEUR, P.F. 2018. Importance of depth and intensity of convection on the isotopic composition of water vapor as seen from IASI and TES $\delta \mathrm{D}$ observations. Earth and Planetary Science Letters, 481(1): 387-394. https://doi. org/10.1016/j.epsl.2017.10.048

LEE, J.; WORDEN, J.; NOONE, D.; CHAE, J.H.; FRANKENBERG, C. 2015. Isotopic changes due to convective moistening of the lower troposphere associated with variations in the ENSO and IOD from 2005 to 2006. Tellus, Series B: Chemical and Physical Meteorology, 67(1): 1-11. https:// doi.org/10.3402/tellusb.v67.26177
LEITE, C.M.C. 2019. Traçadores ambientais como ferramentas de identificação da origem e idade das águas subterrâneas do sistema de abastecimento público no município de São Carlos. Escola de Engenharia de São Carlos, Universidade de São Paulo, São Carlos, Tese de Doutorado, 214 p. https:// doi.org/10.11606/T.18.2020.tde-13022020171557

LEOPOLDO, P.R.; MATSUI, E.; SALATI, E.; FRANKEN, W.; RIBEIRO, M.N.G. 1982. Composição isotópica da água de chuva e da água do solo em floresta amazônica do tipo terra firme, região de Manaus. Supl. Acta Amazonica, 12(3): 7-13. https://doi. org/10.1590/1809-43921982123S007

LESSA FILHO, J.R. 2017. Hidrologia e Isótopos Ambientais Aplicados ao Estudo do Pantanal dos Marimbus, Chapada Diamantina, Brasil. Instituto de Geociências, Universidade Federal da Bahia, Dissertação de Mestrado, Salvador, $104 \mathrm{p}$.

LOPES, E.C.S. 2005. Estudos hidrogeoquímicos e geofísicos na região da braquidobra de Monte Alegre, PA. Centro de Geociências, Universidade Federal do Pará, Dissertação de Mestrado, Belém, 83 p.

LOTT, D.A.; STEWART, M.T. 2016. Base flow separation: A comparison of analytical and mass balance methods. Journal of Hydrology. 535: 525-533. https://doi. org/10.1016/j.jhydrol.2016.01.063

LOUSADA, E.O.; CAMPOS, J.E.G. 2011. Estudos isotópicos em águas subterrâneas do Distrito Federal: subsídios ao modelo conceitual de fluxo. Revista Brasileira de Geociências, 41(2): 355-365.

LUCON, T.N. 2018. Comportamento Hidrogeoquímico da Região Cárstica do Alto São Francisco (MG): Implicações Associadas a Sazonalidade e Ciclo de Contaminantes, Areas de Recarga, Descarga e Comunicações Hidráulicas. Departamento de Geologia da Escola de Minas, Universidade Federal de Ouro Preto, Tese de Doutorado, Ouro Preto, $167 \mathrm{p}$.

LUCON, T.N.; COSTA, A.T.; GALVÃO, P.; LEITE, M.G.P.; MADEIRA, P.; NOGUEIRA, L.B. 
2020. Recharge sources and hydraulic communication of karst aquifer, São Miguel watershed, MG, Brazil. Journal of South American Earth Sciences, 100: 102591. https://doi.org/10.1016/j.jsames.2020.102591

LUZ, J.A.G.; COSTA, A.T.; CAMPOS, J.C.V. 2009. Avaliação sobre as condições atuais de explotação dos poços e dinâmica de fluxo do aquifero Urucuia. Universidade Federal da Bahia, 89 p. Relatório Final.

MALDANER, C.H. 2010. Recarga de aquifero em área urbana: estudo de caso de Urânia (SP). Instituto de Geociências, Universidade de São Paulo, Dissertação de Mestrado, São Paulo, 101 p. https://doi.org/10.11606/D.44.2010.tde08012011-201628

MARCHINA, C.; ZUECCO, G.; CHIOGNA, G.; BIANCHINI, G.; CARTURAN, L.; ENGEL, M.; NATALI, C.; BORGA, M.; PENNA, D. 2020. Alternative methods to determine the $\delta^{2} \mathrm{H}-\delta^{18} \mathrm{O}$ relationship: An application to different water types. Journal of Hydrology, 587: 1-14. https://doi. org/10.1016/j.jhydrol.2020.124951

MARIMON, M.P.C.; KNÖLLER, K.; ROISENBERG, A. 2007. Anomalous fluoride concentration in groundwater-is it natural or pollution? A stable isotope approach. Isotopes Environmental Health Studies, 43(2): 165-175. https://doi. org/10.1080/10256010701360132

MARQUES, J.; SANTOS, J.M.; NOVA, N.A.V.; SALATI, E. 1977. Precipitable water and water vapor flux between Belém and Manaus. Acta Amazonica, 7(3): 355-362. https://doi. org/10.1590/1809-43921977073355

MARTINELLI, L.A.; GAT, J.R.; CAMARGO, P.B.; LARA, L.L.; OMETTO, J.P.H.B. 2004. The Piracicaba river basin: Isotope hydrology of a tropical river basin under anthropogenic stress. Isotopes in Environmental and Health Studies, 40(1): 45-66. https://doi.org/10.1080/10256010310 001652016

MARTINS, V.T.S. 2008. Aplicação de isótopos de $\mathrm{Pb}, \mathrm{Sr}, \mathrm{He}$ Ocomo traçadores da recarga e da contaminação de aqüiferos metropolitanos: um exemplo da Bacia do Alto Tietê. Instituto de Geociências, Universidade de São Paulo, São Paulo, Tese de Doutorado, 177 p. https://doi.org/10.11606/T.44.2008.tde19122008-084523

MATSUI, E. 1971. Medida da Variação Natural da Relação D/H em Amostras de Água. Centro de Energia Nuclear na Agricultura, Piracicaba, BC-001, 31 p.

MATSUI, E.; SALATI, E.; RIBEIRO, M.N.G.; REIS, C.M.; TANCREDI, A.C.S.N.; GAT, J.R. 1983. Precipitation in the Central Amazon Basin: The Isotopic Composition of Rain and Atmospheric Moisture at Belém and Manaus. Acta Amazonica, 13(2): 307-369. https://doi.org/10.1590/180943921983132307

MATSUYAMA, H.; MIYAOKA, K.; MASUDA, K. 2005. Year-to-Year Variations of the Stable Isotopes in Precipitation in February at Cuibá, Located on the Northern Fringe of Pantanal, Brazil. Journal of Hydrometeorology, 6(3): 324-329. https:// www.jstor.org/stable/24910057

MAZOR, E.; VUATAZ, F.D., JAFFÉ, F.C. 1985. Tracing groundwater components by chemical, isotopic and physical parametersExample: Schinznach, Switzerland. Journal of Hydrology, 76(3-4): 233-246. https://doi. org/10.1016/0022-1694(85)90135-0

MENDONÇA, L.A.R.; FRISCHKORN, H.; SANTIAGO, M.M.F.; FILHO, J.M. 2004. Probing the relationship between surface waters and aquifers by ${ }^{18} \mathrm{O}$ measurements on the top of the Araripe Plateau/NE Brazil. Environmental Geology, 46: 295-302. https://doi.org/10.1007/s00254-004-0975-6

MENDONÇA, L.A.R.; FRISCHKORN, H.; SANTIAGO, M.M.F.; FILHO, J.M. 2005. Isotope measurements and ground water flow modeling using MODFLOW for understanding environmental changes caused by a well field in semiarid Brazil. Environmental Geology, 47: 1045-1053. https://doi.org/10.1007/s00254-005-1237-y

MERLIVAT, L.; JOUZEL, J. 1979. Global Climatic Interpretation of the Deuterium-Oxygen 18 Relationship for Precipitation. Journal of 
Geophysical Research, 84(C8): 5029-5033. https://doi.org/10.1029/JC084iC08p05029

MILANI, E.J. 1997. Evolução TectonoEstratigráfica da Bacia do Paraná e seu Relacionamento com a Geodinâmica Fanerozóica do Gondwana Sul-Ocidental. Instituto de Geociências, Universidade Federal do Rio Grande do Sul, Porto Alegre, Tese de Doutorado, 255 p.

MINARDI, P.S.P., BOMTEMPO, V.L. 2000. Traçadores e Técnicas Isotópicas em Hidrologia Subterrânea: A experiência do CDTN/ CNEN, BRASIL. In: JOINT WORLD CONGRESS ON GROUNDWATER, 1, Anais, 17 p. Águas Subterrâneas. Disponível em: https://aguassubterraneas.abas.org/asubterraneas/article/view/23757

MINARDI, P.S.P.; VELÁSQUEZ, L.N.M.; Bomtempo, V.L.; COTA, S.D.S.; RODRIGUES, P.C.H. 2008. Técnica isotópicas aplicadas em estudos hidrogeológicos no município de Araguari, MG. In: ABAS, CONGRESSO BRASILEIRO DE ÁGUAS SUBTERRÂNEAS, 15, Natal, Anais. Disponível em: https://aguassubterraneas. abas.org/asubterraneas/article/view/23839

MIRANDA, T.S. 2011. Estudo Geofísico e Geológico-Estrutural da Chapada do Apodi, Bacia Potiguar. Centro de Tecnologia e Geociências, Universidade Federal do Pernambuco, Recife, Dissertação de Mestrado, $179 \mathrm{p}$.

MONT'ALVERNE, A.A.F. 1996. Projeto Avaliação Hidrogeológica da Bacia Sedimentar do Araripe. Programa Nacional de Estudos dos Distritos Mineiros. Recife: Departamento Nacional de Produção Mineral, Distritos Regionais Pernambuco e Ceará.

MOOK, W.G. 2000. Environmental isotopes in the hydrological cycle. Principles and applications. 39: Volume 1, UNESCO, Paris, $280 \mathrm{p}$.

MOURA, I.B.M. 2013. Estudo das águas da bacia hidrográfica do Rio Banabuiú no trecho entre Quixeramobim e Banabuiú - Ceará, Brasil. Centro de Ciências, Universidade
Federal do Ceará, Fortaleza, Tese de Doutorado, $243 \mathrm{p}$.

MULLER, C.L.; BAKER, A.; FAIRCHILD, I.J.; KIDD, C.; BOOMER, I. 2015. IntraEvent Trends in Stable Isotopes: Exploring Midlatitude Precipitation Using a Vertically Pointing Micro Rain Radar. Journal of Hydrometeorology, 16(1): 194-213. https:// doi.org/10.1175/JHM-D-14-0038.1

NANNI, A.S.; ROISENBERG, A.; HOLLANDA, M.H.B.M.; MARIMON, M.P.C.; VIERO, A.P.; SCHEIBE, L.F. 2013. Fluoride in the Serra Geral Aquifer System: source evaluation using stable isotopes and principal component analysis. Journal of Geological Research, 1013: 309638. https:// doi.org/10.1155/2013/309638

NASCIMENTO, K.R.F.; COSTA, A.B.; ZUCCHI, M.R., MATOS, C.R.A.; AZEVEDO, A.E.G., PEDREIRA, C.B. 2003. Oxygen Isotopic composition of surface and groundwaters from rio das Femeas sub-basin Urucuia aquifer - BA, Brazil. In: SOUTH AMERICAN SYMPOSIUM ON ISOTOPIC GEOLOGY, 4, São Paulo, Short Papers, p. 457-460.

NOSSA, T.C.B. 2011. Avaliação da Vulnerabilidade do Aquífero Cárstico Salitre - Bahia, Através de Análises Hidrogeoquímicas, Isotópicas e Aplicação da Metodologia COP. Instituto de Geociências, Universidade Federal da Bahia, Salvador, Tese de Doutorado, $226 \mathrm{p}$.

NEVES, M.A.N.; MIRANDA, R.F.; TRIGO, M.S.; OLIVEIRA, M.S.M.; PESSOA, A.D.; MANCINI, L.H. 2016. Assinatura isotópica das águas pluviais e subterrâneas na Bacia Hidrográfica do Rio Itapemirim, Estado do Espírito Santo. In: ABAS, CONGRESSO BRASILEIRO DE ÁGUAS SUBTERRÂNEAS, 19, Campinas, Anais. Disponível em: https://aguassubterraneas. abas.org/asubterraneas/article/view/28688

NOGUEIRA SANTOS, G.; KIRCHHEIM, R.E.; LAZZAROTTO, E.M.; FRANZINI, A.S.; MOURÃO, M.A. 2019. The influence of the South Atlantic Convergence Zone upon groundwater levels and isotope ratios in the Bauru and Guarani Aquifer System in the 
Southerneast region of Brazil. International Symposium on Isotope Hydrology: Advancing the Understanding of Water Cycle Processes. Viena: International Atomic Energy Agency (IAEA).

NOVELLO, V.F. 2012. Reconstituição Paleoclimática do Holoceno Recente com base em Estalagmites da Região Central do Estado da Bahia. Instituto de Geociências, Universidade de São Paulo, São Paulo, Dissertação de Mestrado, 165 p. https://doi. org/10.11606/D.44.2012.tde-11052015153510

\section{OEA - ORGANIZAÇÃO DOS ESTADOS} AMERICANOS. 2009. Aquifero Guarani: Programa Estatégico de Ação. Montevideo, $426 \mathrm{p}$.

OLIVEIRA, M.S.M.; NEVES, M.A.; CAXITO, F.A.; MANCINI, L.H.; OLIVEIRA, F.B. 2019. Padrões de recarga do sistema aquífero cristalino a partir de isótopos estáveis ${ }^{18} \mathrm{Oe} \mathrm{e}^{2} \mathrm{H}$ de águas pluviais e subterrâneas. In: ABAS, CONGRESSO INTERNACIONAL DE MEIO AMBIENTE SUBTERRÂNEO, 6 , Belo Horizonte, Anais. Disponível em: https:// aguassubterraneas.abas.org/asubterraneas/ article/view/29856

PACHECO, W.L. 2012. Água subterrânea do Distrito Federal - efeito de sazonalidade e características associadas aos isótopos de deutério, oxigênio e carbono. Instituto de Geociências, Universidade de Brasília, Brasília, Dissertação de Mestrado, 129 p.

PADOVANI, C.R. 2010. Dinâmica espaçotemporal das inundações no Pantanal. Tese (Doutorado). Centro de Energia Nuclear na Agricultura, Universidade de São Paulo, Piracicaba, 175 p. https:// doi.org/10.11606/T.91.2010.tde-14022011170515

PAIVA, A.L.R. 2004. Modelagem computacional $e$ análise da salinização dos aquíferos na área central de Recife. Centro de Tecnologia e Geociências, Universidade Federal de Pernambuco, Recife, Dissertação de Mestrado, $147 \mathrm{p}$.

PAIVA, M.L. 2014. Sistemas aquíferos Serra Geral e Guarani: relação com a oceanografia. Instituto de Oceanografia, Universidade Federal do Rio Grande, Rio Grande, Dissertação de Mestrado, 77 p.

PEDROSA-SOARES,A.C.; JEBER,A.;ALKMIN, F.F.; SCUDINO, P.C.B.; LA TERRA, E.F.; VOLL, E. 2018. SIGA - Circuito das Águas: Caracterização geoambiental, geológica, geofísica, hidrogeológica e hidrogeoquímica do Circuito das Águas de Minas Gerais, com ênfase nos parques hidrotermais de Caxambu, Cambuquira, Marimbeiro, Contendas e Lambari. Companhia de Desenvolvimento de Minas Gerais (CODEMGE), $1^{\mathrm{a}}$ ed., Belo Horizonte, 500 p. http://www.codemge.com.br/wpcontent/uploads/2019/07/siga-circuito-dasaguas-100719.pdf

PEREIRA, E.R.S. 2009. Caracterização hidrogeoquímica da Ilha de Itaparica, Bahia. Instituto de Geociências, Universidade Federal da Bahia, Salvador, Dissertação de Mestrado, 129 p.

PEREIRA, L.; SANTIAGO, M.M.F.; MENDONÇA, L.A.R.; FRISCHKORN, H.; LIMA, J.O.G.; MENDES FILHO, J. 2004. Medidas hidroquímicas e isotópicas em águas subterrâneas que abastecem o município de São Luís - Maranhão. Revista Águas Subterrâneas, 18(1): 103-119 https://doi.org/10.14295/ ras.v18i1.1337

PEREIRA, L. 2006. Estudo isotópico e hidroquímico das águas superficiais e subterrânea no semi-árido cearense em área de preservação ecológica no município de Aiuaba. Centro de Ciências, Universidade Federal do Ceará, Fortaleza, Tese de Doutorado, $123 \mathrm{p}$.

PIMENTA, R.C.; MOREIRA, R.M.; ROCHA, Z.; VIANA, J.H.M.; LINHARES, G.M.G. 2017. Isótopos Estáveis na Caracterização das Águas Subterrâneas na Bacia do Alto Rio Jequitibá, Sete Lagoas, MG. In: ABAS, CONGRESSO INTERNACIONAL DE MEIO AMBIENTE SUBTERRÂNEO, 5, São Paulo, Anais. https://doi.org/10.13140/ RG.2.2.11725.13286

PINO, D.S. 2009. Estudos de isótopos de estrôncio, oxigênio e hidrogênio em um caso de contaminação de flúor no município 
de São Paulo. Instituto de Geociências, Universidade de São Paulo, São Paulo, Monografia de Graduação, 61 p.

PITA, R.C.S.; SILVA JÚNIOR, G.C.; ROSÁRIO, F.F.; SILVA, M.L. 2018. Sistema aquífero Alter do Chão a oeste da cidade de Manaus (AM): processos hidrogeoquímicos, origem da salinidade e relações com aquíferos adjacentes. Geologia USP, Série Científica, 18(1): 273-296. https://doi.org/10.11606/ issn.2316-9095.v18-134253

POVINEC, P.P.; BOKUNIEWICZ, H.; BURNETT, W.C.; CABLE, J.; CHARETTE, M.; COMANDUCCI, J. F.; KONTAR, E.A.; MOORE, W.S.; OBERDORFER, J.A., OLIVEIRA, J.; PETERSON, R.; STIEGLITZ, T.; TANIGUCHI, M. 2008a. Isotope tracing of submarine groundwater discharge offshore Ubatuba, Brazil : results of the IAEA - UNESCO SGD project. Journal of Environmental Radioactivity, 99(10): 1596-1610. https://doi.org/10.1016/j. jenvrad.2008.06.010

POVINEC, P.P.; OLIVEIRA, J.; BRAGA, E. S.; COMANDUCCI, J.F.; GASTAUD, J.; GROENING, M.; LEVY-PALOMO, I.; MORGENSTERN, U.; TOP, Z. 2008b. Isotopic, trace element and nutrient characterization of coastal waters from Ubatuba inner shelf area, south-eastern Brazil. Estuarine, Coastal and Shelf Science, 76(3): 522-542. https://doi.org/10.1016/j. ecss.2007.07.041

PUTMAN, A.L.; FIORELLA, R.P.; BOWEN, G.J.; CAI, Z. 2019. A global perspective on local meteoric water lines: meta-analytic insight into fundamental controls and practical constraints. Water Resources Research, 55(8): 6896-6910. https:/doi. org/10.1029/2019WR025181

RAPOSO, D.B. 2011. Caracterização do aquífero associado ao complexo alcalino carbonatítico do Barreiro, oeste de Minas Gerais. Instituto de Geociências, Universidade Estadual de Campinas, Campinas, Dissertação de Mestrado, 125 p.

REGINATO, P.A.R.; AHLERT, S.; SCHEINER, V.E. 2013. Caracterização Hidroquímica do Sistema Aquífero Serra Geral na Região
Nordeste do Rio Grande do Sul. Revista Águas Subterrâneas, 27(1): 65-78. https:// doi.org/10.14295/ras.v27i1.27061

RIBEIRO, C.; VELÁSQUEZ, L.; FLEMING, P. 2020. Origin of spring water employing a multiparametric approach with special focus on stable isotopes $\delta^{2} \mathrm{H}$ and $\delta^{18} \mathrm{O}$ in the Lagoa Santa Karst region, Southern Brazil. Isotopes in Environmental and Health Studies, 56(2): 158-169. https://doi.org/10.10 80/10256016.2020.1714608.

RIOS, A.P.J. 2016. Isótopos de $O$ e $H$ na análise de anomalias de bário na região de Marília - SP. Instituto de Geociências, Universidade de São Paulo, São Paulo, Dissertação de Mestrado, 129 p. https://dx.doi.org/10.11606/D.44.2017.tde27032017-09345

RISI, C.; BONY, S.; VIMEUX, F. 2008. Influence of convective processes on the isotopic composition $\left(\delta^{18} \mathrm{O}\right.$ and $\left.\delta \mathrm{D}\right)$ of precipitation and water vapor in the tropics: 2. Physical interpretation of the amount effect. Journal of Geophysical Research Atmospheres, 113: D19306. https://doi. org/10.1029/2008JD009943

RISI, C.; BONY, S.; VIMEUX, F.; CHONG, M.; DESCROIXE, L. 2010. Evolution of the stable water isotopic composition of the rain sampled along Sahelian squall lines. Quarterly Journal of the Royal Meteorological Society, 136(S1): 227-242. https://doi.org/10.1002/qj.485

RISI, C.; NOONE，D.; FRANKNBERG，C.; WORDEN, J. 2013. Role of continental recycling in intraseasonal variations of continental moisture as deduced from model simulations and water vapor isotopic measurements. Water Resources Research, 49(7): 4136-4156. https://doi.org/10.1002/ wrcr.20312

ROCHA, L.P.F.O. 2015. Hidroquímica do aquifero costeiro do município de Itarema - Ceará. Centro de Ciências, Universidade Federal do Ceará, Fortaleza, Tese de Doutorado, 312 p.

ROZANSKI，K.; ARAGUÁS-ARAGUÁS，L.; GONFIANTINI, R. 1993. Isotopic Patterns in Modern Global Precipitation. Climate 
Change in Continental Isotopic Records, Monograph 78: 1-36. https://doi.org/10.1029/ GM078p0001

SALATI, E.; DALL'OLIO, A.; MATSUI, E.; GAT, J.R. 1979. Recycling of Water in the Amazon Basin: An Isotopic Study. Water Resources Research. 15(5): 1250-1258. https://doi.org/10.1029/WR015i005p01250

SALLES， L.Q.; LEAL， L.R.B.; PEREIRA, R.G.F.A.; LAUREANO, F.V.; NASCIMENTO, S.A.M.; ZUCCHI, M.R.; BARBOSA, N.S. 2019. Ferramentas Hidrogeoquímicas e Isotópicas $\left(\delta^{18} \mathrm{O}\right.$ e $\left.\delta^{2} \mathrm{H}\right)$ Aplicadas no Entendimento dos Processos de Salinização da Água Subterrânea em Aquíferos Carbonáticos Proterozoicos: Evidência do Semiárido do Nordeste Brasileiro. Anuário do Instituto de Geociências - UFRJ, 42(2): 117-125. http:// dx.doi.org/10.11137/2019_2_117_125

SÁNCHEZ-MURILLO, R.; BIRKEL， C., WELSH, K.; ESQUIVEL-FERNÁNDEZ, G.; CORRALES-SALAZAR, J.; BOLL, J.; BROOKS, E.; ROUPSARD, O.; SÁENZ-ROSALES, O.; KATCHAN, I.; ARCE-MESÉN, R.; SOULSBY, C.; ARAGUÁS-ARAGUÁS, L.J. 2016. Key drivers controlling stable isotope variations in daily precipitation of Costa Rica: Caribbean Sea versus Eastern Pacific Ocean moisture sources. Quaternary Science Reviews, 131(part B): 250-261. https://doi. org/10.1016/j.quascirev.2015.08.028

SÁNCHEZ-MURILLO, R.; ESQUIVELHERNÁNDEZ， G.; SÁENZ-ROSALES, O.; PIEDRA-MARÍN， G.; FONSECASÁNCHEZ, A.; MADRIGAL-SOLÍS, H.; ULLOA-CHAVERRI, F.; ROJASJIMÉNEZ, L.D.; VARGAS-VÍQUEZ, J.A. 2017. Isotopic composition in precipitation and groundwater in the northern mountainous region of the Central Valley of Costa Rica. Isotopes in Environmental and Health Studies, 53(1): 1-17. https://doi.org/10 .1080/10256016.2016.1193503

SANTAROSA, L.V.; GASTMANS, D.; SANCHÉZ-MURILLO, R.; SANTOS, V.; BATISTA, L.V.; BETENCUR, S.B. 2021. Stable isotopes reveal groundwater to river connectivity in a mesoscale subtropical watershed. Isotopes in Environmental and Health Studies, 57(3): 236-253. https://doi.or $\mathrm{g} / 10.1080 / 10256016.2021 .1877701$

SANTIAGO, M.F.; SILVA, C.M.S.V.; MENDES FILHO, J.; FRISCHKORN, H. 1997. Characterization of groundwater in the Cariri (Ceará, Brazil) by environmental isotopes and electric conductivity. Radiocarbon, 39(1): 49-59. https://doi. org/10.1017/S0033822200040893

SANTOS, C.P.L.; LEAL, L.R.B.; AZEVEDO, A.E.G.; ZUCCHI, M.R.; DUTTON, A.R. 2019. Hydrogeological Characterization of the Aquifers of the Salitre Region Through Stable Isotopes ( $\delta \mathrm{D}$ and $\delta 18 \mathrm{O}$ ) and Geochemistry. Brazilian Journal of Geophysics, 37(4): 419-433. http://dx.doi. org/10.22564/rbgf.v37i4.2019

SANTOS, M.R. 2017. Análise estatística de dados hidrogeoquímicos e aplicação de isótopos ambientais estáveis de $\mathrm{H}, \mathrm{O}$ e $\mathrm{Pb}$ no estudo do Sistema Aquífero Fraturado PréCambriano no município de Porto Alegre, $R S$. Instituto de Geociências, Universidade Federal do Rio Grande de Sul, Porto Alegre, Monografia de Graduação, 113 p.

SANTOS, V.; OLIVEIRA, M.D.; BOLL， J.; SÁNCHEZ-MURILLO, R.; ANTONIO, A.M.; GOZZO, L.F.; GASTMANS, D. 2019a. Isotopic composition of precipitation during strong El Niño - Southern Oscillation events in the Southeast Region of Brazil. Hydrological Processes, 33(4): 647-660. https://doi.org/10.1002/hyp.13351

SANTOS, V.; GASTMANS, D.; SANTAROSA, L.V.; BATISTA, L.V.; BETANCUR, S.B.; OLIVEIRA, M.E.D.; FILHO, A.J.P. 2019b. Variabilidade da Composição Isotópica da Precipitação na Região Central do Estado de São Paulo. Águas Subterrâneas, 33(2): 171181. https://doi.org/10.14295/ras.v33i2.29474

SANTOS, V.; GASTMANS, D.; SÁNCHEZMURILLO, R.; GOZZO, L.F.; BATISTA, L.V.; Manzione, R.L.; Martinez, J. 2019c. Regional atmospheric dynamics govern interannual and seasonal stable isotope composition in southeastern Brazil. Journal of Hydrology, 579: 124-136. https://doi. org/10.1016/j.jhydrol.2019.124136 
SHIKLOMANOV, I.A. 2000. Appraisal and assessment of world water resources. Water International, 25(1): 11-32. https://doi. org/10.1080/02508060008686794

SILVA, R.B.G. 1983. Estudo hidroquímico $e$ isotópico das águas subterrâneas do aqüifero Botucatu no Estado de São Paulo. Instituto de Geociências, Universidade de São Paulo, São Paulo, Tese de Doutorado, 133 p. https://doi.org/10.11606/T.44.1983. tde-28082015-135247

SILVA, F.J.A.; ALMEIDA, M.M.M.; FERNANDES, A.L.C. 2002. Hidroquímica de águas subterrâneas do cristalino no trópico semiárido nordestino, Brasil. In: APESB/APRH, SIMPÓSIO LUSOBRASILEIRO DE ENGENHARIA SANITÁRIA E AMBIENTAL, 10, Braga.

SILVA, J.A.F. 2018. Estimativa de recarga e caracterização hidroquímica e isotópica das águas subterrâneas dos aquíferos da região do canal do Jurubatuba. Instituto de Geociências, Universidade de São Paulo, São Paulo, Tese de Doutorado, 219 p. https:// doi.org/10.11606/T.44.2018.tde-10092018140016

SILVA, P.S. 2016. Avaliação de viabilidade de aplicação de técnicas de recarga artificial em aquíferos salinizados, fraturados, Petrolina - PE. Instituto de Geociências, Universidade Federal de Brasília, Dissertação de Mestrado, Brasília, 121 p.

SILVA, T.A.; ROSÁRIO, F.F., SILVA JÚNIOR, G.C. 2020. Environmental isotopes and hydrochemical tracers applied to hydrogeological conceptual modeling of the southwest portion of the Amazon Aquifer System (Acre, Brazil). Applied Geochemistry, 120: 104670. https://doi. org/10.1016/j.apgeochem.2020.104670

SILVEIRA, C.S.; SILVA JUNIOR, G.C. 2002. O Uso de Isótopos Ambientais em Estudos Hidrogeológicos no Brasil: Uma Resenha Crítica. Anuário do Instituto de Geociências, 25: 25-43.

SIMÕES FILHO, F.F.L.; FERNANDES, H.M.; SANTOS, R.R.; SILVA, L. F.; ARAVENA, R., GODOY, M.L.; PEREIRA FILHO, H.A.
2006. Caracterização Hidrogeoquímica, Avaliação da Qualidade e da Recarga em Aquíferos do Semi-Arido associados à mineração de Urânio (Caetité, BA). In: ABAS, CONGRESSO BRASILEIRO DE ÁGUAS SUBTERRÂNEAS, 14, Curitiba, Anais.

SOLER, A.; BONOTTO, D.M. 2015. Hydrochemical and stable isotopes $(\mathrm{H}$, $\mathrm{O}, \mathrm{S})$ signatures in deep groundwaters of Paraná basin, Brazil. Environmental Earth Sciences, 73: 95-113. https://doi.org/10.1007/ s12665-014-3397-0

SOLER, A.; BONOTTO, D.M. 2020. Stable isotopes $(\mathrm{H}, \mathrm{O}, \mathrm{S})$ signatures evidencing evolutionary trends of Brazilian spas groundwaters. Journal of Geochemical Exploration, 210: 106452. https://doi. org/10.1016/j.gexplo.2019.106452

SOUSA, E.S. 2018. Caracterização hidroquímica $e$ isotópica das águas superficiais $e$ subterrâneas no entorno da Lagoa da Confusão, Tocantins, Brasil. Universidade Federal do Tocantins, Palmas, Dissertação de Mestrado, $100 \mathrm{p}$.

SOUZA, M.M. 2013. Determinação das áreas de recarga para a gestão do Sistema Aquífero Fissuro-Cárstico da região de São Sebastião/DF. Instituto de Geociências, Universidade de Brasília, Brasília, Dissertação de Mestrado, 73 p.

SOUZA, E.L.; GALVÃO, P.; ALMEIDA, R.; PINHEIRO, C.; BAESSA, M.; CABRAL, M. 2015. Stable Isotopes Studies in the Urucu Oil Province, Amazon Region, Brazil. Journal of Water Resource and Protection, 7(3): 131-142. https://doi. org/10.4236/jwarp.2015.73011

SRACEK, O.; HIRATA, R. 2002. Geochemical and stable isotopic evolution of the Guarani Aquifer System in the state of São Paulo, Brazil. Hydrogeology Journal, 10: 643-655. https://doi.org/10.1007/s10040-002-0222-8

STRADIOTO, M.R.; CHANG, H.K. 2015. Composição isotópica $-\delta^{18} \mathrm{O}$ e $\delta \mathrm{D}-$ das águas do Sistema Aquífero Bauru no Estado de São Paulo. Geociências, 34(3): 411-422. 
STUTE, M.; FORSTER, M.; FRISCHKORN, H.; SEREJO, A.; CLARK, J.F.; SCHLOSSER, P.; BROECKER, W.S.; BONANI, G. 1995. Cooling of Tropical Brazil $\left(5^{\circ} \mathrm{C}\right)$ During the Last Glacial Maximum. Science, 269(5222):379-383. https://doi.org/10.1126/ science.269.5222.379

TAYLOR, R.G.; SCANLON, B.; DÖLL, P.; RODELL, M.; VAN BEEK, R.; Wada, Y.; LONGUEVERGNE, L.; LEBLANC, M.; FAMIGLIETTI, J.S.; EDMUNDS, M.; KONIKOW, L.; GREEN, T.R.; CHEN, J.; TANIGUCHI, M.; BIERKENS, M.F.P.; MACDONALD, A.; FAN, Y.; MAXWELL, R.M.; YECHIELI, Y.; GURDAK, J.J.; Allen, D.M.; SHAMSUDDUHA, M.; HISCOCK, K.; YEH, P.J.F.; HOLMAN, I.; TREIDEL, H. 2012. Groundwater and climate change. Nature Climate Change, 3(4): 322-329. https://doi.org/10.1038/nclimate1744

TEIXEIRA， Z.A.; KICH， E.M.; RODRIGUES NETO, M.P.; FILGUEIRA, J.G.; MELATI, M.D.; GASTMANS, D. 2018. Composição isotópica $\left(\delta^{2} \mathrm{He} \delta^{18} \mathrm{O}\right)$ das águas subterrâneas dos aquíferos da região do Cariri (CE). In: ABAS, CONGRESSO BRASILEIRO DE ÁGUAS SUBTERRÂANEAS, 20, Campinas, Anais.

TORRI, G.; MA, D.; KUANG, Z. 2017. Stable water isotopes and large-scale vertical motions in the tropics. Journal of Geophysical Research, 122(7): 3703-3717. https://doi.org/10.1002/2016JD026154

UREY, H.C. 1947. The thermodynamic properties of isotopic substances. Journal of the Chemical Society (Resumed), 562-581. https://doi.org/10.1039/JR9470000562

VIDAL, A.C. 2002. Estudo Hidrogeológico do Aqüífero Tubarão na área de afloramento da porção central do Estado de São Paulo. Instituto de Geociências e Ciências Exatas, Universidade Estadual Paulista, Rio Claro, Tese de Doutorado, $122 \mathrm{p}$.

VILLANUEVA, T.C.B.; LEAL, L.R.B.; ZUCCHI, M.R.; AZEVEDO, A.E.G.; MIRANDA, J.G.V.; VILLANUEVA, P.R. 2014. Avaliação Isotópica e Hidroquímica do Aquífero Cárstico Salitre na Região de Irecê, Bahia. Águas Subterrâneas, 28(2): 8294. https://doi.org/10.14295/ras.v28i2.27942
VIVIANI-LIMA, J.B. 2007. Estimativa de recarga em áreas urbanizadas: estudo de caso na bacia do Alto Tietê (SP). Instituto de Geociências, Universidade de São Paulo, São Paulo, Tese de Doutorado, 220 p. https:// doi.org/10.11606/T.44.2007.tde-15052008101148

VUILLE, M.; WERNER, M. 2005. Stable isotopes in precipitation recording South American summer monsoon and ENSO variability: Observations and model results. Climate Dynamics, 25(4): 401-413. https:// doi.org/10.1007/s00382-005-0049-9

WAHNFRIED, I. 2010. Modelo conceitual de fluxo do aquitarde Serra Geral e do Sistema Aquifero Guarani na região de Ribeirão Preto, $S P$. Instituto de Geociências, Universidade de São Paulo, São Paulo, Tese de Doutorado, 135 p. https://doi.org/10.11606/T.44.2010. tde-07072010-163245

WASSENAAR, L.; COPLEN, T.; AGGARWAL, P. 2014. Approaches for achieving longterm accuracy and precision of $\delta^{18} \mathrm{O}$ and $\delta^{2} \mathrm{H}$ for waters analyzed using laser absorption spectrometers. Environmental Science and Technology, 48(2): 1123-1131. https://doi. org/10.1021/es403354n

WINDHORST, D.; WALTZ, T.; TIMBE, E.; FREDE, H. G.; BREUER, L. 2013. Impact of elevation and weather patterns on the isotopic composition of precipitation in a tropical montane rainforest. Hydrology and Earth System Sciences, 17(1): 409-419. https://doi.org/10.5194/hess-17-409-2013

WINNICK, M.J.; CHAMBERLAIN， C.P.; CAVES, J.K.; WELKER, J. M. 2014. Quantifying the isotopic "continental effect". Earth and Planetary Science Letters, 406: 123-133. https://doi.org/10.1016/j. eps1.2014.09.005

WU, H.; ZHANG, X.; XIAOYAN, L.; Li, G.; HUANG, Y. 2015. Seasonal variations of deuterium and oxygen-18 isotopes and their response to moisture source for precipitation events in the subtropical monsoon region. Hydrological Processes, 29(1): 90-102. https://doi.org/10.1002/hyp.10132 
YOSHIMURA, K. 2015. Stable water isotopes in climatology, meteorology, and hydrology: A review. Journal of the Meteorological Society of Japan, 93(5): 513-533. https://doi. org/10.2151/jmsj.2015-036
ZHANG, J; ZHANG, Y; SONG, J; 2017. Evaluating relative merits of four baseflow separation methods in Eastern Australia. Journal of Hydrology. 549: 252-263. https:// doi.org/10.1016/j.jhydrol.2017.04.004

\section{Endereço dos autores:}

Didier Gastmans, Lia Nogueira Garpelli, Vinícius dos Santos, Camila de Lima, Carolina Stager Quaggio - Centro de Estudos Ambientais, Universidade Estadual Paulista, Av. 24A, 1515, Bela Vista, CEP 13506900, Rio Claro, SP, Brasil.E-mails: didier.gastmans@unesp.br; lia.garpelli@unesp.br; vinicius.santos16@ unesp.br; camila.lima89@unesp.br; stager.quaggio@unesp.br

Lucas Vituri Santarosa - Centro de Estudos Ambientais, Universidade Estadual Paulista, Av. 24A, 1515, Bela Vista, CEP 13506-900, Rio Claro, SP, Brasil / Universidad Tecnológica del Uruguay (UTEC), ITR Centro-Sur, Durazno, Uruguay.E-mail: lucas.santarosa@unesp.br, lucas.vituri@utec.edu.br

Roberto Eduardo Kirchheim - Serviço Geológico do Brasil - CPRM, Diretoria de Hidrologia e Gestão Territorial R. Costa, 55, Consolação, CEP 01304-010, São Paulo, SP, Brasil. E-mail: roberto.kirchheim@, cprm.gov.br

Artigo submetido em 4 de dezembro de 2020, aceito em 13 de fevereiro de 2021. 